Alexandre Barbosa Salaroli

\title{
Distribuição de elementos metálicos e As em sedimentos superficiais ao longo do Canal de Bertioga (SP)
}

\begin{abstract}
Dissertação apresentada ao Instituto Oceanográfico da Universidade de São Paulo, como parte dos requisitos para obtenção do título de Mestre em Ciências, área de Oceanografia Química e Geológica.
\end{abstract}

Orientador: Prof. Dr. Rubens Cesar Lopes Figueira 
Universidade de São Paulo

Instituto Oceanográfico

Distribuição de elementos metálicos e As em sedimentos superficiais ao longo do Canal de Bertioga (SP)

\begin{abstract}
Alexandre Barbosa Salaroli
Dissertação apresentada ao Instituto Oceanográfico da Universidade de São Paulo, como parte dos requisitos para obtenção do título de Mestre em Ciências, área de Oceanografia Química e Geológica.
\end{abstract}

Versão Corrigida

Julgada e Aprovada em: 16 / 12 / 2013.

Prof. Dr. Rubens Cesar Lopes Figueira

Conceito

Prof. Dr. Pablo Muniz Maciel

Conceito

Prof. Dr. Denis Modelo Abessa

Conceito 
"Algo superior e poderoso que torna os homens diferentes dos animais e que os faz resistir além de suas forças, alcançar limites acima do possível: a vontade." 
AGRADECIMENTOS

RESUMO

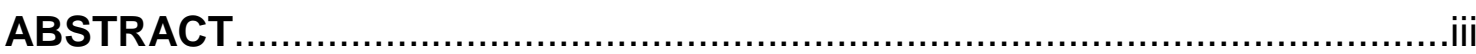

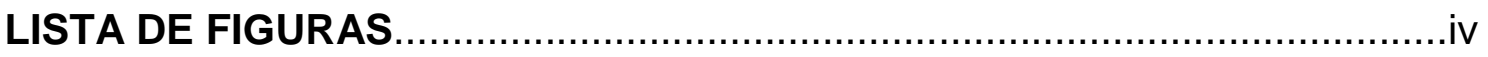

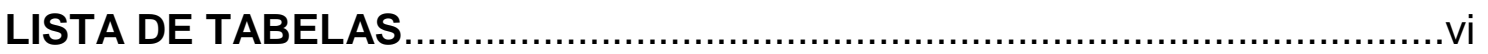

LISTA DE ABREVIAÇÕES ..................................................................... vii

1. INTRODUÇÃO

1.1. Caracterização dos sistemas estuarinos …......................................

1.2. Deposição de metais nos sedimentos ...........................................

1.3. Contaminação por metais e semimetais em estuários......................6

2. OBJETIVOS

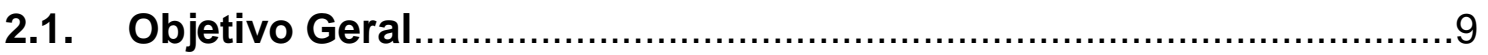

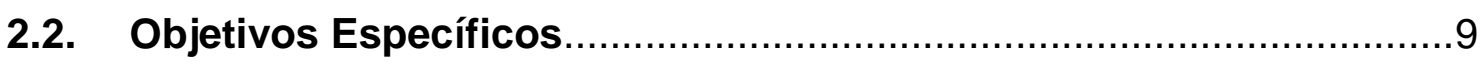

3. ÁREA DE ESTUDO

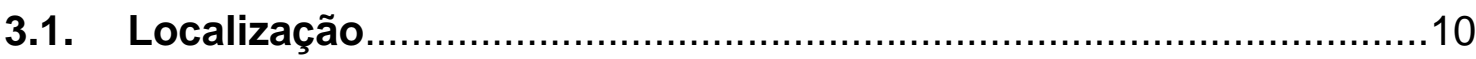

3.2. Caracterização geológica e geomorfológica....................................11

3.3. Dinâmica de sedimentação atual...............................................12

3.4. Situação ambiental do canal e fontes de metais na região ...............13

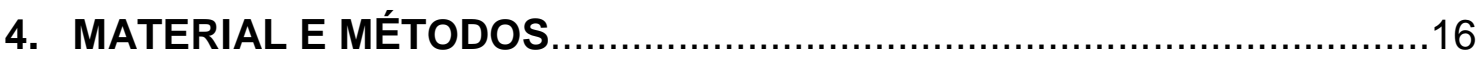

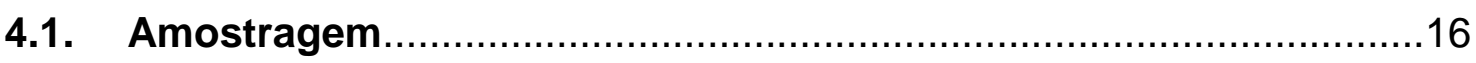

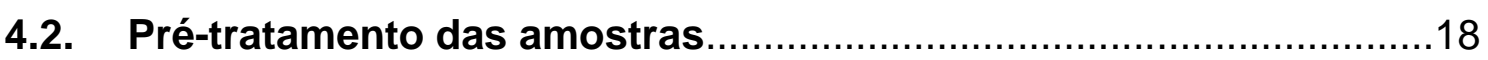

4.3. Análises de metais e As por espectrometria de emissão ótica com plasma indutivamente acoplado (ICP-OES) ..................................18

4.3.1. Abertura das amostras …..................................................

4.3.2. Determinação de metais e As por ICP-OES .............................21

4.3.3. Limites de Detecção e Quantificação........................................23

4.3.4. Curva de calibração.....................................................................24

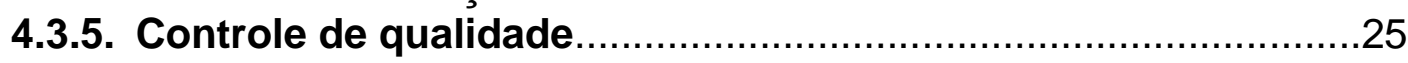

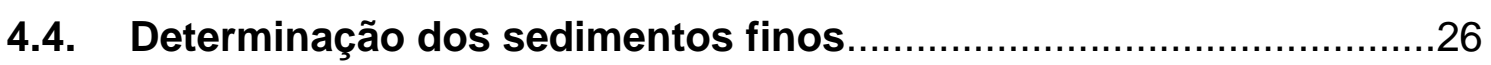


4.5. Análises de conteúdo de carbonato de cálcio, carbono orgânico e nitrogênio total, e das razões isotópicas $\delta^{13} \mathrm{C} /{ }^{12} \mathrm{C}$ e $\delta^{15} \mathrm{~N} /{ }^{14} \mathrm{~N}$ por EAIRMS .27

4.6. Parâmetros geoquímicos para avaliação do grau de contaminação.....................................................................29

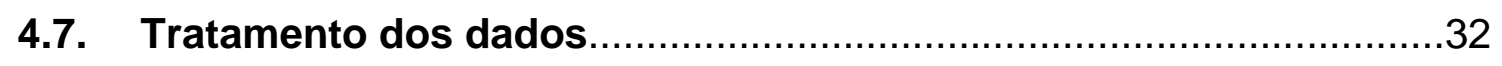

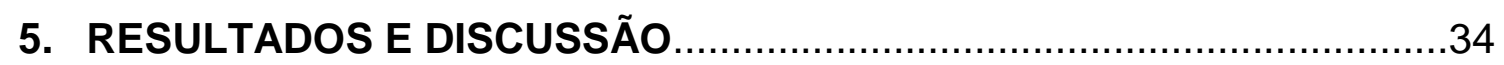

5.1. Distribuição de sedimentos finos.............................................34

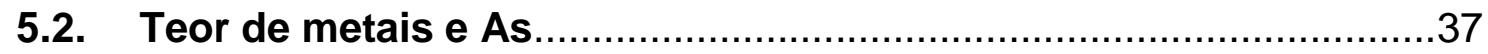

5.3. Caracterização da matéria orgânica sedimentar...........................67

6. CONSIDERAÇÕES FINAIS E CONCLUSÃO ....................................73

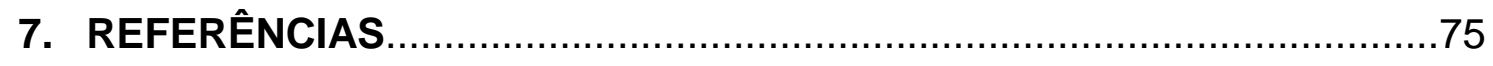

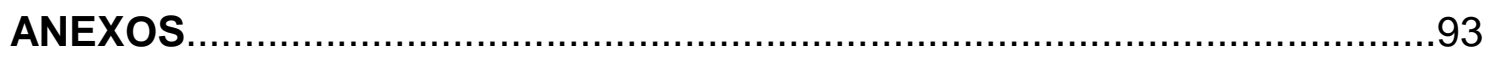




\section{AGRADECIMENTOS}

Meu agradecimento especial ao Prof. Dr. Rubens Cesar Lopes Figueira, que antes de ser meu orientador é um grande amigo, obrigado pela confiança, pelos ensinamentos, incentivo e pelas oportunidades que tem me dado nos últimos cinco anos, serei eternamente grato. Valeu Rubinho!!!

À minha esposa Mariana, que sempre me deu forças para não desistir nos momentos mais difíceis. Te amo!

À minha família, em especial aos meus pais, pela minha criação, educação e investimento durante todos esses anos de vida.

A toda equipe do LaQIMar, em especial ao Dú (mamãe) e ao Charles, pela ajuda e descontração nas coletas de campo, e à Bianca (Korea) pela ajuda nas inúmeras análises realizadas, risadas e por me manter acordado com os cafés, e à Tati (Ferrinho) pela colaboração com a granulometria.

Aos amigos da SALT, em especial ao Coelhão pela ajuda na confecção dos mapas.

Aos meus colegas de trabalho do Instituto Oceanográfico, pela convivência diária, almoços e inúmeras conversas na Didi.

Aos meus amigos que topam qualquer parada: Leito, Nariz, Gordo, Kakareco, Maguila, Vanessinha. Muito obrigado pelas inúmeras cervejas...

Não poderia me esquecer da turma II (Light) do IOUSP.

À FAPESP (processo $n^{0}$ 2009/01211-0), pelo apoio financeiro na execução deste trabalho.

A todos que contribuíram direta e indiretamente para a realização deste trabalho.

E um humilde agradecimento a mim mesmo, sem eu este trabalho não teria sido realizado. 


\section{RESUMO}

A Baixada Santista é um dos locais mais amplamente povoados e explorados do estado de São Paulo. Nas últimas décadas, devido à intensa industrialização, vem sofrendo um intenso processo de degradação ambiental. Os despejos de resíduos industriais vêm se constituindo uma das principais fontes de contaminação por metais das águas e sedimentos do estuário santista. Os metais possuem persistência e muitos deles toxicidade em concentrações variadas, podendo ser depositados nos sedimentos e atingir a biota. Desta forma, a compreensão da importância desta contaminação é condição necessária para o planejamento de uso e ocupação do espaço costeiro. O estudo proposto constitui uma base para a compreensão do nível de contaminação por metais e As no Canal de Bertioga (SP). Foram determinados por ICP-OES os níveis de Al, As, $\mathrm{Cd}, \mathrm{Cr}, \mathrm{Cu}, \mathrm{Fe}, \mathrm{Mn}, \mathrm{Ni}, \mathrm{Pb}, \mathrm{Sc}$, $\mathrm{V}$ e Zn em amostras de sedimento superficial. O grau de contaminação dos sedimentos foi avaliado segundo o padrão de qualidade de sedimentos estabelecidos pela agência ambiental canadense (TEL e PEL), todos os valores obtidos foram abaixo do PEL, e a maioria das amostras apresentaram valores abaixo do TEL, com exceção do $\mathrm{As}$, $\mathrm{Cu}$ e $\mathrm{Pb}$. Foram calculados o Fator de Concentração (FC) e o Fator de Enriquecimento (FE) para identificar a contribuição antropogênica, os índices indicaram contaminação moderada para $\mathrm{Cu}, \mathrm{Pb}$ e $\mathrm{Zn}$ na região próxima ao estuário de Santos, e para As próximo à cidade de Bertioga, indicando uma possível entrada desses elementos, e para os demais elementos ausência de contaminação.

Palavras-chaves: metais; sedimento; contaminação; estuário de Santos; Canal de Bertioga; ICP-OES. 


\begin{abstract}
The region of Santos is one of the most widely explored and populated location of the state of São Paulo. In recent decades, due to the intensive industrialization, has undergone an intense process of environmental degradation. Wastewater from industrial comes to constitute a major source of metal contamination of waters and sediments of the Santos estuary. The metals are toxic and persistent in varying concentrations and may be incorporate by sediments and biota. Thus, understanding the importance of this contamination is necessary to the coastal planning. The proposed study provides a basis for understanding the level of metal contamination and As at Bertioga Channel (SP). The levels of $\mathrm{Al}, \mathrm{As}, \mathrm{Cd}, \mathrm{Cr}, \mathrm{Cu}, \mathrm{Fe}, \mathrm{Mn}, \mathrm{Ni}, \mathrm{Pb}, \mathrm{Sc}, \mathrm{V}$ and $\mathrm{Zn}$ in superficial sediment samples were determined by ICP-OES. The degree of sediment contamination was evaluated according to the quality standard set by sediment Canadian environmental agency (TEL and PEL), all values were below the PEL, and most of the samples had values below the TEL, with the exception of $\mathrm{As}$, $\mathrm{Cu}$ and $\mathrm{Pb}$. Concentration Factor (CF) and Enrichment Factor (EF) were calculated to identify anthropogenic inputs, and the index indicated moderate contamination for $\mathrm{Cu}, \mathrm{Pb}$ and $\mathrm{Zn}$ in the region near the estuary of Santos, and close to the city of Bertioga, indicating a possible input of these elements, and absence of contamination for other elements.
\end{abstract}

Keywords: metals, sediment, contamination; Santos estuary; Bertioga Channel; ICP-OES. 


\section{LISTA DE FIGURAS}

Figura 1. Complexo estuarino santista - área de estudo (Canal de Bertioga SP) 10

Figura 2. Localização dos pontos de coleta no Canal de Bertioga e Rio Itapanhaú 16

Figura 3. Van Veen utilizado na coleta do sedimento.....................................17

Figura 4. Fluxograma método de extração EPA 3050B.................................19

Figura 5. Solubilização das amostras em chapa aquecedora..........................20

Figura 6. Amostras sendo filtradas e avolumadas para $100 \mathrm{~mL}$.....................20

Figura 7. Equipamento utilizado nas determinações de metais e As (ICPOES).

Figura 8. Curva de calibração construída para leitura do $\mathrm{Pb}(220,353 \mathrm{~nm}) \ldots . .24$

Figura 9. Porcentagem de finos (silte + argila) obitdos nas amostras..............35

Figura 10. Distribuição de sedimentos finos ao longo do Canal de Bertioga....36

Figura 11. Potenciais interferentes espectrais do $\operatorname{Cd}(\lambda=214,439$ e 226,502 $\mathrm{nm})$

Figura 12. Gráfico de correlação linear de Cd medido no comprimento de onda 214,439 e 226,502 X Fe. .38

Figura 13. Distribuição espacial de As em $\mathrm{mg} \mathrm{kg}^{-1}$ 40

Figura 14. Distribuição espacial de $\mathrm{Al} \mathrm{em} \mathrm{mg} \mathrm{kg}^{-1}$ .41

Figura 15. Distribuição espacial de $\mathrm{Cr}$ em $\mathrm{mg} \mathrm{kg}^{-1}$ .42

Figura 16. Distribuição espacial de Cu em $\mathrm{mg} \mathrm{kg}^{-1}$ .43

Figura 17. Distribuição espacial de Fe em $\mathrm{mg} \mathrm{kg}^{-1}$. .44

Figura 18. Distribuição espacial de $\mathrm{Mn}$ em $\mathrm{mg} \mathrm{kg}^{-1}$ 45

Figura 19. Distribuição espacial de $\mathrm{Ni}$ em $\mathrm{mg} \mathrm{kg}^{-1}$ 46

Figura 20. Distribuição espacial de $\mathrm{Pb}$ em $\mathrm{mg} \mathrm{kg}^{-1}$ .47

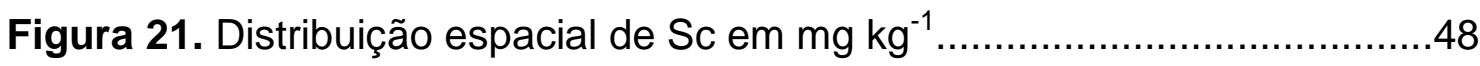

Figura 22. Distribuição espacial de $\mathrm{V}$ em $\mathrm{mg} \mathrm{kg}^{-1}$........................................4.

Figura 23. Distribuição espacial de $\mathrm{Zn}$ em $\mathrm{mg} \mathrm{kg}^{-1}$... .50 
Figura 24. Variação do Fator de Concentração de $\mathrm{Cr}, \mathrm{Cu}, \mathrm{Ni}, \mathrm{Pb}, \mathrm{Zn}$ e As nas amostras de sedimento superficial ao longo do Canal de Bertioga e

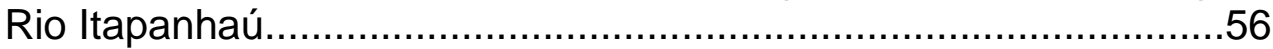

Figura 25. Distribuição do Fator de Enriquecimento de $\mathrm{Cr}, \mathrm{Cu}, \mathrm{Ni}, \mathrm{Pb}, \mathrm{Zn}$ e As nas amostras de sedimento superficial ao longo do Canal de

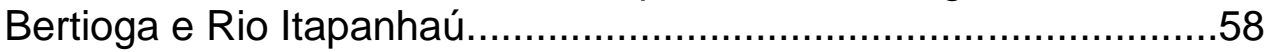

Figura 26.Gráficos de correlação do $\mathrm{As}, \mathrm{Al}, \mathrm{Cr}, \mathrm{Cu}, \mathrm{Fe}$ e $\mathrm{Mn}$ contra a porcentagem de sedimentos finos 63

Figura 27. Gráficos de correlação do $\mathrm{Ni}, \mathrm{Pb}, \mathrm{Sc}, \mathrm{V}$ e $\mathrm{Zn}$ contra a porcentagem de sedimentos finos.....................................................................64

Figura 28. Análise de Agrupamento das amostras coletadas..........................65

Figura 29. Análise de Agrupamento das variáveis estudadas..........................66

Figura 30. Distribuição espacial de Carbonato de Cálcio em \%........................68

Figura 31. Distribuição espacial de Carbono Orgânico Total em \%.................70 


\section{LISTA DE TABELAS}

Tabela 1. Coordenadas Geográficas dos pontos de coleta no Canal de Bertioga $-\mathrm{SP}$. 94

Tabela 2. Coordenadas Geográficas dos pontos de coleta no Rio Itapanhaú..96

Tabela 3. Comprimento de onda utilizado, LDM e LQM para cada elemento...23

Tabela 4. Resultados do material de referência certificado SS-1 $(n=5) \ldots \ldots \ldots \ldots . .25$

Tabela 5. Resultados do material de referência certificado SS-2 $(n=5) \ldots \ldots \ldots \ldots . .26$

Tabela 6. Valores de concentração,em $\mathrm{mg} \mathrm{kg}^{-1}$, estabelecidos pelo CEGQ (2001).

Tabela 7. Dados da análise granulométrica para as amostras de sedimento, em $\%$ finos (silte + argila).

Tabela 8. Parâmetros descritivos de metais e As, em mg kg${ }^{-1}$. 37

Tabela 9. Resultados dos níveis de metais e As, em mg kg${ }^{-1}$, em sedimentos superficiais do Canal da Bertioga.

Tabela 10. Resultados dos níveis de metais e As, em mg kg${ }^{-1}$, em sedimentos superficiais do Rio Itapanhaú.....

Tabela 11. Valores máximos e mínimos de As e metais em diferentes estudos e regiões do Brasil 53

Tabela 12. Matriz de correlação obtida entre as variáveis estudadas no Canal de Bertioga $(p<0,05)$

Tabela 13. Matriz do coeficiente de determinação $\left(r^{2}\right)$ obtida entre as variáveis estudadas no Canal de Bertioga. 62

Tabela 14. Parâmetros descritivos das características da MO sedimentar. .67 


\section{LISTA DE ABREVIAÇÕES}

CONAMA: Conselho Nacional do Meio Ambiente.

COT: Carbono Orgânico Total.

EA-IRMS: Elemental Analyzer - Isotope Ratio Mass Spectrometer - Analisador Elementar acoplado com um Espectrômetro de Massas para Razão Isotópica.

FC: Fator de Concentração.

FE: Fator de Enriquecimento.

ICP-OES : Inductively Coupled Plasma Optical Emission Spectrometry Espectrometria de Emissão Óptica com Plasma Indutivamente Acoplado.

IOUSP: Instituto Oceanográfico da Universidade de São Paulo.

LaQIMar: Laboratório de Química Inorgânica Marinha.

LD: Limite de Detecção.

LDM: Limite de Detecção do Método.

LQM: Limite de Quantificação do Método.

MO: Matéria Orgânica

MRC: Material de Referência Certificado.

NT: Nitrogênio Total.

PEL: Probable Effect Level - concentração acima da qual são esperados efeitos adversos severos sobre organismos aquáticos.

TEL: Threshold Effect Level - concentração abaixo da qual não são esperados efeitos adversos sobre organismos aquáticos.

USEPA: United States Environmental Agency - Agência de Proteção Ambiental dos Estados Unidos. 


\section{INTRODUÇÃO}

Durante o século $\mathrm{XVI}$ devido as condições de relevo e hidrografia da costa que favorecem a navegação, a colonização do território brasileiro se deu, principalmente, a partir do litoral. Nos séculos seguintes, em particular no século $X X$, a ação do homem ao longo de toda a costa brasileira ocasionou forte pressão sobre os frágeis ecossistemas que aí se encontram (AB'SABER, 2003).

Para uma avaliação de compatibilidade entre exploração e proteção dos ecossistemas costeiros, é de extrema importância qualificar e quantificar os impactos causados pelas atividades antrópicas que afetam as regiões marinhas. As fontes pontuais de poluição têm sido uma das atividades específicas com maior impacto significativo em ambientes marinhos que afetam mais as zonas costeiras e entremarés do que as regiões oceânicas, onde a circulação local ajuda na redistribuição e dispersão dos poluentes (WEBER, 1992; CUNHA, 2007). Estas fontes podem variar em sua intensidade de impacto sobre as condições ecológicas das comunidades e em sua distribuição espacial (HALPERN et al., 2008).

Segundo DIEGUES (1987) e LUIZ-SILVA et al. (2006), das 25 regiões metropolitanas brasileiras, 14 são encontradas em estuários onde se localizam os principais polos petroquímicos e sistemas portuários do país, responsáveis por uma intensa degradação e contaminação destes ecossistemas.

O litoral paulista foi desde os primórdios de sua história de ocupação um dos locais mais amplamente explorados e ocupados do estado. Devido a sua localização estratégica, a região da Baixada Santista é considerada uma das regiões economicamente mais importantes do Brasil, nela estão inseridos os sistemas estuarinos de Santos e São Vicente, compreendendo o espaço costeiro delimitado politicamente entre os municípios de Bertioga e Praia Grande (SILVA et al., 1994).

Ao longo de todo o século $X X$ ocorreram grandes modificações para a Baixada Santista, como melhorias na estrutura portuária de Santos (maior porto da América Latina), a implantação do polo petroquímico de Cubatão e a construção de modernas rodovias, contudo com isso levou a intensas 
interferências no meio ambiente costeiro, advindas da ocupação humana decorrente do desenvolvimento econômico da região (CETESB, 1998).

O Sistema Estuarino de Santos representa um dos maiores exemplos brasileiro de degradação ambiental por poluição hídrica e atmosférica de origem industrial em ambientes costeiros (LAMPARELLI et al. 2001). A região comporta o complexo industrial mais importante do país, o Complexo de Cubatão, que possui mais de 1100 indústrias petroquímicas, siderúrgicas e de fertilizantes, que descarregam cerca de $100000 \mathrm{~kg} / \mathrm{mês}$ de vários poluentes tais como metais e produtos petroquímicos (CETESB, 2001).

As principais fontes de contaminação por metais das águas $\mathrm{e}$ sedimentos dos canais estuarinos da Baixada Santista provêm atualmente dos despejos de resíduos industriais, dejetos humanos e domésticos (ABESSA, 2002; HURTADO, 2003; ECOSAN, 2007).

Os processos de urbanização e industrialização da Baixada Santista, ao longo do tempo, vem interferindo diretamente nos equilíbrios naturais. $O$ principal resultado da atuação antrópica é a aceleração dos processos de remoção de solos, aterros em manguezais, ratificações em canais fluviais, extração de areias em praias e dunas, e as descargas de efluentes industriais no ambiente trouxeram grandes alterações no balanço sedimentar da linha de costa, e dos sistemas fluvio-marinhos como um todo (FUKUMOTO, 2007).

Um importante segmento do complexo estuarino da Baixada Santista é a sua porção mais a nordeste, denominado Canal de Bertioga, com aproximadamente $25 \mathrm{~km}$ de extensão, que liga o alto estuário santista diretamente ao oceano por uma desembocadura situada próximo ao município de Bertioga. Neste segmento estão presentes conjuntos de áreas de manguezais com sedimentos que apresentam potencial para a contaminação por metais pesados, pois funcionam como um filtro aos sedimentos provenientes do alto estuário santista e foram transportados em direção ao oceano.

Devido aos planos de ampliação do Porto de Santos e ao processo de assoreamento no estuário ser intenso, levando à necessidade de contínuas dragagens do canal navegação e pontos de atracação do porto, os quais contribuem para a ressuspensão de muitos compostos contaminantes que haviam se depositado no sedimento, também ocorre o descarte do material 
dragado em áreas limítrofes aos canais estuarinos, ou em áreas externas de mar aberto indicando uma necessidade de estudos no canal de Bertioga, a fim de verificar o potencial da área em suportar as modificações advindas das questões ambientais existentes.

\subsection{Caracterização dos sistemas estuarinos}

Os estuários caracterizam-se por ser uma das regiões mais importantes da zona costeira, estão entre os ecossistemas mais produtivos do mundo sendo locais de grande importância ecológica, econômica e social. Muitas das grandes cidades portuárias no Brasil e no mundo (Ex: Santos, Rio de Janeiro, Salvador, Hong Kong, Londres, Melbourne, entre outras) desenvolveram-se em zonas estuarinas por serem regiões privilegiadas para a fixação das civilizações, sendo locais abrigados favoráveis à instalação dos portos.

Estuários são definidos como corpos de água costeiros, semiconfinados e livremente conectados com o oceano, onde a água salgada marinha é mensuravelmente diluída pela água doce fluvial, vinda do continente (PRITCHARD, 1967 apud BAPTISTA NETO et al., 2004).

São ambientes sedimentares costeiros cuja evolução depende da interação entre parâmetros hidráulicos, sedimentares e aspectos morfológicos, e onde a atividade biológica é uma condicionante fundamental. Constituindo meios receptores de sedimentos por excelência, onde os processos produtivos são rápidos, esses ambientes são importantes zonas de investigação da morfodinâmica atual e fáceis deposicionais da história geológica recente (FRAZÃO, 2003).

Por serem sistemas dinâmicos, os estuários se movimentam e sofrem alterações constantemente em razão dos ventos, marés e escoamento de rios. A circulação é uma das características mais importantes porque determina a dispersão horizontal das partículas. Assim, para a compreensão do transporte e destino de poluentes nestes sistemas é necessário conhecer processos físicos, químicos, geológicos e biológicos, além das propriedades dos próprios contaminantes.

Os oceanos têm grande capacidade de diluição, porém, os estuários e baías, além de receberem um aporte maior de compostos de origem 
antropogênica, são ambientes mais susceptíveis em função de uma baixa hidrodinâmica a qual pode determinar uma dispersão de contaminantes menos eficiente. A introdução direta ou indireta de substâncias e de energia pelo homem podem atingir níveis de elevada concentração causando a contaminação das águas estuarinas com efeitos nocivos para os recursos vivos, perigo para a saúde humana e outros (MIRANDA et al., 2002). A contaminação ocorre quando esses aportes aumentam a concentração de substâncias na água do mar, no sedimento ou nos organismos, acima dos níveis naturais para aquela área (SINDERMAN, 1996).

Os estuários são locais onde ocorre a deposição de sedimentos, bem como dos contaminantes a eles associados, impedindo que grande parte destes deposite na região da plataforma continental (BAPTISTA NETO et al., 2004). Dessa forma, uma particular atenção no controle ambiental e, a compreensão e avaliação do impacto que sofrem esses ambientes são cruciais para a preservação dessas regiões.

\subsection{Deposição de metais nos sedimentos}

O sedimento é um compartimento importante de um sistema aquático que funciona como habitat para muitas espécies. A importância da proteção da qualidade aquática dos sedimentos é fundamental porque muitos organismos vivem no seu interior e na interface sedimento-água (SILVÉRIO, 2003).

São amplamente utilizados como indicadores da qualidade ambiental, pois são locais em que ocorre a deposição, incorporação e acumulação de muitos compostos químicos, especialmente metais pesados e compostos orgânicos e, a partir deles, as espécies químicas podem ser transferidas para as águas, levando à bioacumulação e transferência na cadeia trófica (BAIRD, 2002; COTTA et al., 2006).

As fontes de contaminação de metais nas regiões estuarinas são principalmente provenientes da deposição atmosférica, utilização e derrames de combustíveis fósseis, descarga de águas resíduárias das indústrias e esgotos domésticos, bem como das atividades de mineração (LI et al., 2000; MARINS et al., 2002). Há também as fontes naturais de metais que são provenientes da erosão e intemperismos sobre as rochas. 
Metais desempenham um importante papel no funcionamento da vida em nosso planeta, em pequenas quantidades fazem parte da constituição dos organismos marinhos e alguns são extremamente essenciais, mas dependendo da sua concentração, são altamente tóxicos (BRYAN, 1971; TEMPLETON et al., 2000).

A deposição de metais em sedimentos aquáticos de acordo com FÖRSTNER \& PATCHINEELAM (1981), pode seguir quatro mecanismos básicos:

1) São transportados e depositados pelos minerais detríticos provenientes de rochas e solos, de resíduos orgânicos e por perda do material sólido;

2) A sorção e a troca de cátions tomam lugar em substâncias constituídas de grãos finos, onde a superfície de contato é maior facilitando a agregação dos metais;

3) $\mathrm{O}$ aumento do $\mathrm{pH}$ promove, na zona estuarina, a formação de hidróxido de metais e carbonatos. $O$ aumento da salinidade causa a instabilidade dos colóides, pela adsorção de íons $\mathrm{Ca}^{2+}{\mathrm{e} \mathrm{Mg}^{2+} \text { nas }}^{2}$ superfícies de partículas orgânicas, ou de hidróxido de ferro III. Isto resulta na coagulação destes materiais e na sua precipitação, que também pode implicar na coprecipitação de outros metais;

4) Em águas ricas em matéria orgânica, a solubilidade é efetuada pela combinação de processos de complexação e redução. A incorporação ao sedimento envolve mecanismos de adsorção, floculação, polimerização e precipitação.

A maior parte dos contaminantes é adsorvida na matéria particulada em suspensão, que pode ser transportada para o sedimento por floculação e sedimentação.

A remobilização dos metais dos sedimentos para a coluna d'água depende de sua forma química ou natureza de ligação, e ocorre devido a inúmeros processos químicos, físicos e biológicos, que pode ser potencialmente perigoso para o ecossistema marinho e também para o homem (LAW \& BISCAYA, 1994; QUEVAUVILLER, 1998). 


\subsection{Contaminação por metais e semimetais em estuários}

Devido à importância dos ambientes estuarinos existem diversos trabalhos sobre a contaminação dessas regiões no Brasil e no mundo, com a finalidade de avaliar, monitorar e recuperar áreas que já se encontram degradadas, mas também proteger as regiões não impactadas que são passíveis de contaminação resultantes da degradação ambiental, possibilitando o uso sustentável das mesmas.

CETESB (2001) realizou um levantamento da contaminação ambiental do Sistema Estuarino de Santos e São Vicente analisando diversas amostras em diferentes matrizes (água, sedimentos e material biológico) na região, encontrando valores acima do PEL (Probable Effect Level) que representa a concentração acima da qual é esperado efeitos tóxicos para os organismos para os elementos $\mathrm{Cd}, \mathrm{Cu}, \mathrm{Hg}, \mathrm{Ni}, \mathrm{Pb}$ e $\mathrm{Zn}$. As áreas com maiores valores localizavam-se bem próximas das potenciais fontes de contaminação, as indústrias presentes no pólo industrial de Cubatão.

MAHIQUES et al. (2013) determinaram as concentrações de $\mathrm{Cr}, \mathrm{Cu}, \mathrm{Pb}$ e $\mathrm{Zn}$ por ICP-OES em quatro testemunhos coletados no sistema estuarino lagunar Cananéia-Iguape em São Paulo. As concentrações encontradas de Pb indicaram valores bem maiores do que os sedimentos contaminados do estuário santista, concluindo que a entrada de metais pesados na região, principalmente o chumbo, foram associados com a empresa mineradora Plumbum S/A que realizaram suas atividades na região do Rio Ribeira de 1945 até 1995, e que a entrada desses elementos ainda ocorrem no sistema devido ao desgaste das pilhas de resíduos que encontram-se presentes nas margens do Rio.

RIBEIRO (2006) avaliou a contaminação por $\mathrm{Cd}, \mathrm{Cu}, \mathrm{Ni}, \mathrm{Pb}$ e $\mathrm{Zn}$ em 65 amostras de sedimentos superficiais da baía de Sepetiba - RJ, indicando valores acima do PEL para $\mathrm{Cd}$ e $\mathrm{Zn}$, que comparados com outros dados do Brasil apresenta os maiores níveis relativos desses metais presentes na costa brasileira.

MACHADO (2007) e SÁ \& MACHADO (2007) em estudos realizados sobre contaminação por metais e semimetais nos sedimentos da baía de Paranaguá - PR encontraram concentrações acima do TEL (Threshold Effect 
Level) que é a probabilidade de ocorrência de efeitos adversos aos organismos aquáticos para As e Ni. Os outros metais analisados $\mathrm{Cd}, \mathrm{Cr}, \mathrm{Cu}, \mathrm{Hg}, \mathrm{Pb}$ e $\mathrm{Zn}$ não ultrapassaram valores estabelecidos pelo CONAMA 344/04.

ZHOU et al. (2007) analisaram a distribuição espacial de Al, Ba, Cd, Cr, $\mathrm{Cu}, \mathrm{Fe}, \mathrm{Hg}, \mathrm{Mn}, \mathrm{Ni}, \mathrm{Pb}, \mathrm{V}$ e $\mathrm{Zn}$ em 59 amostras de sedimentos marinhos em Hong Kong. A partir dos teores encontrados foram calculados os fatores de enriquecimento (FE), devido aos altos valores encontrados para $\mathrm{Cr}$, $\mathrm{Cu}$ e $\mathrm{Zn}$, os autores concluíram que estes elementos estão sendo introduzidos pela atividade antrópica, enquanto $\mathrm{Al}, \mathrm{Ba}, \mathrm{Fe}, \mathrm{Mn}$ e $\mathrm{V}$ são originados do intemperismo das rochas, por obterem FE menores.

MUTHU \& JAYAPRAKASH (2008) avaliaram a distribuição e o enriquecimento de $\mathrm{Cd}$, $\mathrm{Co}, \mathrm{Cr}, \mathrm{Cu}$, Fe. $\mathrm{Mn}, \mathrm{Ni}, \mathrm{Pb}$ e $\mathrm{Zn}$ em sedimentos superficiais na costa Ennore, região altamente industrializada, localizada na baía de Bengala, sudoeste da Índia. A partir dos resultados obtidos foram calculados os fatores de concentração (FC) e o índice de geoacumulação $\left(I_{\text {geo }}\right)$. Os valores de $\mathrm{FC}$ obtiveram a seguinte ordem $\mathrm{Cd}>\mathrm{Cu}>\mathrm{Cr}>\mathrm{Pb}>\mathrm{Ni}>\mathrm{Zn}$. Os valores de $\mathrm{Cd}$ mostraram-se extremamente altos com $\mathrm{FC}>50$, indicando que a região está altamente contaminada por esse elemento, informação confirmada quando calculado o $\mathrm{I}_{\mathrm{geo}}$. Os níveis de metais foram associados aos efluentes industriais lançados no sistema: $\mathrm{Cr}, \mathrm{Cu}, \mathrm{Fe}, \mathrm{Mn}$ e $\mathrm{Ni}$ foram associados às siderúrgicas e queima de carvão enquanto $\mathrm{Cd}, \mathrm{Pb}$ e $\mathrm{Zn}$ estão relacionados as inúmeras refinarias localizadas na área.

CORTESÃO \& VALE (1995) avaliaram o estuário de Sado em Portugal, analisaram em 50 amostras de sedimento superficial os elementos $\mathrm{Ag}, \mathrm{Al}, \mathrm{Ca}$, $\mathrm{Cd}$, Co, $\mathrm{Cr}, \mathrm{Cu}, \mathrm{Fe}, \mathrm{Mg}, \mathrm{Mn}, \mathrm{Ni}, \mathrm{Pb}, \mathrm{Si}$ e $\mathrm{Zn}$. Os resultados foram normalizados pelo teor de Al mostrando variações consideráveis ao longo do estuário, principalmente devido as diferentes origens do sedimento $e$ do aporte antropogênico de metais. A análise das componentes principais (PCA) aplicadas às razões metal/Al demostraram que o $\mathrm{Co}, \mathrm{Cr}, \mathrm{Cu}, \mathrm{Fe}$ e $\mathrm{Ni}$ estão mais relacionados com os sedimentos depositados próximos da área industrial.

Os trabalhos aqui apresentados apontam para a importância na determinação de metais e relatam as interações destes com diferentes compartimentos que compõem as regiões costeiras e estuarinas, no qual, 
diferentes parâmetros (químicos, físicos, geológicos, hidrodinâmicos entre outros) contribuem para a introdução e distribuição dos mais diversos elementos químicos. Logo, um estudo aprofundado, e o monitoramento ao longo do tempo fazem-se necessário, com o objetivo de interpretar as possíveis alterações causadas tanto pela atividade antrópica como por processos naturais. 


\section{OBJETIVOS}

\subsection{Objetivo Geral}

O presente trabalho tem como objetivo principal determinar os níveis de metais e semimetais em sedimentos superficiais do Canal de Bertioga (SP) a fim de avaliar os níveis de contaminação por estes elementos.

Esse estudo fez parte do projeto de pesquisa "Histórico da atividade antrópica no Canal da Bertioga. Níveis de metais e semimetais em colunas sedimentares", coordenado pelo Dr. Rubens Cesar Lopes Figueira e financiado pela FAPESP (processo oㅜ 2009/01211-0).

\subsection{Objetivos Específicos}

Este trabalho apresenta os seguintes objetivos específicos:

- Determinar os níveis de $\mathrm{Al}, \mathrm{As}, \mathrm{Cd}, \mathrm{Cr}, \mathrm{Cu}, \mathrm{Fe}, \mathrm{Mn}, \mathrm{Ni}, \mathrm{Pb}, \mathrm{Sc}, \mathrm{V}$, e Zn em amostras de sedimento superficial do Canal da Bertioga - SP utilizando a técnica de digestão parcial, seguida da análise dos elementos por espectrometria de emissão óptica por plasma indutivamente acoplado (ICP-OES);

- Caracterizar a matéria orgânica do sedimento com base na determinação dos conteúdos de carbono orgânico e nitrogênio total, bem como suas razões isotópicas $\delta^{13} \mathrm{C} /{ }^{12} \mathrm{C}$ e $\delta^{15} \mathrm{~N} /{ }^{14} \mathrm{~N}$, através do analisador elementar IRMS;

- Estimar parâmetros importantes na avaliação de metais em sedimentos tais como: fator de concentração e fator de enriquecimento;

- Comparar os valores obtidos com outros trabalhos desenvolvidos na região e em outros locais do Brasil;

- Estabelecer uma base de dados dos níveis de metais e As, e da matéria orgânica em sedimento superficial que poderão auxiliar nos processos de gestão costeira e ambiental na região. 


\section{3. ÁREA DE ESTUDO}

\subsection{Localização}

O Canal da Bertioga está inserido no complexo estuarino santista situado entre as latitudes de $23^{\circ} 51^{\prime} \mathrm{S}$ e $23^{\circ} 57^{\prime} \mathrm{S}$ e longitudes $46^{\circ} 08^{\prime} \mathrm{W}$ e $46^{\circ} 19^{\prime} \mathrm{W}$, com uma área total de aproximadamente 51.500 ha.

O canal é considerado como uma conexão secundária do oceano ao complexo estuarino de Santos com sua desembocadura a nordeste localizada próxima à cidade de Bertioga, e à desembocadura oposta próxima ao canal do alto estuário santista (Figura 1). Possui $25 \mathrm{~km}$ de extensão, com profundidade média entre 3-6 metros. A região da barra é a que apresenta maior influência de águas da plataforma continental e as maiores profundidades que pode atingir até 15 metros (MIRANDA et. al. 1998).

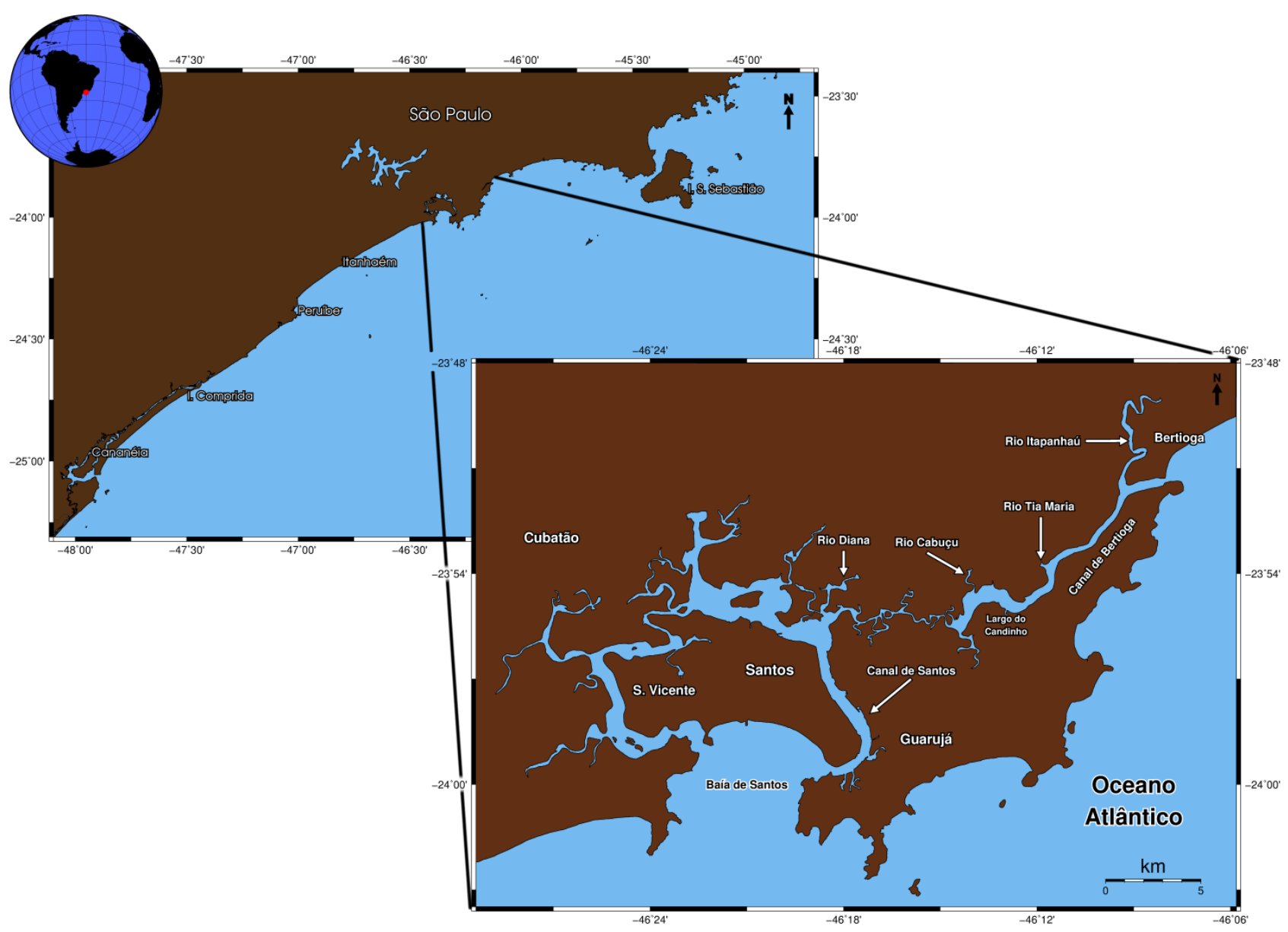

Figura 1. Complexo estuarino santista - área de estudo (Canal de Bertioga - SP). 
O canal constitui um corpo hídrico que em alguns locais atingem mais de $1 \mathrm{~km}$ de largura, sendo o receptáculo da foz do rio Itapanhaú formando a maior bacia hidrográfica da Baixada Santista. Segundo SCHAEFFER-NOVELLI (1986), os rios que deságuam no canal são pouco extensos, com alta competência, sendo os principais, além do Itapanhaú, os rios Caiubura, Iriri, Tia Maria, Cabuçu e Trindade.

\subsection{Caracterização geológica e geomorfológica}

A Baixada Santista e o canal de Bertioga na caracterização geomorfológica de São Paulo estão inseridos no domínio da Planície Costeira, esse domínio subdivide-se nas subzonas Serra do Mar e Baixada Litorânea. A subzona Serra do Mar apresenta relevo abrupto formado predominantemente por escarpas, este relevo com desnível acentuado apresenta alta densidade de drenagem. Nesta região serrana estão presentes vales, que condicionam a drenagem que escoa na região, e se constituem nos núcleos exportadores dos materiais terrígenos que adentram a planície costeira paulista. A subzona das baixadas litorâneas apresenta relevo de terrenos baixos, predominantemente planos, com baixa densidade de drenagem, de padrão meandrante, e com altitudes pouco elevadas em relação ao nível do mar atual (IPT, 1981).

De acordo com SUGUIO \& MARTIN (1978) o litoral paulista foi dividido em quatro grandes unidades (Cananéia-Iguape, Itanha bém-Santos, Bertioga, Ilha de São Sebastião e llha de São Sebastião-Serra de Paratí). Esta subdivisão contempla, ainda, uma individualização do litoral paulista em dois grandes compartimentos, com características geomorfológicas bem diferenciadas, entre as planícies costeiras, desenvolvidas ao longo dos eventos de variação relativa do nível do mar no Quaternário. A planície costeira de Santos tem a forma de um crescente de $40 \mathrm{~km}$ de extensão por $15 \mathrm{~km}$ de largura máxima, a gênese desta planície está diretamente vinculada aos mecanismos de variação do nível marinho ocorrido ao longo do Quaternário superior quando, nos máximos transgressivos do Pleistoceno superior (Transgressão Cananéia 120.000 anos A.P.), e do Holoceno (Transgressão Santos 5.100 anos A.P.), a área foi recoberta pelas águas marinhas que atingiram, respectivamente, cotas entre 8 e $10 \mathrm{~m}$ e entre 4 e $5 \mathrm{~m}$ acima do 
nível atual. No intervalo entre esses máximos transgressivos, com o recuo do nível marinho atingindo aproximadamente as atuais cotas de -110 metros, expondo as atuais planícies costeiras e quase toda a plataforma continental paulista, ocorreram as deposições de sistemas de cordões arenosos sobre o conjunto de sedimentos argilo-arenosos transicionais e de areias litorâneas transgresssivas. No evento regressivo que teve seu máximo a cerca de 17.000 anos A.P., os sedimentos expostos sofreram erosão, originando os vales que durante o evento transgressivo subseqüente foram afogados. Estes vales afogados resultaram em extensas lagunas, onde se depositaram sedimentos argilo-arenosos, ricos em matéria orgânica Ainda ao longo deste evento ocorreu também a erosão das partes mais elevadas dos cordões arenosos pleistocênicos, possibilitando a ressedimentação desses materiais erodidos.

Na planície costeira de Santos à medida que o nível do mar atingia sua posição atual foi formada à retaguarda destes depósitos arenosos, uma vasta laguna que está sendo colmatada e colonizada pela vegetação de mangue.

\subsection{Dinâmica de sedimentação atual}

O canal de Bertioga possui regime de micromarés, e de acordo com MIRANDA et al. (1998), o canal apresenta marés mistas que são predominantemente semidiurnas com desigualdades diurna, de amplitudes moderadas podendo variar entre 0,73 e 1,5 metros. O aporte fluvial é realizado por pequenos rios, mas principalmente pelo Itapanhaú, localizado próximo à cidade de Bertioga. Essa descarga fluvial é uma das principais forçantes da circulação estacionária no canal.

De acordo com FÚLFARO \& PONÇANO (1976), a dinâmica de sedimentação do canal da Bertioga mostra um efeito de fluxo fluvial residual mínimo, devendo-se creditar às correntes de maré o papel de agente principal de remobilização sedimentar do sistema. Quanto ao padrão de sedimentação, com exceção de suas desembocaduras, onde ocorre areia fina, os sedimentos são finos, variando de argila a silte médio.

As áreas de maior influência das correntes de maré podem ser observadas junto à cidade de Bertioga, próximo à desembocadura oceânica do 
canal, com um pequeno decréscimo desta influência na região do rio Sandí, nas proximidades da confluência do canal com o Canal do Porto, em Santos. Os rios que desembocam no canal da Bertioga parecem ter a sua carga sedimentar depositada pela ação das correntes de maré, que ao se propagar em sentidos opostos, pelas duas desembocaduras do canal da Bertioga tendem a se anular. Este fato resulta em uma movimentação das correntes de fundo em velocidades inferiores à velocidade crítica de transporte, eliminando 0 transporte de fundo e, caracterizando o canal da Bertioga como um corredor onde predomina 0 transporte de sedimentos finos em suspensão. Estes sedimentos são depositados, preferencialmente, junto a área de confluência de correntes de maré de sentido de deslocamento opostos (tombo das águas), junto ao largo do Candinho, que corresponde a uma das raras áreas do estuário santista em que se depositam predominantemente sedimentos argilosos, com alta porcentagem de matéria orgânica (FÚLFARO \& PONÇANO, 1976).

\subsection{Situação ambiental do canal e fontes de metais na região}

O Canal de Bertioga e adjacências têm grande importância social, ambiental e econômica, em suas imediações encontra-se o maior porto do Brasil e o complexo industrial de Cubatão. O canal é utilizado para fins turísticos, recreativos, pesca artesanal e esportiva, 17 espécies de peixes foram encontradas e são exploradas na região (FUNDESPA, 1991). Aproximadamente 21 espécies de crustáceos e 16 de moluscos habitam os manguezais que circundam o canal (SCHAEFFER-NOVELLI, 1986). De acordo com SOARES (1997), a pesca era a principal atividade econômica, e o turismo se desenvolveu como uma fonte secundária de renda para a região.

Os mangues com melhor desenvolvimento estrutural da Baixada Santista são encontrados no Canal de Bertioga (SCHAEFFER-NOVELLI, 1986), que perfazem uma área de aproximadamente $23 \mathrm{~km}^{2}$ (HERZ, 1991). Devido à proximidade do canal a importantes regiões do país, a região vem sofrendo nas últimas décadas crescimento desordenado da sua ocupação, descaracterizando seu ambiente natural. Dentre as atividades impactantes 
temos a construção de oleodutos, rodovias de transporte e a mineração. As atividades antrópicas proporcionam para a região problemas ambientais, como o desmatamento, erosão e contaminação dos corpos de água e do solo (ZARONI, 2006).

Segundo CETESB (2001), as principais fontes de metais nos ambientes aquáticos provêm de ações antrópicas tais como atividades industriais, portuárias, agrícolas e lançamentos de esgotos. Na região da Baixada Santista as refinarias de petróleo, os terminais portuários, as indústrias siderúrgicas, de fertilizantes, químicas e petroquímicas são as principais responsáveis pelo lançamento de $\mathrm{Cd}, \mathrm{Cr}, \mathrm{Cu}, \mathrm{Hg}, \mathrm{Pb}, \mathrm{Mn}, \mathrm{Ni}$ e $\mathrm{Zn}$ que contribuem para a contaminação do sistema estuarino como um todo (CETESB, 2001; HORTELANNI et al., 2008). Fontes secundárias de metais estão associadas ao lançamento de esgotos domésticos e do porto, contribuição dos "lixões", dos canais pluviais e do emissário de Santos. Os maiores teores são encontrados na região do alto estuário e vão decrescendo rumo à baía de Santos (ECOSAN, 2007).

TOMMASI (1979) encontrou valores mais elevados de $\mathrm{Hg}$ nos sedimentos do Canal de Santos do que na região da Baía de Santos. ABESSA (2002) analisou 28 amostras de sedimento do Sistema Estuarino de Santos em março de 1998, e dentre as amostras localizadas no canal de navegação encontrou em duas os metais $\mathrm{Zn}, \mathrm{Ni}, \mathrm{Pb}$ e $\mathrm{Hg}$ quantificados acima do nível 1 da CONAMA 344/04. SIQUEIRA et al. (2005) encontraram Hg em concentrações acima do nível 1 em algumas amostras no canal do Porto de Santos, coletadas em 2000. BURUAEM et al. (2012) também observaram valores de $\mathrm{Hg}$ e $\mathrm{Zn}$ acima dos valores orientadores da CONAMA 344/04 em amostras do estuário de Santos.

Ao longo do canal de Bertioga há a presença de habitações, marinas de médio porte, pequenas indústrias e estaleiros, "lixão" clandestino, que liberam efluentes de esgoto, resíduos de petróleo, entre outros que são prováveis fontes atuais de contaminação para a região (ZARONI, 2006).

Segundo a CETESB (2001), os elevados teores de metais contidos atualmente nos sedimentos no canal de Bertioga, estão diretamente vinculados ao período de expansão industrial da baixada santista. 
Derramamentos de petróleo causaram a inserção de poluentes no Canal de Bertioga, como foi o caso do rompimento do oleoduto pertencente à PETROBRAS e ao naufrágio da Barcaça Gisela (SCHAEFFER-NOVELLI, 1984 e 1986)

De acordo com ABESSA (2002), o canal de Bertioga até o Largo do Candinho recebe durante a maré enchente a influência das águas contaminadas da Baía de Santos, verificando a presença de contaminantes como $\mathrm{Hg}, \mathrm{Zn}$ e hidrocarbonetos aromáticos indicando a presença de poluentes associados às refinarias, indústrias siderúrgicas e de fertilizantes.

QUINÁGLIA (2006) em amostras de sedimento realizadas no Canal de Bertioga encontrou valores acima do TEL para arsênio, estando os demais metais analisados dentro dos limites permitidos pela legislação.

GONÇALVES et al. (2013) analisaram os níveis de As, $\mathrm{Cd}, \mathrm{Cr}, \mathrm{Cu}, \mathrm{Ni}$, $\mathrm{Pb}$ e $\mathrm{Zn}$ em cinco testemunhos sedimentares ao longo do Canal de Bertioga. A fim de identificar a toxicidade relativa dos elementos e sua contribuição antropogênica foram calculados o índice de carga de poluição (PLI) e o fator de enriquecimento (FE), os resultados obtidos indicaram a ausência de contaminação pelos metais e uma entrada elevada de As nos testemunhos com maiores taxas de sedimentação, devido aos processos naturais de intemperismo e sedimentação. $O$ enriquecimento observado corresponde ao final do século XIX, época em que o Porto de Santos foi inaugurado, e à década de 70, com a expansão nas atividades do porto. 


\section{MATERIAL E MÉTODOS}

\subsection{Amostragem}

Foram coletadas 127 amostras de sedimento superficial do Canal de Bertioga e 20 amostras ao longo do Rio Itapanhaú (Figura 2). A amostragem foi realizada por meio probabilístico (aleatório), pelo método sistemático (USEPA, 2001), onde o primeiro local de coleta foi escolhido aleatoriamente e os pontos de coleta subsequentes foram selecionados em intervalos regulares, coletando um ponto em cada margem, um no meio do canal e dependendo da largura um ou mais pontos adicionais, ou apenas um ponto no local onde o canal é estreito. $\mathrm{Na}$ entrada e na desembocadura foi realizada uma maior quantidade de pontos amostrais.

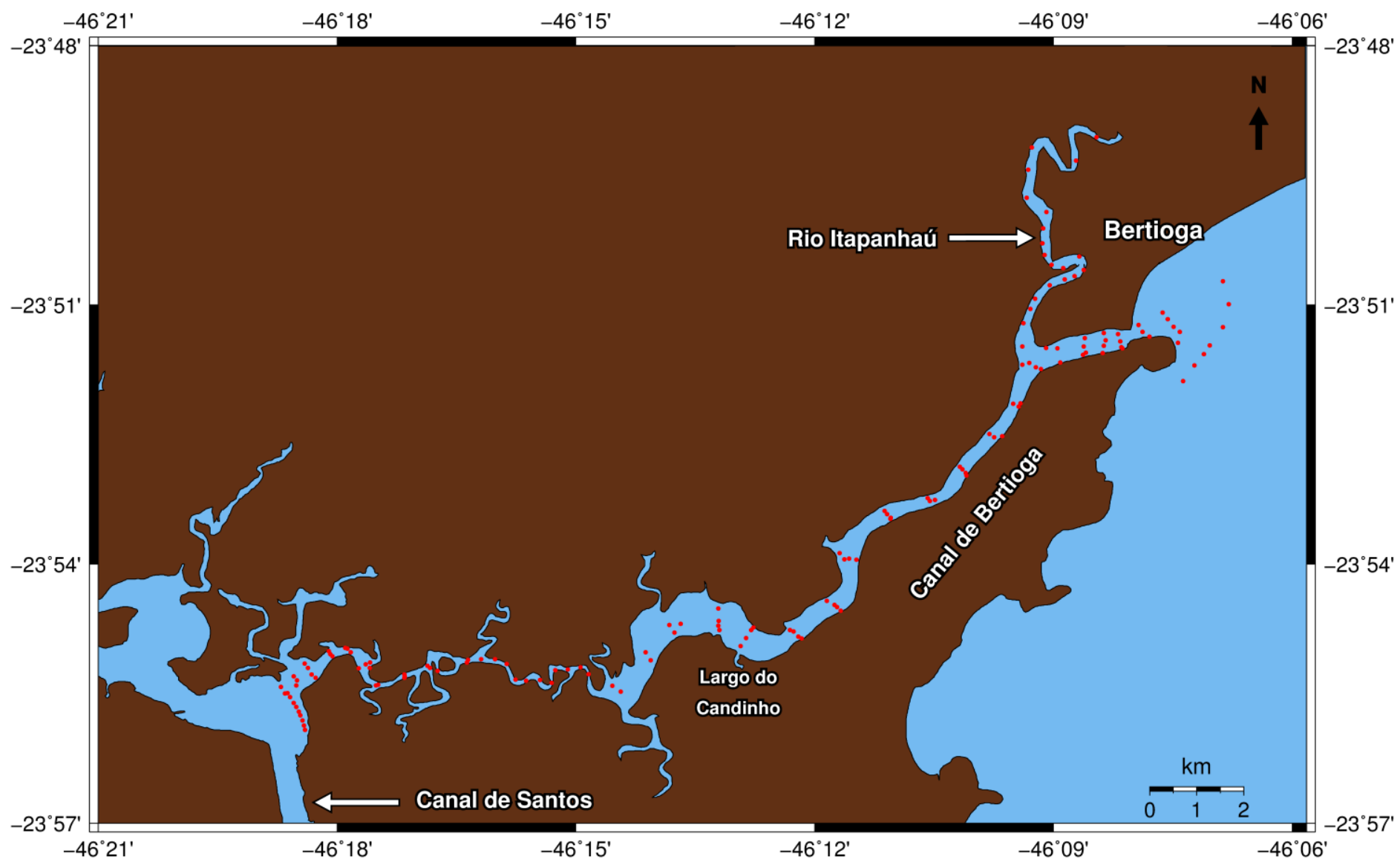

Figura 2. Localização dos pontos de coleta no Canal de Bertioga e Rio Itapanhaú. 
A posição de cada ponto foi determinada através de um GPS (Global Positioning System) manual da marca Garmin modelo GPSmap76S, utilizandose o datum WGS 84 para a região, as estações foram nomeadas em ordem crescente a partir da desembocadura do canal de Bertioga (\#1 a \#127). As amostras do Rio Itapanhaú foram nomeadas de \#1a até \#20a, a partir da foz do rio. As coordernadas geográficas, latitudes e longitudes, estão presentes nas Tabelas 1 e 2 do ANEXO.

Optou-se executar 20 pontos extras de coleta no Rio Itapanhaú que constitui a principal bacia hidrográfica da área e a principal fonte potencial de sedimentos, cuja descarga ocorre a apenas $2,5 \mathrm{~km}$ da desembocadura do Canal (SCHAEFFER-NOVELLI, 1986).

A coleta foi realizada nos dias 31 de janeiro, 01, 02 e 03 de fevereiro de 2011 ao longo do Canal, e no dia 24 de agosto de 2011 no Rio Itapanhaú, por meio do amostrador de fundo Van Veen (Figura 3), fabricado com aço inoxidável. O material coletado foi colocado em bandeja de plástico, com o auxílio de uma espátula de inox, foram amostrados os primeiros cinco centímetros do sedimento e este transferido para potes de polietileno. As amostras foram então identificadas e refrigeradas.

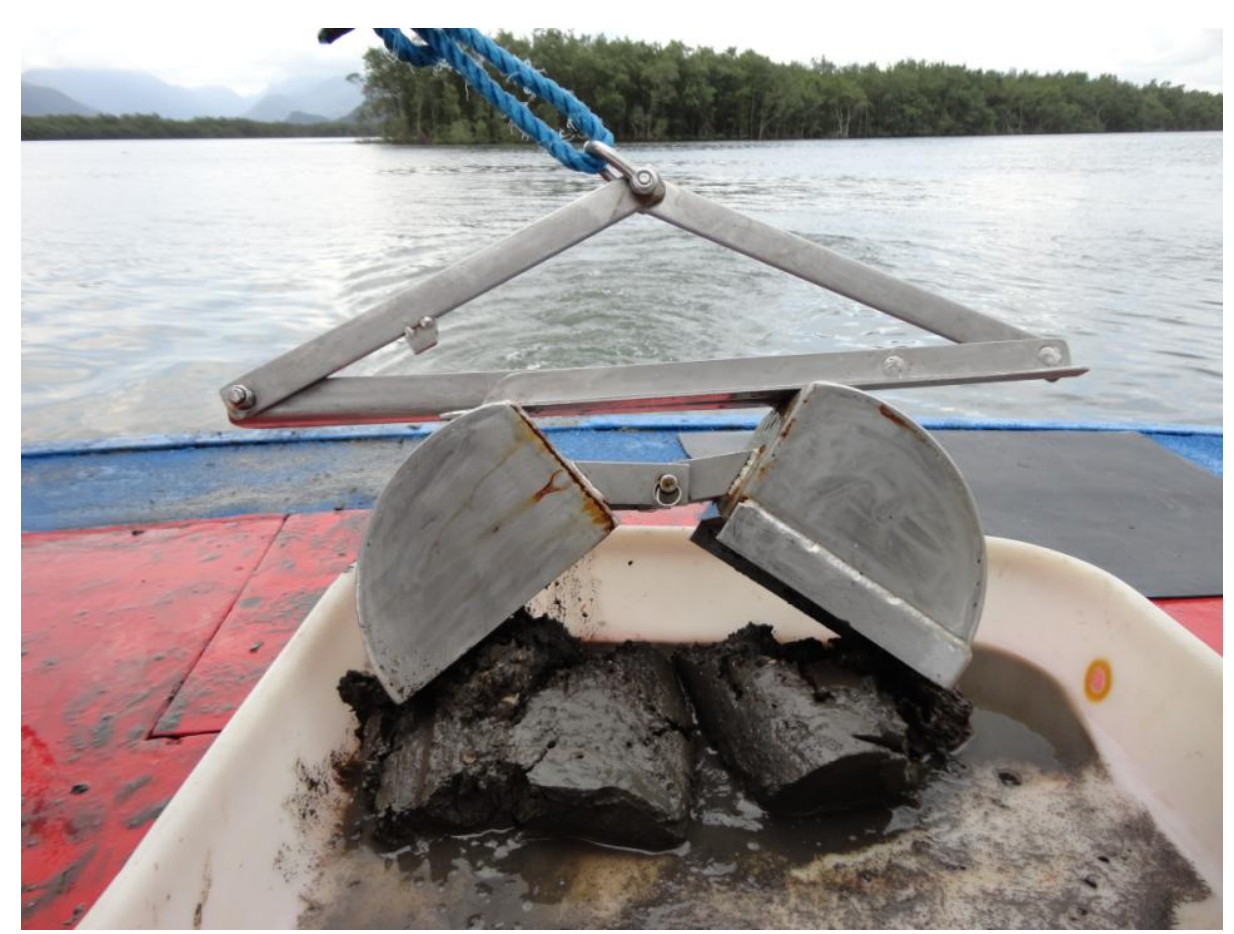

Figura 3. Van Veen utilizado na coleta do sedimento. 


\subsection{Pré-tratamento das amostras}

No Laboratório de Química Inorgânica Marinha (LaQIMar) do Instituto Oceanográfico da Universidade de São Paulo (IOUSP), as amostras coletadas foram congeladas e posteriormente liofilizadas. Para garantir a qualidade e confiabilidade dos resultados analíticos, após a liofilização foram maceradas e homogeneizadas em almofariz, e acondicionadas em frascos de polietileno.

\subsection{Análises de metais e As por espectrometria de emissão óptica com plasma indutivamente acoplado (ICP-OES)}

\subsubsection{Abertura das amostras}

A maioria das técnicas espectrométricas envolve a introdução das amostras na forma de soluções, sendo necessária a abertura (solubilização) das amostras sólidas.

Para analisar a disponibilidade dos metais no ambiente, foi feita a abertura das amostras mediante lixiviação por ataque ácido, segundo método 3050B U.S. EPA (United States Environmental Agency) (USEPA, 1996), ou seja, a digestão parcial da amostra. Este método consiste em uma digestão ácida capaz de dissolver a maior parte dos elementos de origem antrópica, liberando os elementos fracamente ligados ao sedimento (associados à matéria orgânica, argilas, óxidos, hidróxidos e carbonatos), sem causar ataque aos fragmentos cristalinos (constituídos pela matriz de silicato e elementos a ela associados) (MOZETO et al., 2006)

Para isso pesou-se na balança analítica aproximadamente $2 \mathrm{~g}$ da fração total de sedimento seco, foram adicionados $10 \mathrm{~mL}$ de $\mathrm{HNO}_{3}$ (1:1) sob aquecimento em chapa a $95^{\circ} \mathrm{C}$ por 15 minutos em sistema aberto, foi colocado um vidro de relógio sob o béquer para evitar eventuais perdas do analito de interesse por evaporação. Adicionou-se $5 \mathrm{~mL}$ de $\mathrm{HNO}_{3}$ concentrado e continuou-se o aquecimento por mais 30 minutos. Adicionou-se $5 \mathrm{~mL}$ de $\mathrm{HNO}_{3}$ concentrado até a completa oxidação da amostra, verificada pela ausência de vapores marrons, continuando o aquecimento por mais 1 hora e 30 minutos. A 
solução foi resfriada, adicionou-se então $2 \mathrm{~mL}$ de água e $3 \mathrm{~mL}$ de $\mathrm{H}_{2} \mathrm{O}_{2} 30 \%$, sob aquecimento. $\mathrm{O}$ procedimento continuou com a adição de $1 \mathrm{~mL}$ de $\mathrm{H}_{2} \mathrm{O}_{2}$ $30 \%$, até a completa eliminação da matéria orgânica. A solução foi filtrada em papel de filtro faixa lenta e, a seguir, foi diluída para $100 \mathrm{~mL}$ em balão volumétrico, procedendo-se então a análise (Figuras 4, 5 e 6 ).

Os materiais de referência e os brancos de reagentes foram processados da mesma forma que as amostras.

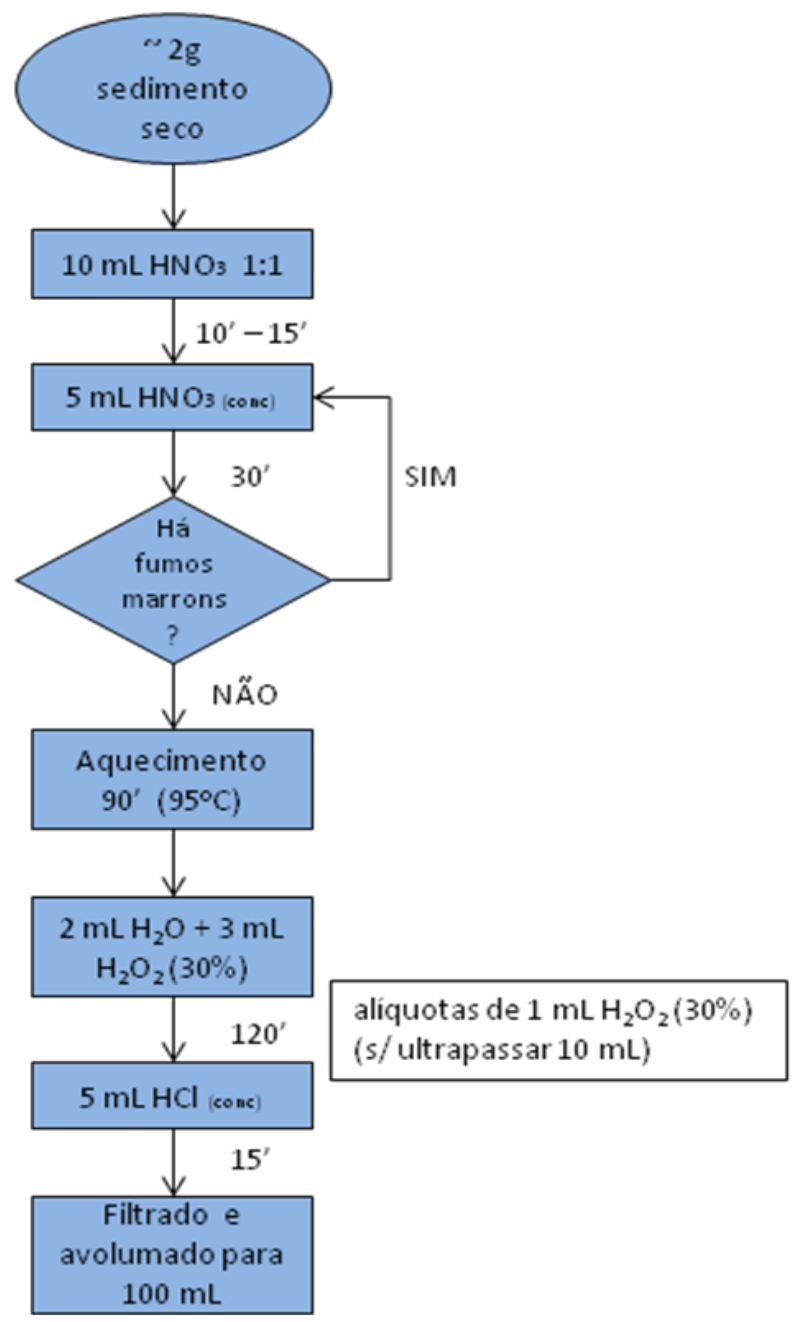

Figura 4. Fluxograma método de extração 3050B. 


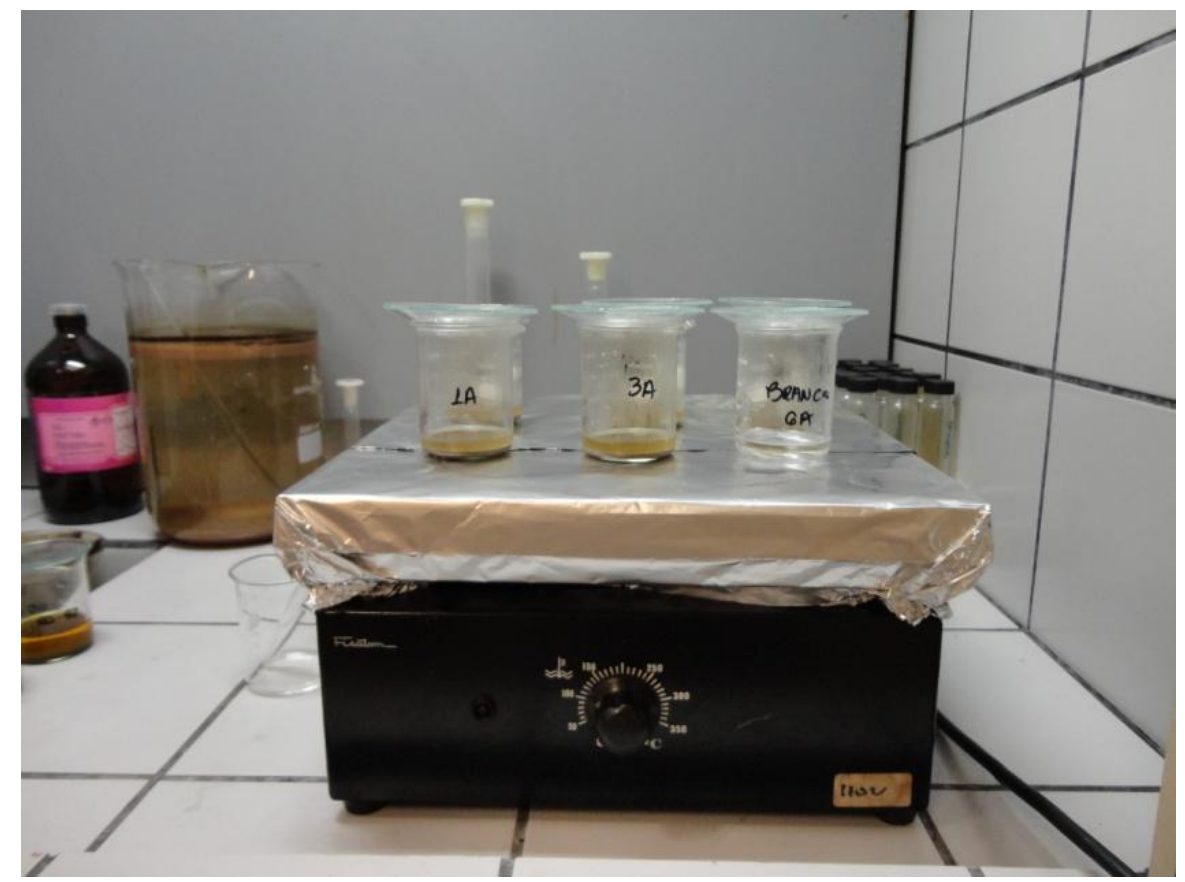

Figura 5. Solubilização das amostras em chapa aquecedora.

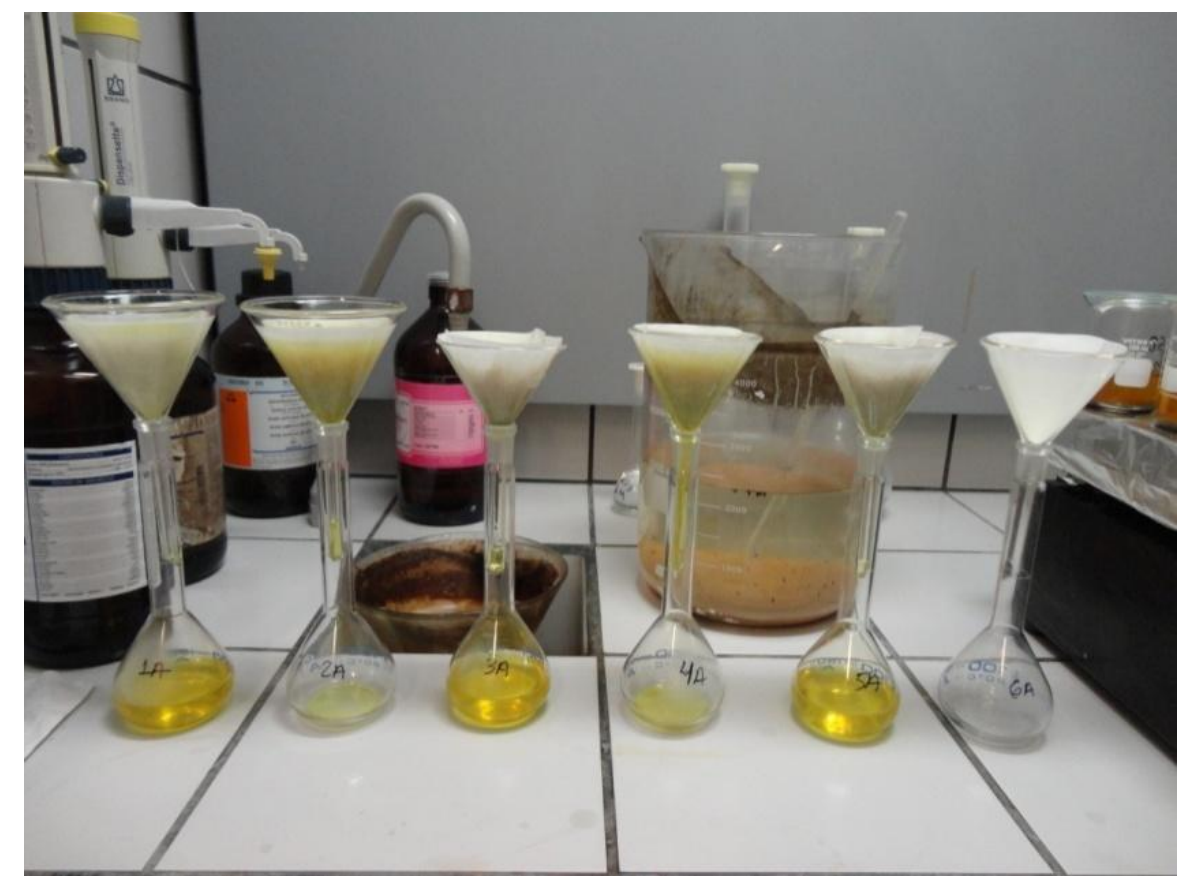

Figura 6. Amostras sendo filtradas e avolumadas para $100 \mathrm{~mL}$. 


\subsubsection{Determinação de metais e As por ICP-OES}

A determinação dos teores de alumínio $(\mathrm{Al})$, arsênio $(\mathrm{As})$, cádmio $(\mathrm{Cd})$, cromo $(\mathrm{Cr})$, cobre $(\mathrm{Cu})$, ferro $(\mathrm{Fe})$, manganês $(\mathrm{Mn})$, níquel $(\mathrm{Ni})$, chumbo $(\mathrm{Pb})$, escândio (Sc), vanádio (V) e zinco (Zn) foram quantificados por espectrometria de emissão óptica com plasma indutivamente acoplado (ICP-OES), segundo o método SW-846 US EPA 6010c (USEPA, 2007).

O equipamento utilizado foi um ICP-OES da marca Varian, modelo 710ES (Figura 7).

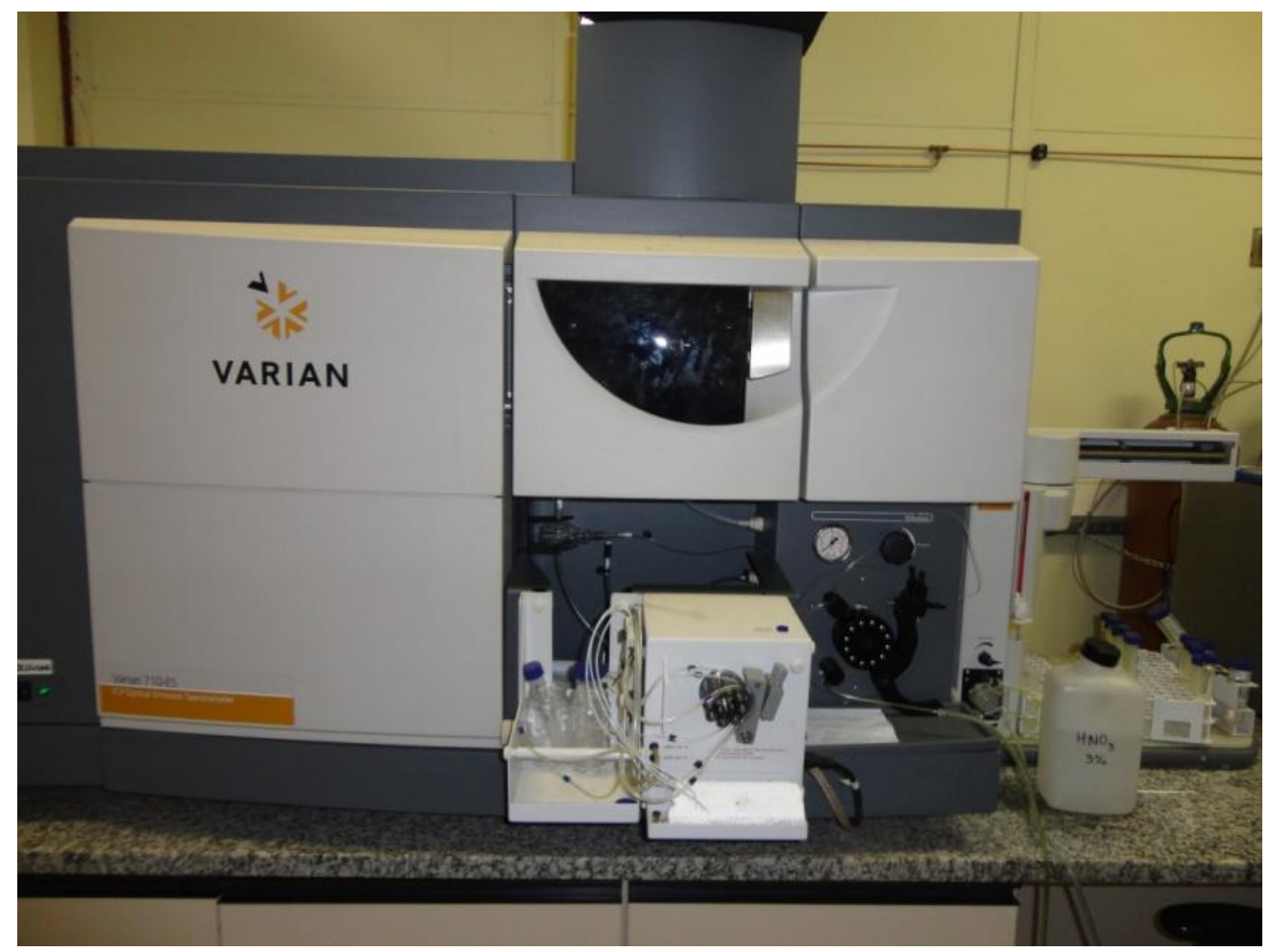

Figura 7. Equipamento utilizado nas determinações de metais e As (ICP-OES).

A espectrometria de emissão óptica usando plasma indutivamente acoplado (ICP) foi desenvolvida na década de 1960, como um método rápido, sensível e conveniente para determinação de elementos-traço, incluindo metais, em solução, em diversas matrizes (SKOOG et al., 1998).

A solução é transportada e convertida em um aerossol através do processo de nebulização. O aerossol é conduzido até o plasma de argônio e os átomos ou íons dos elementos são excitados por esta fonte de plasma em altas 
temperaturas (7.000-10.000K) para níveis maiores de energias. Imediatamente, os elétrons em estado excitado retornam ao estado fundamental emitindo energia na forma de luz (fótons), cada elemento possui suas radiações características. Essas radiações são direcionadas ao policromador que as decompõem e as separam por comprimentos de onda, que são correlacionadas às concentrações correspondentes através das curvas de calibração. A radiação selecionada é direcionada para um detector, CCD (Charge Coupled Device - detectores de estado sólido) (BOSS \& FREDDEN, 1997).

Uma grande vantagem da técnica de ICP-OES é a determinação de muitos elementos em uma mesma corrida analítica, as análises são realizadas com extrema precisão e exatidão suficiente para determinação em níveis traço. A excitação eficiente proporcionada pelo ICP resulta em baixos limites de detecção para muitos elementos. Este fato, associado à extensa faixa linear, permite uma determinação multielementar efetiva (BOSS \& FREDDEN, 1997).

A concentração dos elementos foram calculados com base na Equação1:

$$
[E]=\frac{V p X F d X V f}{m}
$$

sendo:

[E] : concentração do elemento de interesse, em mg/kg;

$\mathrm{Vp}$ : valor encontrado no plasma, em $\mathrm{mg} / \mathrm{L}$;

Vf : volume final, em $\mathrm{mL}$;

Fd : fator de diluição;

$\mathrm{m}$ : massa, em $\mathrm{g}$.

Foram realizadas três medidas da mesma amostra pelo equipamento, e os resultados obtidos são reportados pela média dos valores. 


\subsubsection{Limites de Detecção e Quantificação}

O limite de detecção (LD) é a menor concentração que um analito pode ser detectado, mensurado e reportado com $99 \%$ de confiança de que a sua concentração é maior do que zero (WADE \& CANTILLO, 1994).

Para a determinação do limite de detecção do método (LDM) dos elementos em estudo, foi realizada a análise de sete replicatas com concentrações conhecidas, preparadas a partir de soluções padrão. A concentração conhecida era a menor que o equipamento conseguiu detectar para cada elemento, o desvio-padrão das sete medidas foi multiplicado pelo valor de $t$-Student $(3,143)$ para um nível de confiança de $99 \%$.

O limite de quantificação do método (LQM) foi determinado considerando cinco vezes o LDM, o fator de diluição e a massa de sedimento utilizada no método de extração.

As linhas de emissão utilizadas na determinação de cada elemento, bem como os limites de detecção do método (LDM) e o limite de quantificação do método (LQM) estão apresentados na Tabela 3.

Tabela 3. Comprimento de onda utilizado, LDM e LQM para cada elemento.

\begin{tabular}{cccc}
\hline Elemento & $\begin{array}{c}\text { Comprimento de } \\
\text { onda } \\
(\mathbf{n m})\end{array}$ & $\begin{array}{c}\text { Limite de } \\
\text { detecção do } \\
\text { método } \\
\mathbf{( m g / k g})\end{array}$ & $\begin{array}{c}\text { Limite de } \\
\text { quantificação } \\
\text { do método } \\
\text { (mg/kg) }\end{array}$ \\
\hline $\mathbf{A l}$ & 396,152 & 0,3 & 1,6 \\
\hline $\mathbf{A s}$ & 188,980 & 0,1 & 0,4 \\
\hline $\mathbf{C d}$ & 214,439 & 0,1 & 0,6 \\
\hline $\mathbf{C r}$ & 226,502 & 0,1 & 0,5 \\
\hline $\mathbf{C u}$ & 267,716 & 0,07 & 0,3 \\
\hline $\mathbf{F e}$ & 327,395 & 0,2 & 1,2 \\
\hline $\mathbf{M n}$ & 238,204 & 0,2 & 1,0 \\
\hline $\mathbf{N i}$ & 257,610 & 0,05 & 0,3 \\
\hline $\mathbf{P b}$ & 231,604 & 0,1 & 0,7 \\
\hline $\mathbf{V}$ & 220,353 & 0,2 & 1,0 \\
\hline $\mathbf{Z n}$ & 292,401 & 0,4 & 2,0 \\
\hline
\end{tabular}




\subsubsection{Curva de calibração}

As curvas analíticas de calibração foram realizadas com padrões multielementares, para cada elemento de interesse foi construída uma curva com seis pontos com concentrações crescentes a partir de soluções padrão. As curvas foram obtidas sempre com coeficientes de correlação iguais ou maiores que 0,999 .

Na Figura 8, temos o exemplo de uma curva de calibração feita pelo software do equipamento para realização da análise de $\mathrm{Pb}$ nas amostras, no comprimento de onda 220,353 .

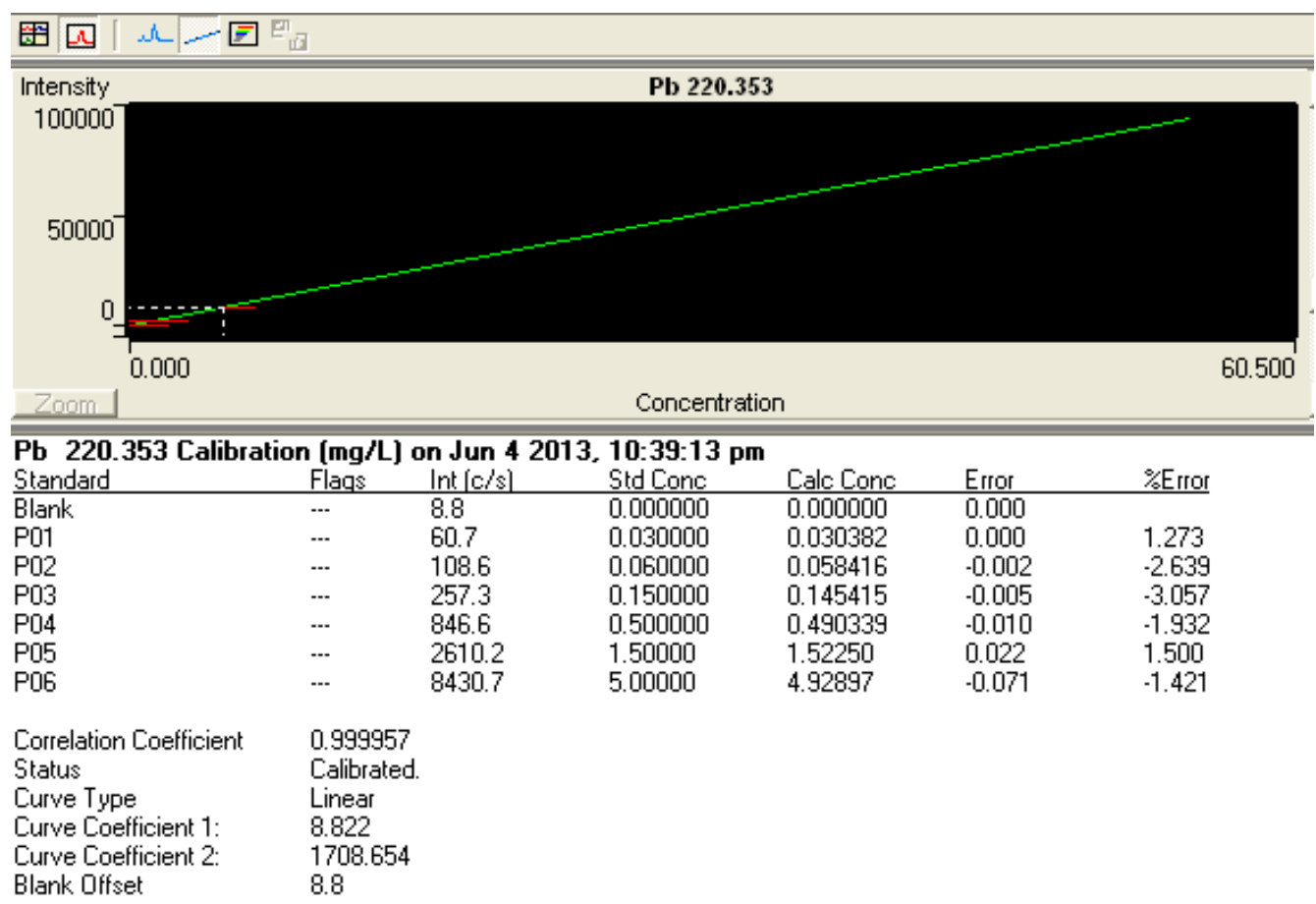

Figura 8. Curva de calibração construída para leitura do $\mathrm{Pb}(220,353 \mathrm{~nm})$.

Caso a concentração medida na amostra ultrapassasse o ponto da curva de maior valor, a amostra era então diluída obedecendo ao intervalo linear da curva de calibração. Para a leitura de Al e Fe, as amostras foram diluídas em até cem vezes. 


\subsubsection{Controle de qualidade}

A cada dez amostras analisadas, um padrão da curva de calibração foi medido novamente para verificar a variação do equipamento. A fim de verificar se houve efeito memória no ICP-OES, um branco foi analisado após a leitura das amostras.

Dois materiais de referência certificados (MRC) de solos contaminados SS-1 e SS-2 (EnviroMAT Contaminated Soil) foram submetidos ao mesmo método de extração das amostras (EPA 3050B) para controle da qualidade analítica, verificando a eficiência de extração. Nas Tabelas 4 e 5 estão apresentados os resultados obtidos das médias dos materiais de referência utilizados: SS-1 e SS-2 $(n=5)$, bem como o valor certificado, o intervalo de tolerância e as porcentagens de recuperação.

Foram realizados brancos de reagentes também sujeitos a mesma extração, a fim de eliminar as possibilidades de contaminações através dos mesmos.

Tabela 4. Resultados do material de referência certificado SS-1 $(n=5)$.

\begin{tabular}{|c|c|c|c|c|c|}
\hline Elemento & $\begin{array}{c}\text { Valor de } \\
\text { Referência } \\
(\mathbf{p p m})\end{array}$ & $\begin{array}{c}\text { Intervalo de } \\
\text { Confiança } \\
(\mathbf{p p m})\end{array}$ & $\begin{array}{c}\text { Intervalo de } \\
\text { Tolerância } \\
(\mathbf{p p m})\end{array}$ & $\begin{array}{c}\text { Média SS-1 } \\
(\mathbf{n = 5}) \\
(\mathbf{m g} / \mathbf{k g})\end{array}$ & $\begin{array}{c}\% \\
\text { recuperação }\end{array}$ \\
\hline $\mathbf{A l}$ & 9518 & $8417-10619$ & $3276-15760$ & 9971,05 & 104,76 \\
\hline $\mathbf{A s}$ & 18 & $17-19$ & $13-23$ & 17,92 & 99,55 \\
\hline $\mathbf{C d}$ & 34 & $32-36$ & $24-44$ & 29,78 & 87,59 \\
\hline $\mathbf{C r}$ & 64 & $55-73$ & $13-115$ & 60,89 & 95,14 \\
\hline $\mathbf{C u}$ & 690 & $657-723$ & $503-877$ & 682,28 & 98,88 \\
\hline $\mathbf{F e}$ & 20406 & $19037-21775$ & $12645-28167$ & 21544,38 & 105,58 \\
\hline $\mathbf{M n}$ & 425 & $406-444$ & $317-533$ & 362,60 & 85,32 \\
\hline $\mathbf{N i}$ & 231 & $218-244$ & $157-305$ & 208,25 & 90,15 \\
\hline $\mathbf{P b}$ & 233 & $219-247$ & $152-314$ & 191,90 & 82,36 \\
\hline $\mathbf{V}$ & 19 & $17-21$ & $8-30$ & 18,08 & 95,14 \\
\hline $\mathbf{Z n}$ & 6775 & $6467-7083$ & $5066-8484$ & 5084,24 & 75,04 \\
\hline
\end{tabular}


Tabela 5. Resultados do material de referência certificado SS-2 $(n=5)$.

\begin{tabular}{|c|c|c|c|c|c|}
\hline Elemento & $\begin{array}{c}\text { Valor de } \\
\text { Referência } \\
(\mathbf{p p m})\end{array}$ & $\begin{array}{c}\text { Intervalo de } \\
\text { Confiança } \\
(\mathbf{p p m})\end{array}$ & $\begin{array}{c}\text { Intervalo de } \\
\text { Tolerância } \\
(\mathbf{p p m})\end{array}$ & $\begin{array}{c}\text { Média SS-2 } \\
(\mathbf{n = 5}) \\
(\mathbf{m g} / \mathbf{k g})\end{array}$ & $\begin{array}{c}\% \\
\text { recuperação }\end{array}$ \\
\hline $\mathbf{A l}$ & 13265 & $12114-14416$ & $6743-19787$ & 12111,59 & 91,30 \\
\hline $\mathbf{A s}$ & 75 & $65-85$ & $25-125$ & 74,61 & 99,47 \\
\hline $\mathbf{C d}$ & 2 & - & - & 1,82 & 91,25 \\
\hline $\mathbf{C r}$ & 34 & $30-38$ & $14-54$ & 31,80 & 93,52 \\
\hline $\mathbf{C u}$ & 191 & $182-200$ & $139-243$ & 185,69 & 97,22 \\
\hline $\mathbf{F e}$ & 21046 & $19597-22495$ & $12831-29261$ & 20273,48 & 96,33 \\
\hline $\mathbf{M n}$ & 457 & $433-481$ & $324-590$ & 428,38 & 93,74 \\
\hline $\mathbf{N i}$ & 54 & $50-58$ & $33-75$ & 49,50 & 91,66 \\
\hline $\mathbf{P b}$ & 126 & $116-136$ & $68-184$ & 104,62 & 83,03 \\
\hline $\mathbf{V}$ & 34 & $31-37$ & $17-51$ & 34,37 & 101,09 \\
\hline $\mathbf{Z n}$ & 467 & $444-490$ & $337-597$ & 439,51 & 94,11 \\
\hline
\end{tabular}

Os resultados dos valores de recuperação obtidos para os MRC foram satisfatórios para todos os elementos em estudo, com porcentagem de recuperação dentro da faixa recomendada pela USEPA (1996) entre 75-125\%.

\subsection{Determinação dos sedimentos finos}

Os valores de granulometria são de grande importância para este trabalho uma vez que o tamanho dos grãos influi diretamente no teor de metais e na caracterização da matéria orgânica sedimentar. A análise granulométrica possibilita a quantificação dos componentes, areia, silte e argila, expressos em percentagem de cada fração granulométrica em relação à fração total de sedimento seco em estufa.

Optou-se por determinar nas amostras de sedimento deste estudo apenas a porcentagem da fração fina (silte + argila) que é fração menor do que $0,062 \mathrm{~mm}$, isso devido a maior parte dos contaminantes serem adsorvidas nos grãos finos, onde a superfície de contato é maior (FÖRSTNER \& SALOMONS, 1980). Variações nas concentrações dos elementos em função da granulometria do sedimento são atribuídas a diferenças no seu potencial de adsorção sobre minerais argilosos, óxidos metálicos e matéria orgânica, os quais tendem a estar concentrados em agregados menores (KERSTEN \& FÖRSTNER, 1995). 
A determinação dos sedimentos finos foi feita por peneiramente úmido passando-se uma alíquota da amostra ( $10 \mathrm{~g}$ de sedimento seco) pela peneira de $0,062 \mathrm{~mm}$. O material que ficou retido na peneira foi seco em estufa a $60 \stackrel{\circ}{\mathrm{C}}$ e pesado novamente para determinação do teor de areia $(>0,062 \mathrm{~mm})$, a diferença da massa inicial menos a massa de areia é a fração fina $(<0,062$ $\mathrm{mm}$ ) que corresponde às frações silte mais argila (lama).

\subsection{Análises de conteúdo de carbonato de cálcio, carbono orgânico e nitrogênio total, e das razões isotópicas $\delta^{13} \mathrm{C} /{ }^{12} \mathrm{C}$ e $\delta^{15} \mathrm{~N} /{ }^{14} \mathrm{~N}$ por EA- IRMS}

O conteúdo em carbonato de cálcio $\left(\mathrm{CaCO}_{3}\right)$ foi determinado pesandose aproximadamente $1 \mathrm{~g}$ de sedimento o qual foi digerido com $2 \mathrm{~mL}$ de $\mathrm{HCl}$ $10 \%$, permanecendo nessa solução por 24 horas. Foram adicionadas algumas gotas de $\mathrm{HCl}$ concentrado a fim de certificar a total eliminação de carbonato de cálcio verificada pela ausência de formação de bolhas, em seguida completouse $o$ volume até $9 \mathrm{~mL}$ com água Milli-Q e as amostras foram centrifugadas a $2100 \mathrm{rpm}$ por 11 minutos. O líquido sobrenadante foi descartado e a lavagem foi repetida por 5 vezes ou mais até a total eliminação do ácido, com a verificação do sobrenadante com papel indicador de $\mathrm{pH}$. As amostras foram secas em estufa a $60 \stackrel{\circ}{\circ} \mathrm{C}$ e o teor de $\mathrm{CaCO}_{3}$ foi determinado por diferença em massa antes e após o ataque.

A porcentagem de carbono orgânico total (COT) e a razão isotópica $\delta^{13} \mathrm{C} /{ }^{12} \mathrm{C}$ foram determinados em alíquota de sedimento submetido ao ataque de $\mathrm{HCl}$ (sem $\mathrm{CaCO}_{3}$ ). Aproximadamente $10 \mathrm{mg}$ da amostra foram acondicionados em cápsulas de estanho e submetidas no analisador elementar Costech Instruments Elemental Combustion System acoplado ao detector de espectrometria de massas com razão isotópica Thermo Scientific Delta $V$ Advantage Isotope Ratio MS (EA-IRMS).

$\mathrm{O}$ teor de nitrogênio total (NT) e a razão isotópica $\delta^{15} \mathrm{~N} /{ }^{14} \mathrm{~N}$ foram determinados pesando-se $10 \mathrm{mg}$ de sedimento sem $\mathrm{o}$ ataque ácido e acondicionadas em cápsula de estanho, sendo submetidas a análise no 
espectrômetro de massas EA-IRMS (Elemental Analyzer - Isotope Ratio Mass Spectrometer).

Os conteúdos de COT e NT foram apresentados em porcentagem (\%), e as razões isotópicas $\delta^{13} \mathrm{C}$ e $\delta^{15} \mathrm{~N}$ foram expressas na forma de $\delta \%$, de acordo com a seguinte equação:

$$
\delta=\left(\frac{R \text { amostra }}{R \text { referência }}-1\right) X 1000
$$

sendo:

$\mathrm{R}_{\text {amostra: }}$ razão isotópica determinada na amostra de interesse;

$\mathrm{R}_{\text {referência: }}$ razão isotópica determinada no padrão de referência (gás: $\mathrm{CO}_{2}$ para $\delta^{13} \mathrm{C}$ e $\mathrm{N}_{2}$ para $\delta^{15} \mathrm{~N}$ ).

A porcentagem em massa de COT e NT foi obtida através da relação entre as proporções do padrão e das áreas correspondentes aos picos obtidos do padrão e da amostra:

$$
\%=\left(\frac{\% \text { padrão } x \text { m padrão }}{A \text { padrão }}\right) \times \text { A amostra }
$$

sendo:

$m$ padrão: massa do padrão utilizada;

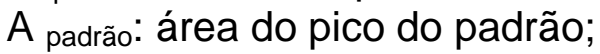

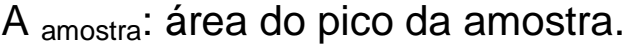

O padrão utilizado para a quantificação das porcentagens foi o Solo LECO 502- 309 - LECO Corporation, cujo teor de carbono é 13,77\% e de nitrogênio 0,092 \%.

A cada corrida de 40 amostras é injetado dois padrões certificados para avaliar a calibração do equipamento. Um deles é o USGS-40 com valores de $\delta^{13} \mathrm{C}=-26,388 \%$ e de $\delta^{15} \mathrm{~N}=-4,5 \%$, o outro é o IAEA-600 com $\delta^{13} \mathrm{C}=-$ $27,777 \%$ e de $\delta^{15} \mathrm{~N}=+1,0 \%$. 
Para a avaliação da repetibilidade das medidas foi injetada a cada 10 amostras uma amostra de sedimento utilizado pelo Laboratório como padrão secundário.

Para determinação dos conteúdos de carbono orgânico e nitrogênio total, bem como dos isótopos estáveis $\delta^{13} \mathrm{C} /{ }^{12} \mathrm{C}$ e $\delta^{15} \mathrm{~N} /{ }^{14} \mathrm{~N}$, foi pesado em balança analítica da marca Sartorius $10 \mathrm{mg}$ da amostra (amostra sem carbonato para análise de carbono e amostra sem o ataque ácido para análise de nitrogênio) em cápsulas de estanho. Esses conteúdos foram determinados através do analisador elementar IRMS acoplado com Delta $\mathrm{V}$ da Thermo Scientific. Esses dados composicionais serão utilizados como índices auxiliares para a identificação de variações ambientais.

\subsection{Parâmetros geoquímicos para avaliação do grau de contaminação}

A interpretação dos resultados de metais e As é dificultada pelo fato de que a concentração absoluta é influenciada por diversos fatores que podem alterar a acumulação de metais no sedimento, como a mineralogia dos sedimentos, teor de matéria orgânica, granulometria e o aporte antrópico. Os métodos de normalização foram criados para tentar minimizar esses erros. Segundo CLARK et al. (2000) os procedimentos podem ser divididos em cinco grupos:

- normalização pela granulometria, através dos tamanhos das partículas;

- extrapolação da curva de regressão;

- correção com mineral inerte;

- fração quimicamente móvel;

- fator de enriquecimento, que é a comparação com um elemento conservativo.

Todos esses métodos apresentam vantagens e desvantagens e segundo HORTELLANI et al. (2008), a melhor forma de minimizar esses erros é a combinação de diferentes métodos. Neste trabalho optou-se avaliar o grau de contaminação do sedimento pelo fator de concentração e pelo fator de enriquecimento.

O Fator de Concentração (FC) indica quantas vezes o elemento está enriquecido em relação aos valores naturais de background. Esses valores de 
background geoquímico litogênico foram obtidos de SARTORETTO (2011), que também fez parte do Projeto FAPESP "Histórico da atividade antrópica no Canal da Bertioga. Níveis de metais e semimetais em colunas sedimentares". Nesse trabalho foram analisados cinco testemunhos longos dentro do Canal de Bertioga, os valores de background foram obtidos através da média dos valores de digestão total das amostras da base desses testemunhos.

O FC pode ser calculado através da seguinte expressão:

$$
F C=\frac{[E] \text { amostra }}{[E] \text { background }}
$$

sendo:

FC: fator de concentração;

[ E ] amostra : concentração do elemento na amostra de interesse, em mg/kg;

[ E ] background: concentração background do elemento, em mg/kg.

Valores de FC maiores do que 1 indicam que há uma contribuição antrópica do elemento em estudo, com valores acima dos níveis naturais esperados.

O fato de as diversas camadas do sedimento de fundo revelar registros históricos dos níveis naturais de background e da acumulação de metais induzida pelo homem torna essencial a diferenciação entre os metais associados aos componentes naturais e não naturais do sedimento. Assim sendo, cada área deve ser estudada com relação às suas interferências particulares, considerando-se os diversos sistemas geológicos, geoquímicos e antrópicos presentes.

Para a quantificação e comparação do grau de contaminação em ambiente fluvial e estuarino tem sido utilizado também o fator de enriquecimento (SZEFER et al., 1998). Segundo KERSTEN et al. (1989), a utilização de fatores de enriquecimento é uma forma de relacionar os teores de metais nos sedimentos com os teores de fundo. O elemento normalizador é, em geral, um elemento químico pouco móvel, deve ter predominantemente origem natural e ser um importante constituinte das partículas carreadoras de metais traço e refletir a variação granulométrica dos sedimentos. Os valores de 
referência podem ser as composições médias crustais ou os teores no nível de base (background). Segundo LORING \& RANTALA (1992) os elementos mais utilização como normalizadores são: Al, Fe e Sc. Neste estudo optou-se pela utilização do Escândio (Sc) como referência, pois sua concentração não é significativamente afetada por atividades antrópicas, apresenta boa correlação com a granulometria e é conservativo em materiais sedimentares.

O fator de enriquecimento (FE) pode ser calculado de acordo com a Equação 5 (SZEFER et al., 1998).

$$
F E=\frac{\left(\frac{[E]}{[N]}\right) \text { amostra }}{\left(\frac{[E]}{[N]}\right) \text { background }}
$$

sendo:

FE: fator de enriquecimento;

[ E ] : concentração do elemento de interesse, em mg/kg;

[ N ] : concentração do elemento de normalizador, em mg/kg.

Quando os valores de Fator de Enriquecimento estão abaixo de 2, estes são considerados normais, ou seja, a principal fonte do metal é considerada como sendo a crosta terrestre. Valores entre 2 e 5 representam uma contaminação moderada. A poluição no ambiente é considerada significativa com valores de FE entre 5 e 20. Com valores encontrados entre 20 e 40, a poluição é caracterizada como alta. Valores de FE acima de 40 representam um local extremamente poluído (ANDREWS \& SUTHERLAND, 2004). 


\subsection{Tratamento dos dados}

Os resultados obtidos foram plotados na forma de mapas, onde podemos observar sua distribuição espacial. Os mapas foram gerados através do programa Generic Mapping Tools (GMT) versão 4.5.8, para melhor representação das análises, os valores obtidos foram interpolados respeitando a linha de costa. Foi utilizada a interpolação por vizinhos por busca em 8 quadrantes com raio de alcance da busca de 1,2 km ao redor do nó na grade de interpolação. Quando mais de um valor for encontrado, é realizada uma média ponderada pelas distâncias entre os valores e o nó da grade de interpolação. O espaçamento entre os nós é regular e de 100 metros.

Foi realizada uma estatística descritiva dos resultados, tendo por objetivo sintetizar a série de dados obtidos, permitindo uma visão geral da variação desses parâmetros. Para tal, foram calculados os valores máximos e mínimos, a média, o desvio-padrão e a mediana.

Visando agrupar os resultados obtidos em grandes conjuntos de dados em novas variáveis facilitando a interpretação dos mesmos, foi realizada a análise da correlação de Pearson e a estatística multivariada utilizando a Análise de Agrupamentos (Cluster analysis), o software utilizado foi o STATISTICA versão 7.1 .

Como a legislação brasileira não dispõe de critérios que estabeleça condições e padrões de qualidade para avaliar o sedimento, optou-se por utilizar os critérios estabelecidos pela agência ambiental canadense (ENVIRONMENT CANADA, 1999a), que apresentam dois níveis de classificação : TEL (Threshold Effect Level) ou Nível 1 - concentração abaixo da qual não são esperados efeitos adversos sobre organismos aquáticos e PEL (Probable Effect Level) ou Nível 2 - concentração acima da qual são esperados efeitos adversos severos sobre organismos aquáticos. Na faixa entre TEL (Nível 1) e PEL (Nível 2) situam-se os valores onde ocasionalmente espera-se tais efeitos.

O grau de contaminação química do sedimento foi avaliado segundo o padrão de qualidade de sedimentos estabelecido pelo Canadian Sediment Quality Guidelines for the Protection of Aquatic Life (CEQG, 2001) e estão expressos na Tabela 6. 
Tabela 6. Valores de concentração, em mg kg${ }^{-1}$, estabelecidos pelo CEGQ (2001).

\begin{tabular}{|c|c|c|}
\hline $\begin{array}{c}\text { Metais e } \\
\text { Metalóides }\end{array}$ & $\begin{array}{c}\text { TEL } \\
\text { (Nível1) }\end{array}$ & $\begin{array}{c}\text { PEL } \\
\text { (Nível2) }\end{array}$ \\
\hline $\mathbf{A s}$ & 7,24 & 41,60 \\
\hline $\mathbf{C r}$ & 52,3 & 160 \\
\hline $\mathbf{C u}$ & 18,7 & 108 \\
\hline $\mathbf{N i}$ & 20,9 & 51,6 \\
\hline $\mathbf{P b}$ & 30,2 & 112 \\
\hline $\mathbf{Z n}$ & 124 & 271 \\
\hline
\end{tabular}




\section{RESULTADOS E DISCUSSÃO}

\subsection{Distribuição de sedimentos finos}

A Tabela 7 presente no ANEXO apresenta a porcentagem da fração fina $(<0,062 \mathrm{~mm})$ para cada ponto amostrado. De acordo com as Figuras 9 e 10 , os resultados variaram bastante ao longo do canal com valor mínimo apresentado de $1,39 \%$ e máximo de $99,11 \%$.

De um modo geral, o teor de areia (fração maior $>0,062 \mathrm{~mm}$ ) prevaleceu sobre os finos na parte oriental do canal, nos pontos próximos a desembocadura (\# 1 a 51 ) devido a forte influência das correntes de maré nessa região favorecendo a deposição dos sedimentos mais grossos.

A partir da amostra \#52, localizada próximo ao Rio Tia Maria e Iriri prevalecem os sedimentos finos. Na região central do canal (Largo do Candinho) foi verificada uma maior porcentagem de sedimentos finos, com valores maiores que $90 \%$, local onde não é verificada a influência da maré (MIRANDA et al., 1998), favorecendo a sedimentação dos mesmos.

Ao longo do Rio Itapanhaú as amostras, com exceção de três pontos (\#5a, 6a e 13a), apresentaram valores abaixo de 50\% para o teor de finos, prevalecendo os sedimentos arenosos, verificando a existência de um grande aporte fluvial para o Canal de Bertioga, e também a possibilidade deste rio localizado próximo a barra estar sobre forte influência das marés.

Segundo EICHLER (2001) a composição sedimentar do Canal é de sedimentos finos, principalmente lama nas regiões mais internas, já as regiões mais externas (desembocaduras do canal) apresentam sedimentos arenosos o que condiz com os resultados apresentados neste trabalho. 


\section{$\%$ finos (silte + argila)}

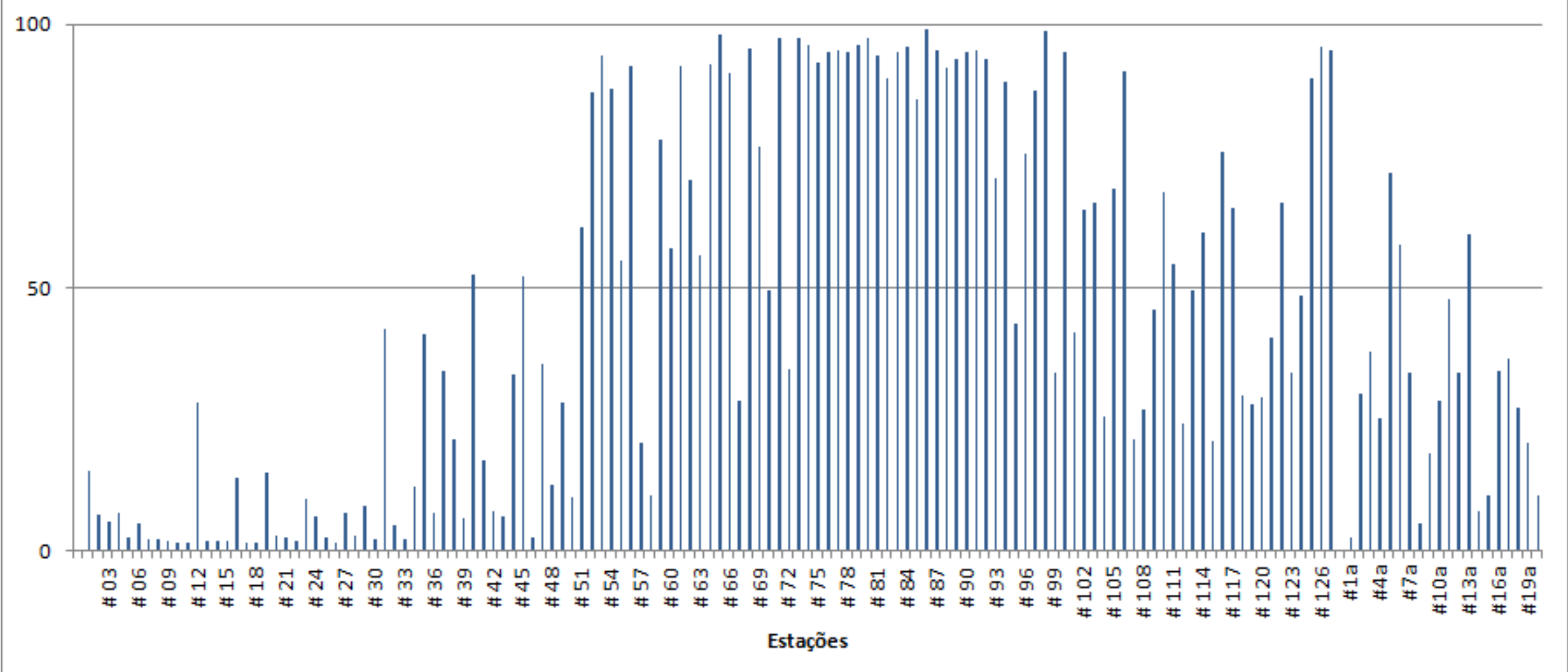

Figura 9. Porcentagem de finos (silte + argila) obitdos nas amostras. 


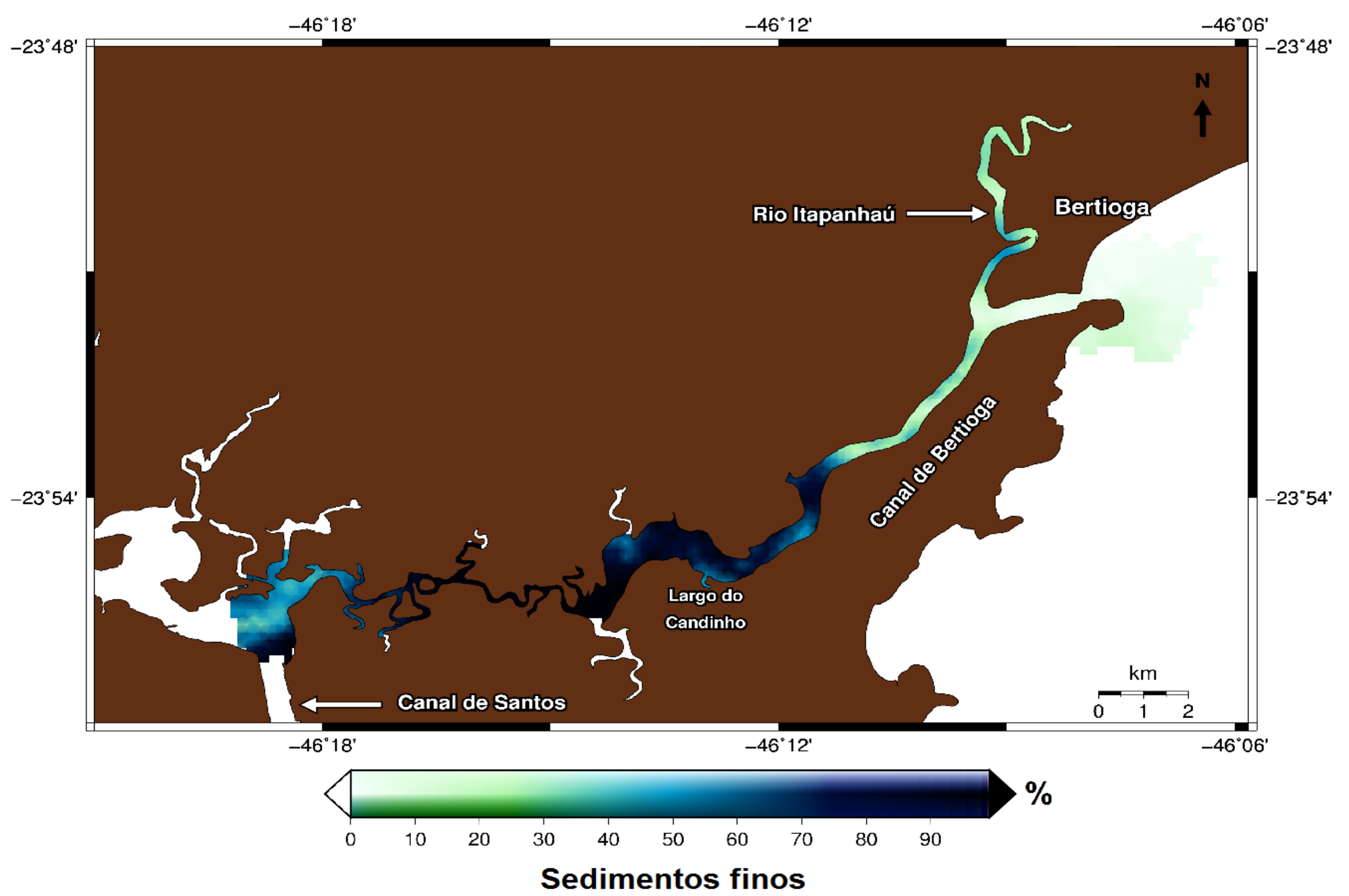

Figura 10. Distribuição de sedimentos finos ao longo do Canal de Bertioga. 


\subsection{Teor de metais e As}

A Tabela 8 apresenta os parâmetros descritivos dos teores de metais e As para o sedimento superficial do Canal de Bertioga e Rio Itapanhaú. Nas Tabelas 9 e 10 do ANEXO estão representados os valores obtidos para todos os pontos de amostragem.

Tabela 8. Parâmetros descritivos de metais e As, em $\mathrm{mg} \mathrm{kg}^{-1}$.

\begin{tabular}{|c|c|c|c|c|c|c|c|c|c|c|c|}
\hline Elemento & $\mathrm{As}$ & $\mathrm{Al}$ & $\mathrm{Cr}$ & $\mathrm{Cu}$ & $\mathrm{Fe}$ & $\mathrm{Mn}$ & $\mathrm{Ni}$ & $\mathrm{Pb}$ & $\mathrm{Sc}$ & $\mathrm{V}$ & $\mathrm{Zn}$ \\
\hline máximo & 14,74 & 38336,30 & 33,13 & 23,29 & 33747,80 & 630,04 & 12,81 & 43,43 & 5,87 & 37,83 & 94,39 \\
\hline mínimo & 0,46 & 2305,14 & 3,14 & 0,70 & 3348,12 & 37,90 & 1,16 & 1,54 & 0,53 & 4,72 & 7,45 \\
\hline média & 7,48 & 14569,55 & 15,83 & 6,99 & 17136,25 & 212,19 & 6,12 & 9,65 & 2,83 & 20,08 & 39,73 \\
\hline mediana & 7,76 & 13676,10 & 14,20 & 6,06 & 16226,30 & 189,85 & 5,58 & 7,49 & 2,60 & 18,70 & 35,17 \\
\hline $\begin{array}{c}\text { desvio } \\
\text { padrão }\end{array}$ & 3,15 & 9005,48 & 8,40 & 5,31 & 8252,97 & 117,73 & 3,42 & 6,57 & 1,60 & 9,33 & 22,86 \\
\hline
\end{tabular}

Com relação ao elemento $\mathrm{Cd}$, apesar de ter apresentado uma recuperação satisfatória nos materiais de referência SS-1 e SS-2 (Tabela 4 e 5), os resultados obtidos nas amostras não foram reportados e discutidos neste trabalho em virtude deste metal apresentar forte interferência espectral pelo $\mathrm{Fe}$ nas energias 214,439 e $226,502 \mathrm{~nm}$, conforme visto pelas figuras abaixo (Figuras 11 e 12). O ferro é um dos interferentes mais comuns, pois ele geralmente está presente como elemento maior em amostras de sedimentos e possui um espectro de emissão bastante extensa (MCLAREN et al., 1981). Uma vez que os teores de Cd obtidos nas amostras foram abaixo de $0,5 \mathrm{mg} / \mathrm{kg}$, a correção desta interferência não foi aplicada pois os resultados ficariam abaixo do LQM do equipamento analítico (ICP-OES). 

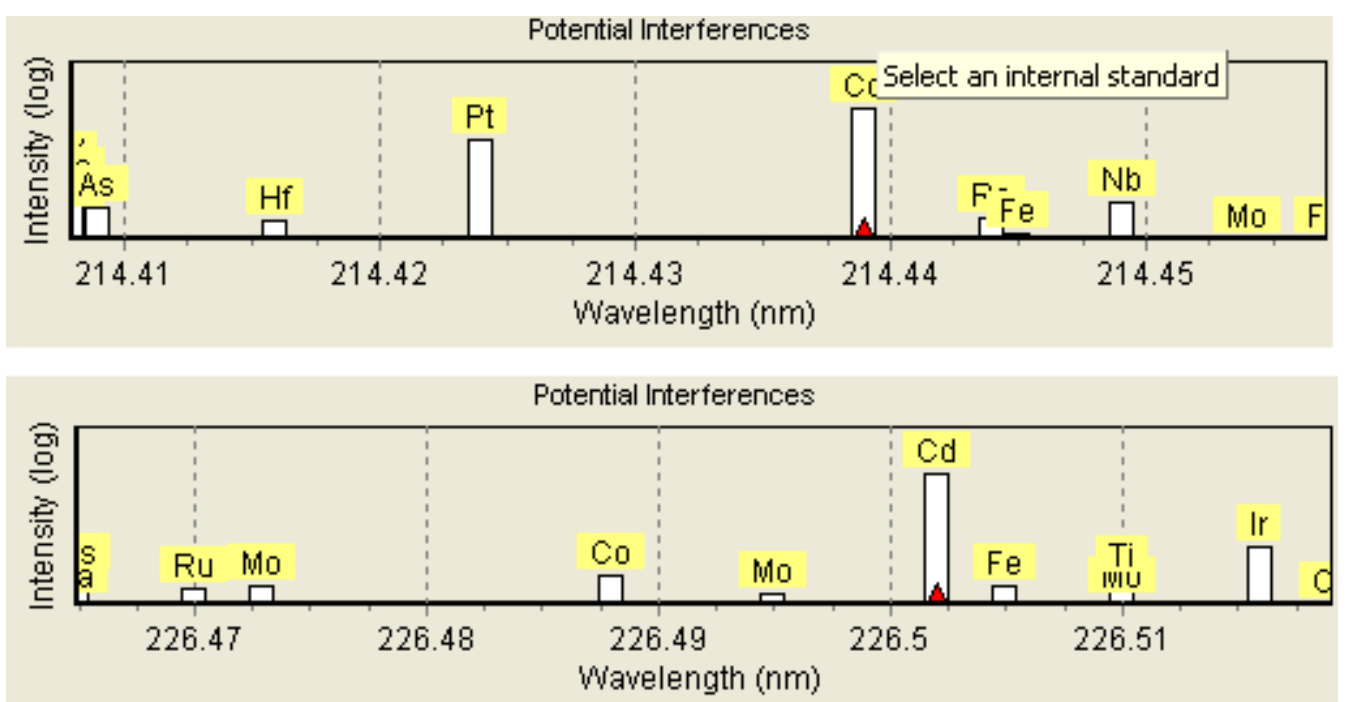

Figura 11. Potenciais interferentes espectrais do $\mathrm{Cd}(\lambda=214,439$ e 226,502 $\mathrm{nm})$.

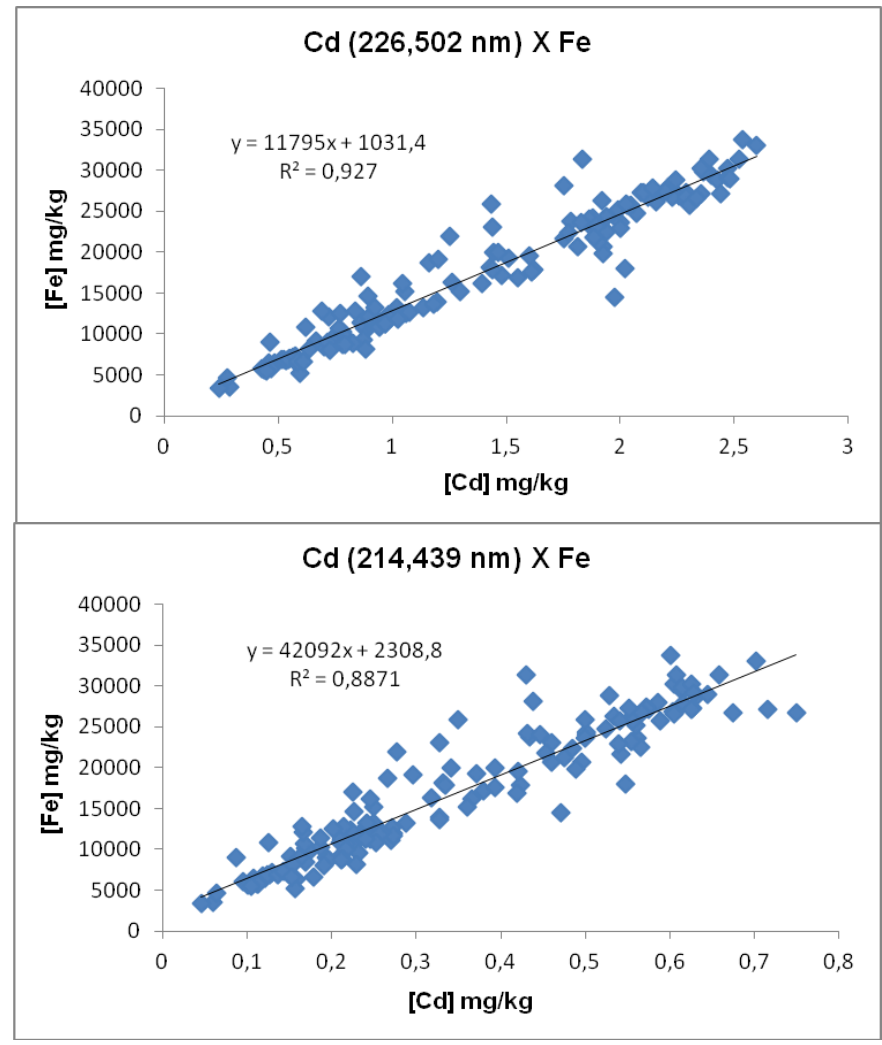

Figura 12. Gráfico de correlação linear de Cd medido no comprimento de onda 214,439 e $226,502 \times$ Fe. 
A concentração de arsênio variou entre 0,46 e 14,74 mg/kg, a média dos valores foi de $(7,48 \pm 3,15) \mathrm{mg} / \mathrm{kg}$. Os menores teores foram localizados entre a desembocadura do Rio Tia Maria e Itapanhaú, e nas amostras ao longo do Itapanhaú. Valores mais altos foram apresentados próximos à cidade de Bertioga, e do meio Canal para a parte ocidental (Figura 13), um padrão diferenciado em relação aos demais elementos analisados.

De um modo geral concentrações de $\mathrm{Al}, \mathrm{Cr}, \mathrm{Fe}, \mathrm{Mn}, \mathrm{Ni}, \mathrm{Sc}, \mathrm{V}$ e $\mathrm{Zn}$ apresentaram padrões de distribuição espacial semelhantes, com os menores valores encontrados na parte oriental do canal próximos à desembocadura no Oceano Atlântico e nas amostras ao longo do Rio Itapanhaú, os valores maiores de concentração são observados na região do Largo do Candinho até o Canal de Santos (porção ocidental da área de estudo). Já para os valores de $\mathrm{Cu}$ e $\mathrm{Pb}$ os maiores teores são localizados próximos à Santos com um decréscimo em direção à cidade de Bertioga. Nas Figuras de 13 a 23 estão apresentadas a distribuição destes elementos. 


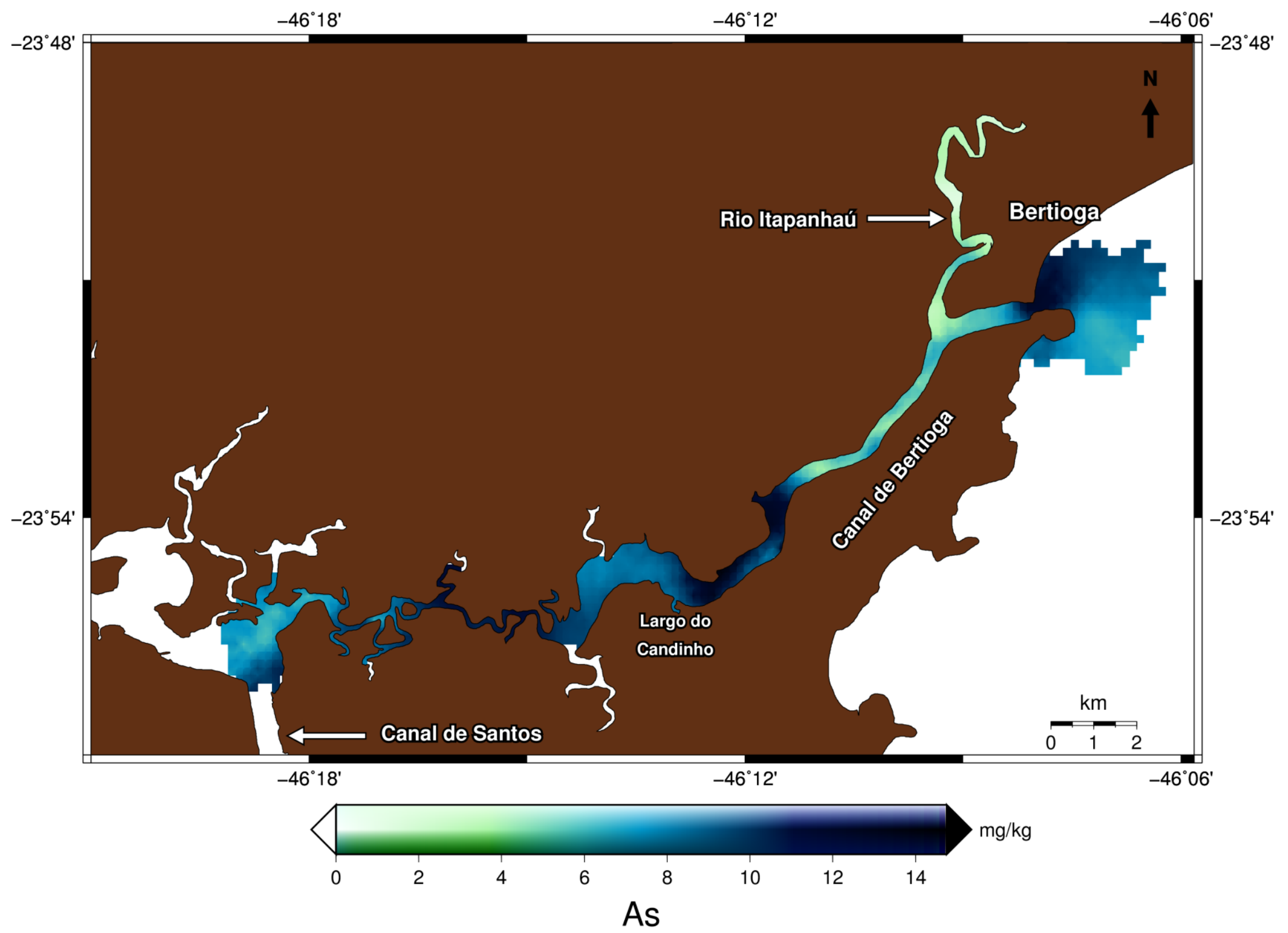

Figura 13. Distribuição espacial de As em $\mathrm{mg} \mathrm{kg}^{-1}$. 


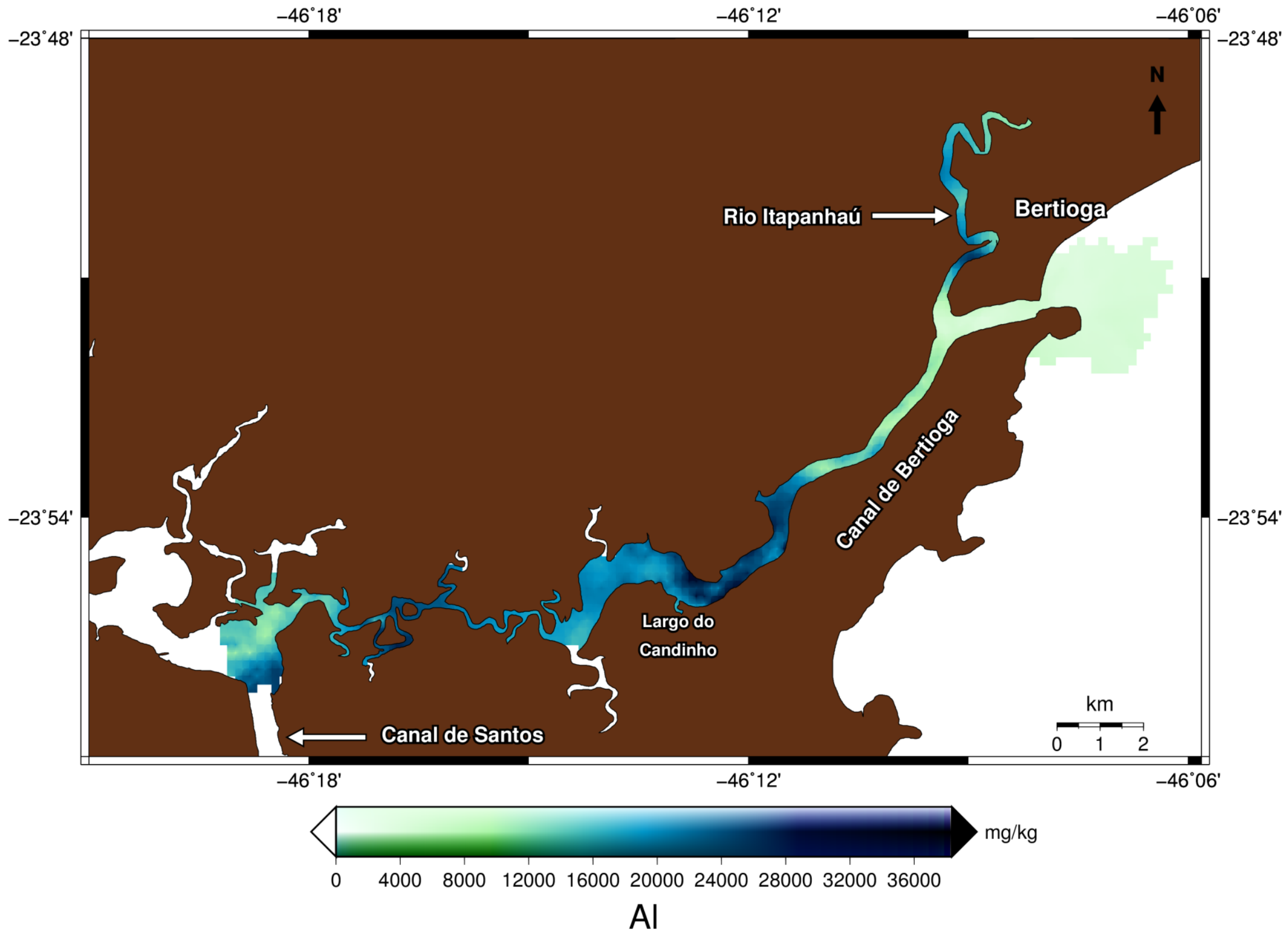

Figura 14. Distribuição espacial de $\mathrm{Al} \mathrm{em} \mathrm{mg} \mathrm{kg}^{-1}$. 


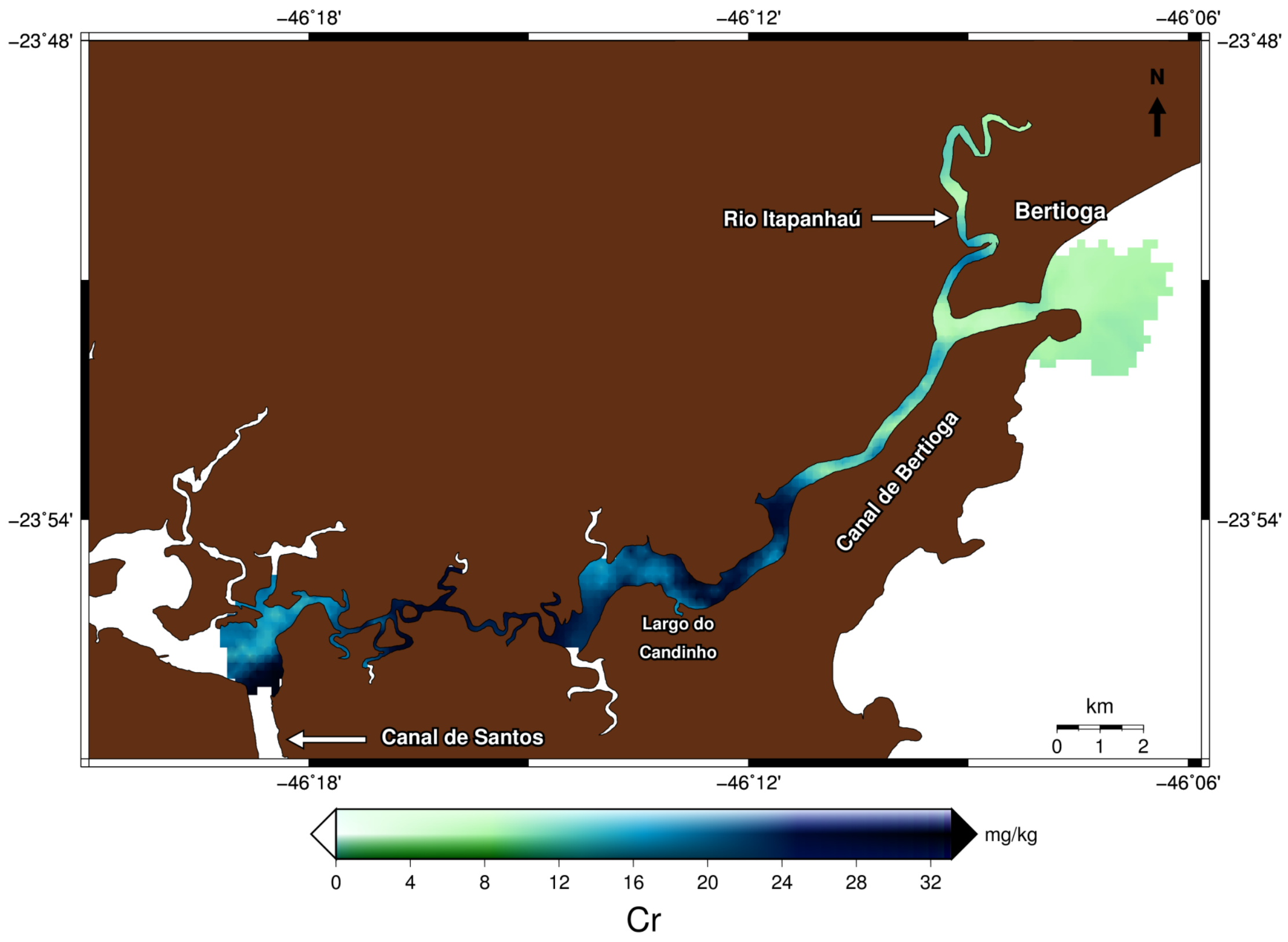

Figura 15. Distribuição espacial de $\mathrm{Cr}$ em $\mathrm{mg} \mathrm{kg}^{-1}$. 


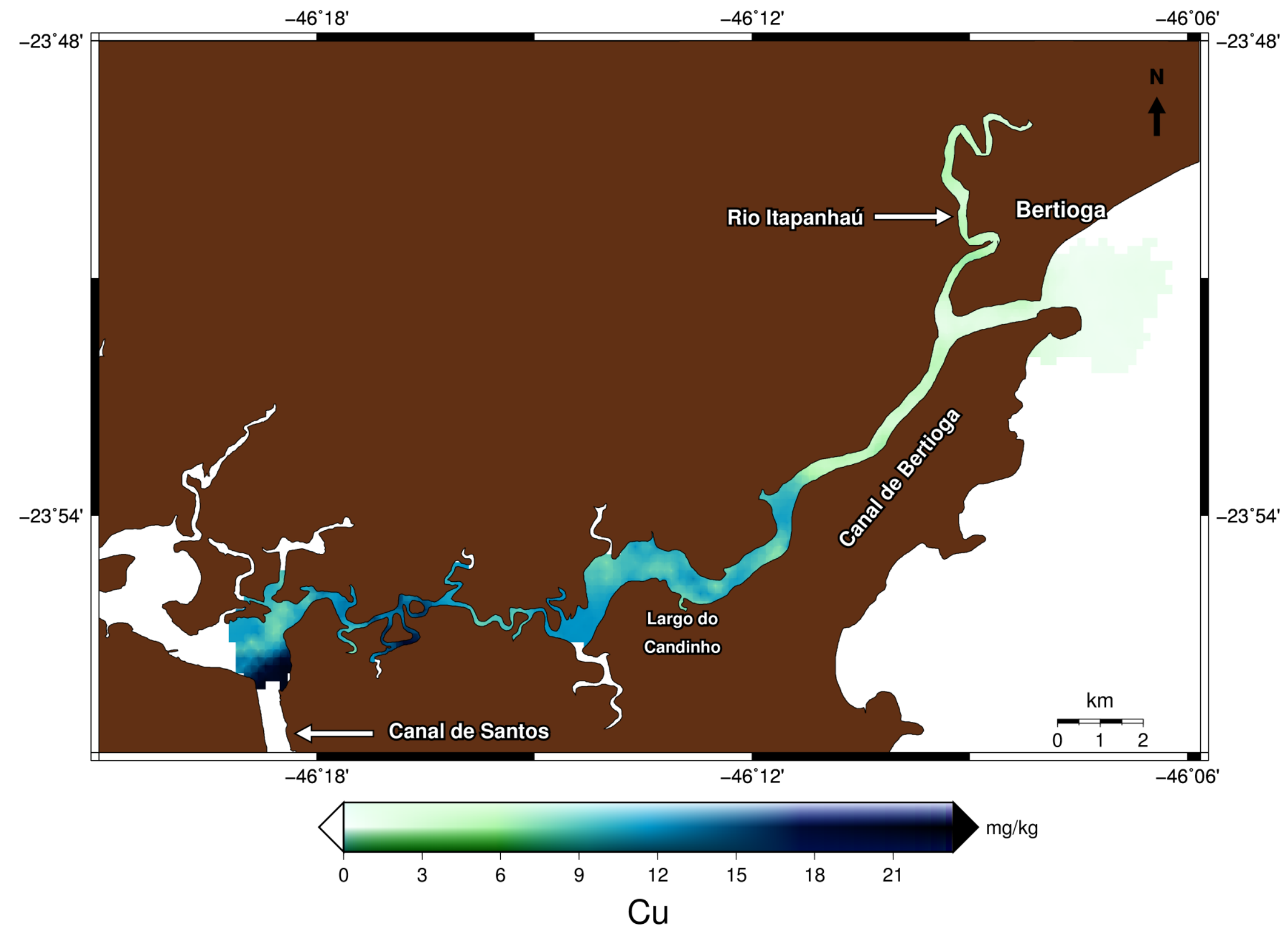

Figura 16. Distribuição espacial de $\mathrm{Cu}$ em $\mathrm{mg} \mathrm{kg}^{-1}$. 


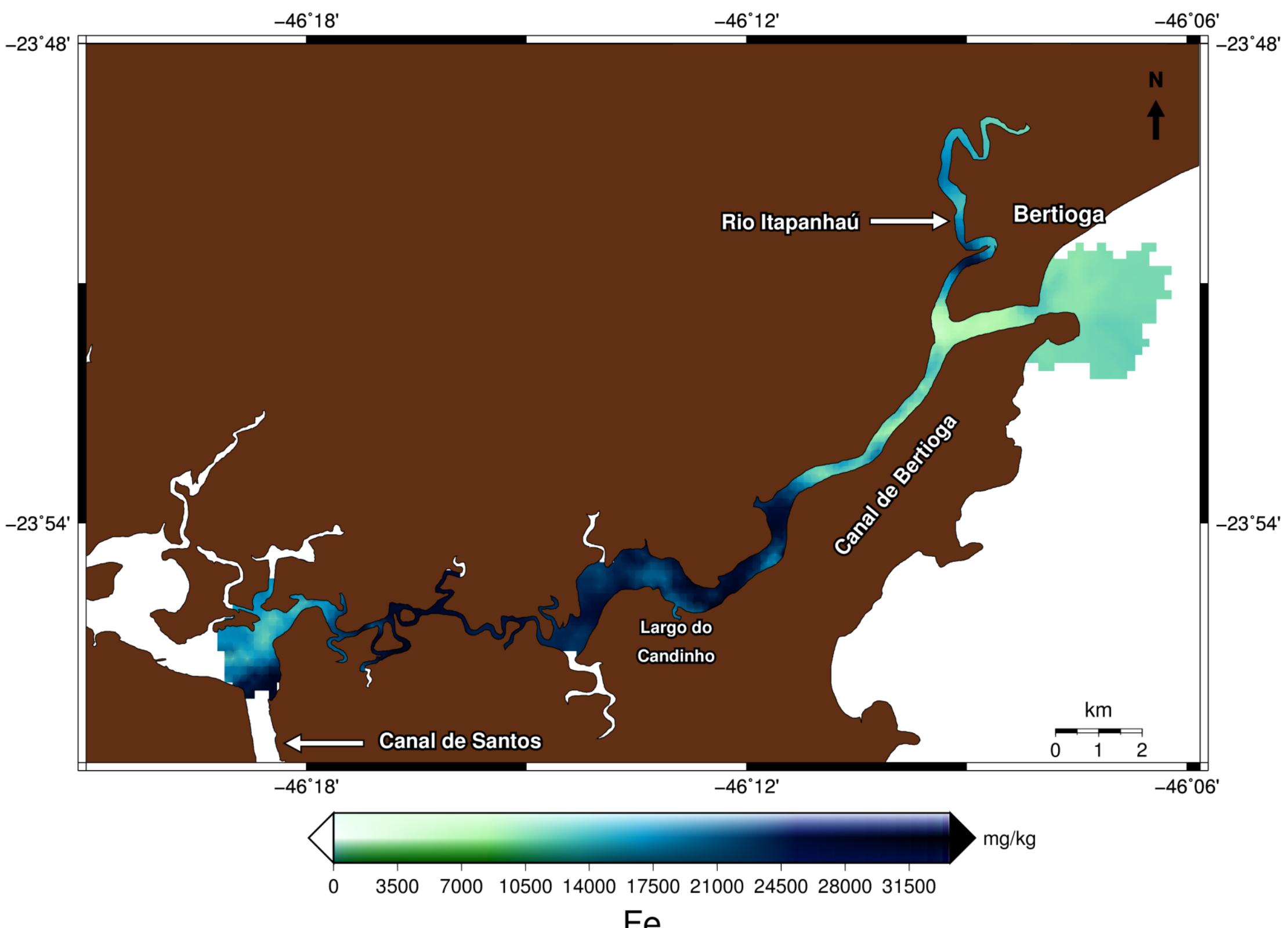

$\mathrm{Fe}$

Figura 17. Distribuição espacial de Fe em $\mathrm{mg} \mathrm{kg}^{-1}$. 


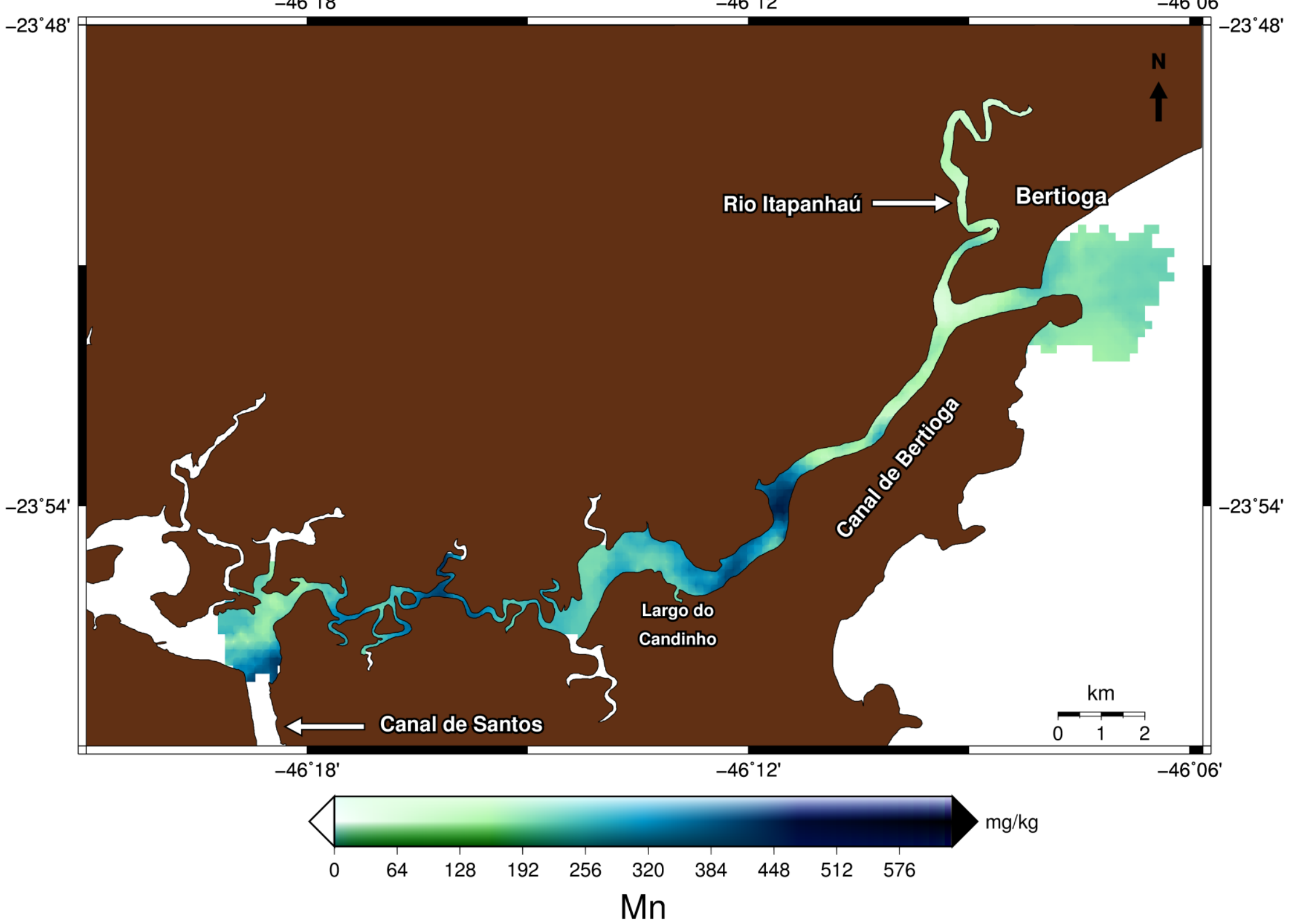

Figura 18. Distribuição espacial de $\mathrm{Mn}$ em $\mathrm{mg} \mathrm{kg}^{-1}$. 


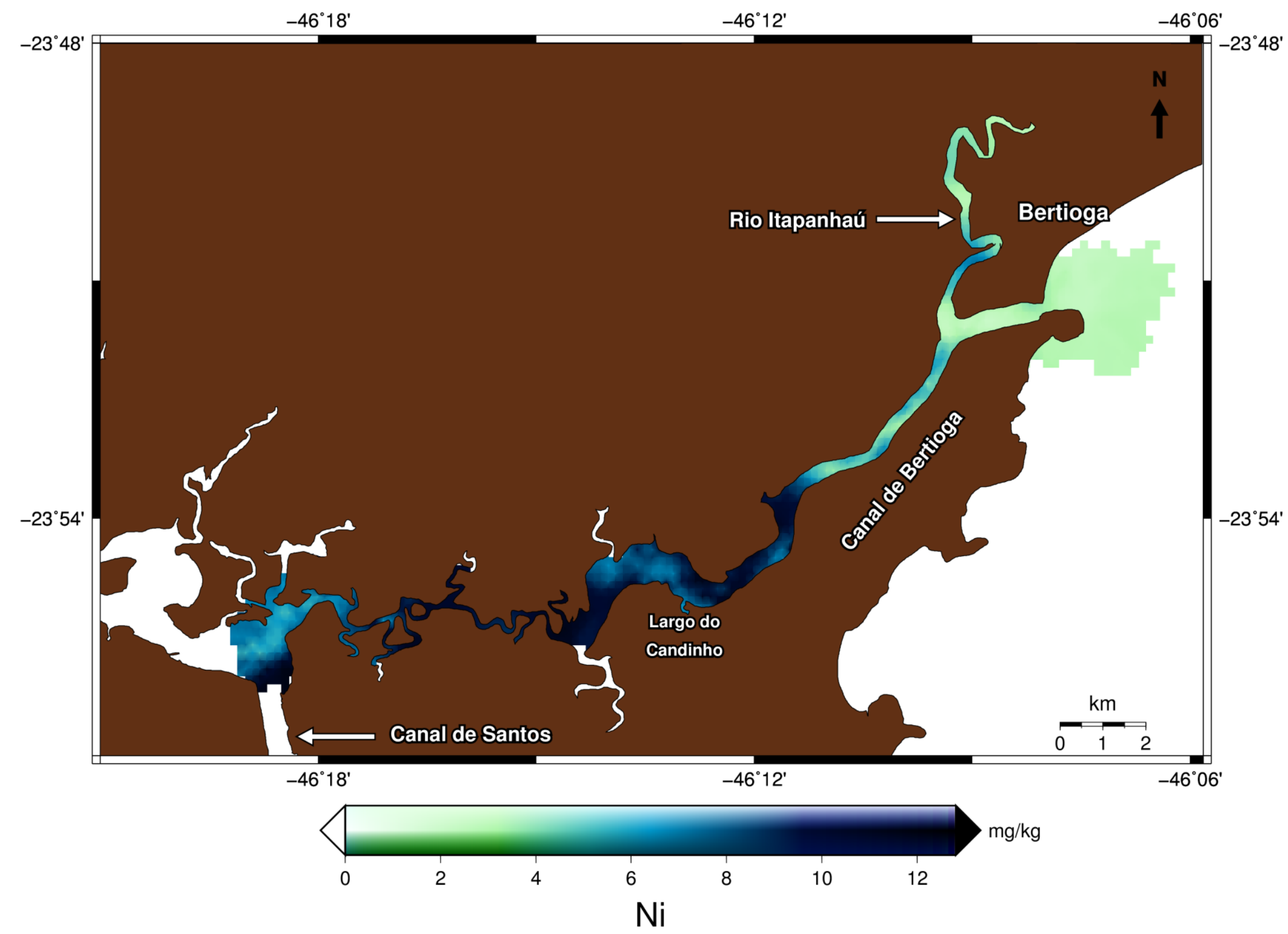

Figura 19. Distribuição espacial de $\mathrm{Ni} \mathrm{em} \mathrm{mg} \mathrm{kg}^{-1}$. 


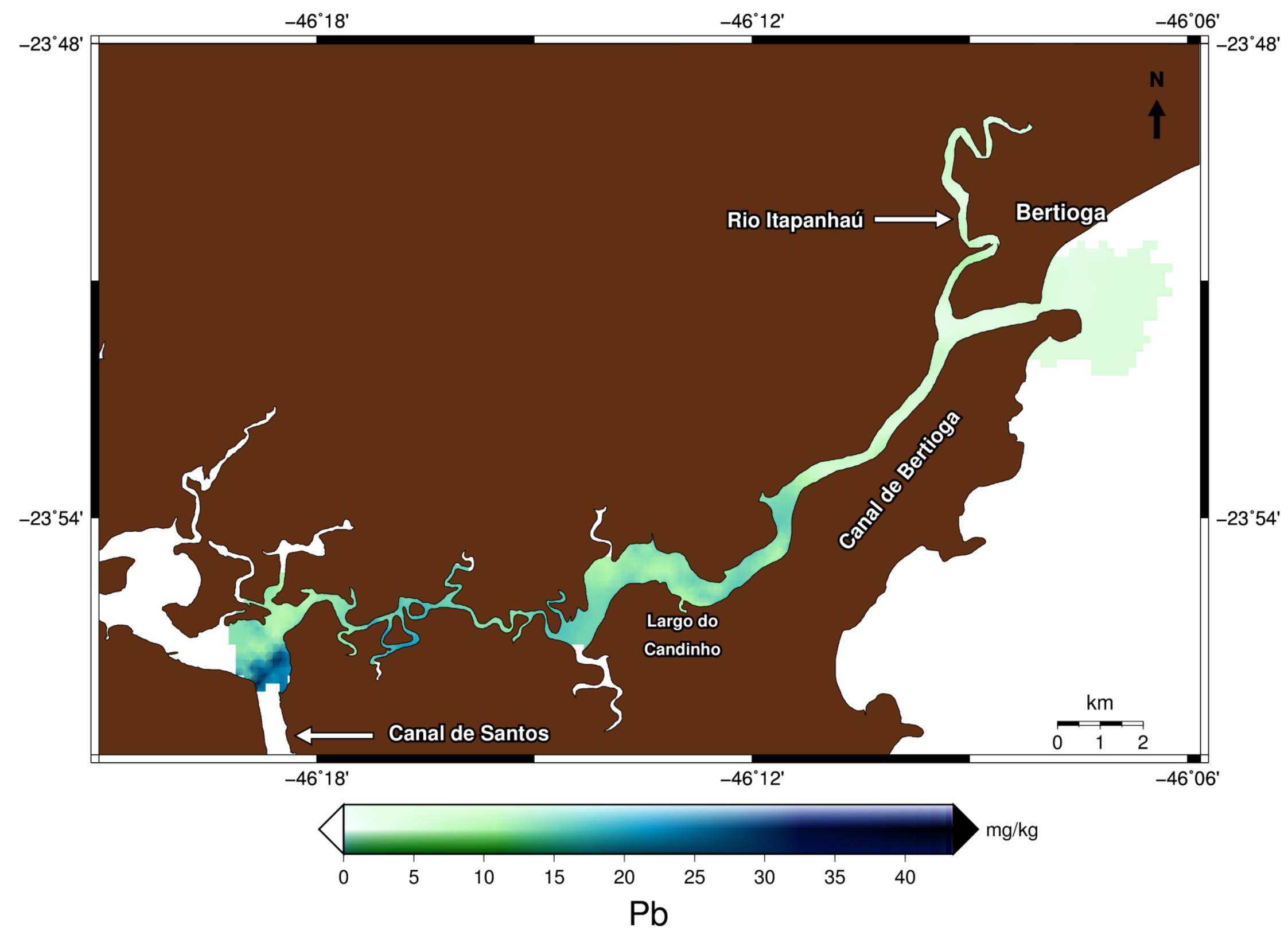

Figura 20. Distribuição espacial de $\mathrm{Pb}$ em $\mathrm{mg} \mathrm{kg}^{-1}$. 


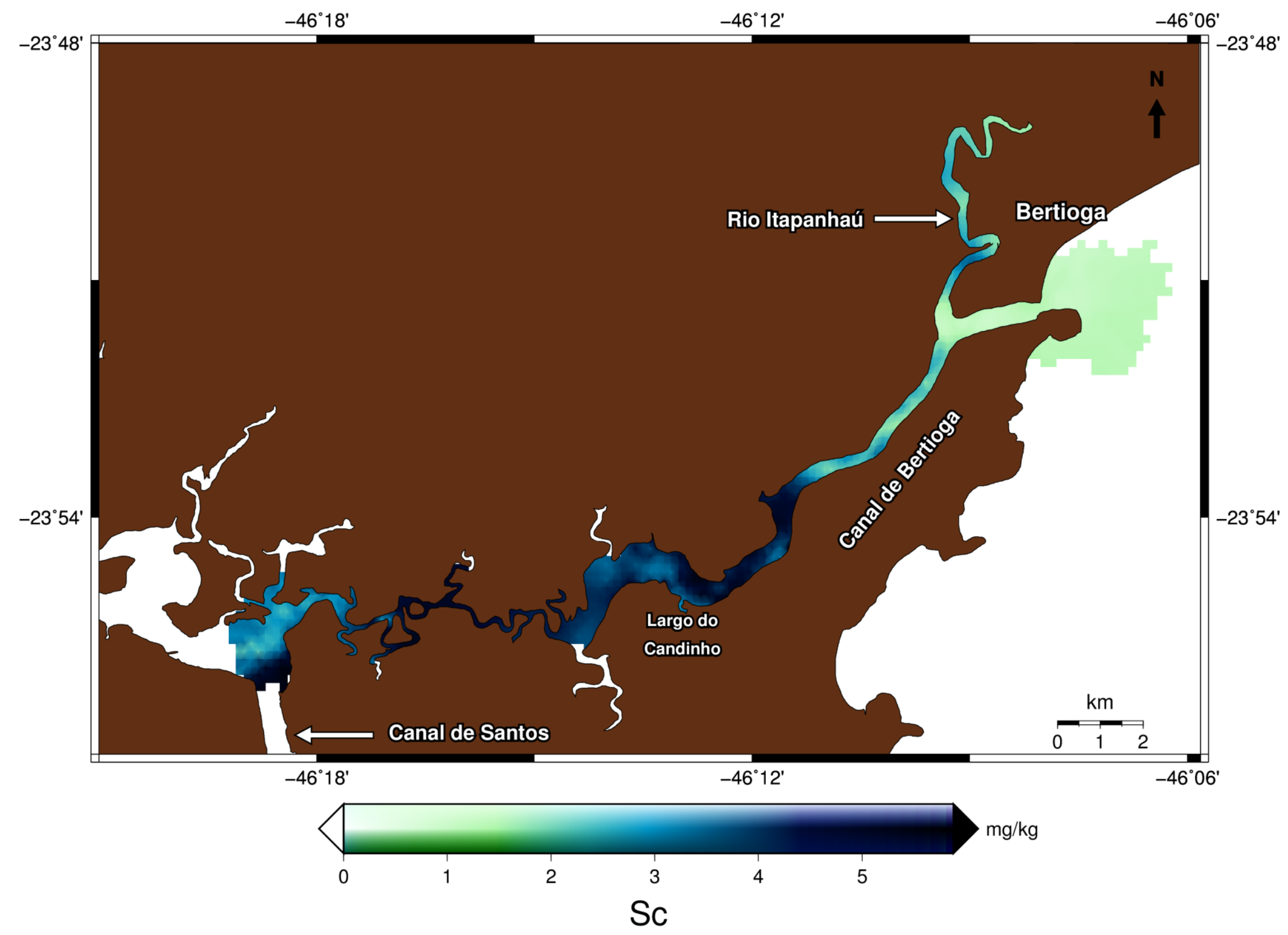

Figura 21. Distribuição espacial de Sc em $\mathrm{mg} \mathrm{kg}^{-1}$. 


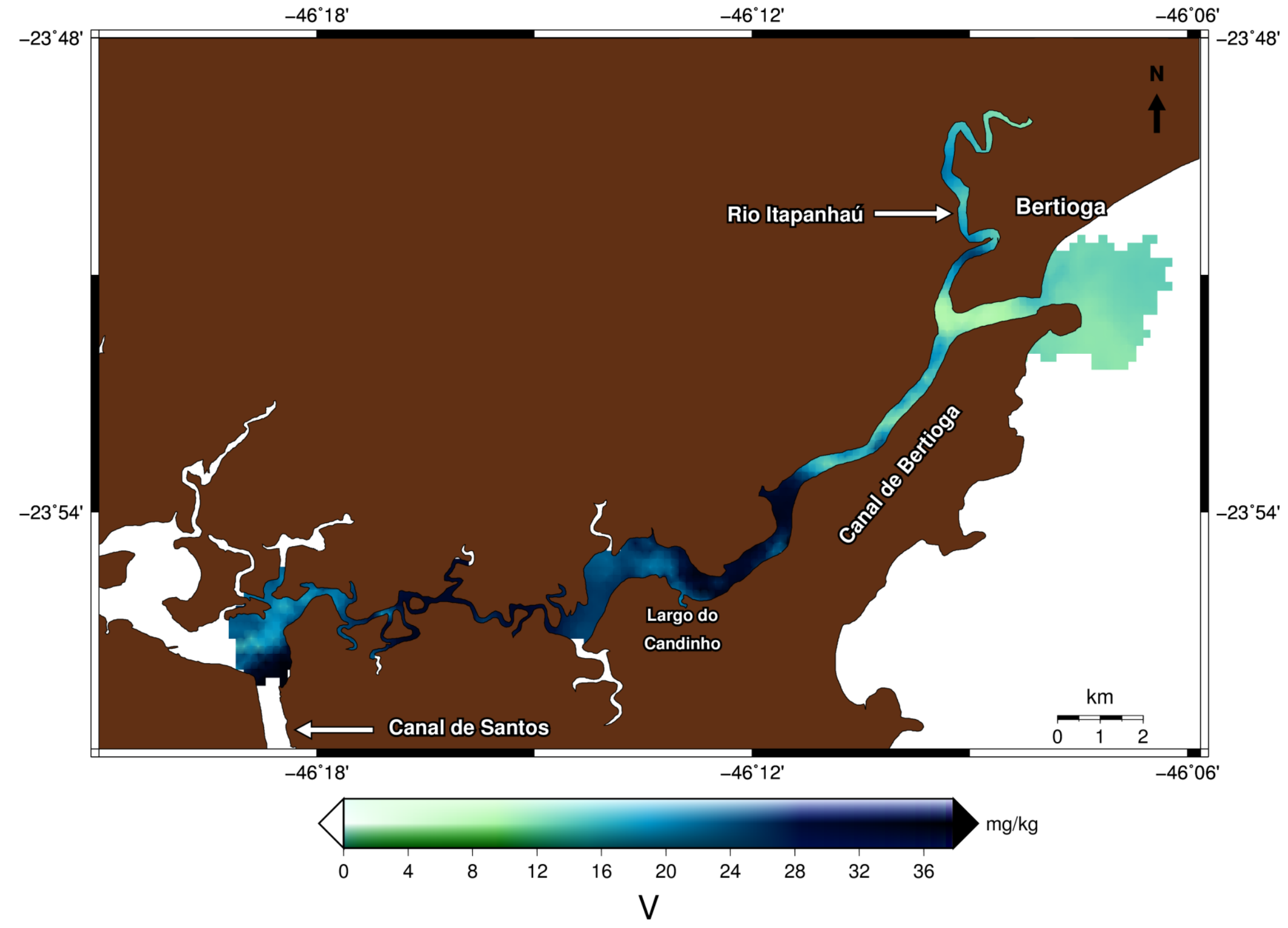

Figura 22. Distribuição espacial de $\mathrm{Vem} \mathrm{mg} \mathrm{kg}^{-1}$. 


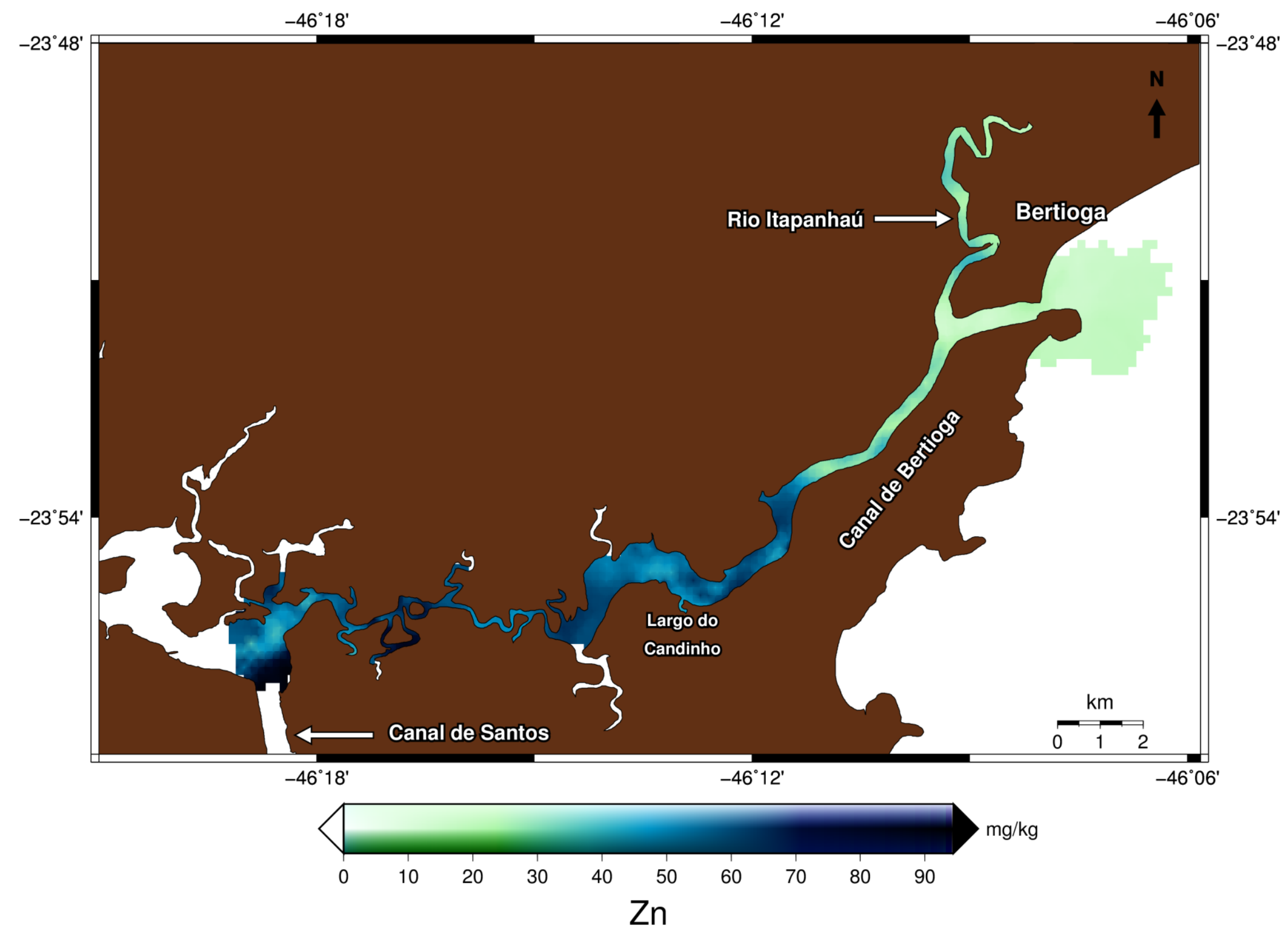

Figura 23. Distribuição espacial de $\mathrm{Zn} \mathrm{em} \mathrm{mg} \mathrm{kg}{ }^{-1}$. 
Para este trabalho foi realizada uma avaliação mais completa dos seguintes elementos: $\mathrm{As}, \mathrm{Cr}, \mathrm{Cu}, \mathrm{Ni}, \mathrm{Pb}$ e $\mathrm{Zn}$ pois dentre estes, o cobre e o zinco são essenciais para o metabolismo dos organismos, porém em altas concentrações podem se tornar tóxicos. Já os demais são potencialmente tóxicos mesmo em baixas concentrações. São, portanto, os elementos mais estudados em trabalhos de contaminação (RAND et al., 1995; HAYNES et al., 2000).

Todos os elementos apresentaram valores abaixo do limiar que é esperado impacto negativo na biota; ou seja, todos os resultados encontrados não apresentaram valores da concentração superiores aos valores de PEL para nenhuma amostra.

A maioria das amostras apresentaram valores abaixo do qual raramente esperam-se efeitos adversos à biota, indicando uma contaminação mínima ou ausente, com exceção do $\mathrm{As}, \mathrm{Cu}$ e $\mathrm{Pb}$. Analisando o elemento As constata-se que em 80 amostras (54\%) houve valores superiores ao TEL, pontos distribuídos próximos à cidade de Bertioga, Rio Itapanhaú, e do Rio Tia Maria até o encontro com o Estuário de Santos. Para o Cu em 7 amostras ( 5\%) localizadas na parte ocidental do Canal próximo ao Canal de Santos, apresentaram concentrações acima do TEL, e o Pb apresentou apenas uma amostra com concentração acima do TEL, também localizada próxima à Santos (este ponto pode ser descartado, considerado como outlier, valor atípico que pode acarretar em prejuízos na interpretação dos resultados). As amostras com os valores que ultrapassaram o TEL para As e $\mathrm{Cu}$, podem ser indícios de contaminação.

De forma a avaliar as concentrações de metais encontradas no Canal de Bertioga é apresentado na Tabela 11 a seguir, um comparativo entre os teores de metais e As encontrados em diferentes tipos de ambientes no Brasil.

As concentrações de $\mathrm{As}, \mathrm{Cr}$, $\mathrm{Cu}, \mathrm{Ni}$ e $\mathrm{Zn}$ encontram-se na mesma ordem de grandeza das reportadas por QUINÁGLIA (2006), que também realizou suas análises nos sedimentos do Canal de Bertioga. Com relação ao $\mathrm{Pb}$ neste trabalho foram observados valores mais elevados.

As concentrações encontradas por outros trabalhos nas regiões adjacentes a este estudo (Estuário de Santos e São Vicente) são bastante superiores aos valores encontrados no Canal de Bertioga. 
Analisando as concentrações de metais reportadas pela literatura, percebe-se que os resultados obtidos neste trabalho não apresentam valores anômalos. Além disso, os teores encontrados estão dentro da faixa de variação apresentada para a região da plataforma continental de SP e RJ. Os resultados obtidos também foram ligeiramente mais elevados quando comparados a uma região não impactada como Cananéia (SP) e muito menor do que em regiões portuárias como o Estuário de Santos (SP) e as baías de Guanabara e Sepetiba (RJ). 
Tabela 11. Valores máximos e mínimos de As e metais em diferentes estudos e regiões do Brasil.

\begin{tabular}{|c|c|c|c|c|c|c|c|c|}
\hline \multicolumn{9}{|c|}{ Metais (mg.kg-1) } \\
\hline Região estudada & As & $\mathrm{Cr}$ & $\mathrm{Cu}$ & $\mathrm{Ni}$ & $\mathrm{Pb}$ & Zn & Método de análise & Referência \\
\hline & Min. Máx. & Min. Máx. & Min. Máx. & Min. Máx. & Min. Máx. & Min. Máx. & & \\
\hline Estuário de Santos - SP & - & $5,0-97,5$ & - & $1,3-44,2$ & $2,0-205$ & $7,6-312$ & Extração total & Abessa (2002) \\
\hline Baía de Guanabara - RJ & - & $<10,0-9230$ & $5,0-590$ & $<10,0-1300$ & $<10,0-2290$ & $<10,0-31,0$ & Extração parcial & $\begin{array}{l}\text { SEMA/FEEMA (1982); } \\
\text { Machado et al. (2002) }\end{array}$ \\
\hline Ubatuba - SP & - & $0,25-60,2$ & $0,08-34,2$ & - & - & $9,92-110$ & Extração parcial & $\begin{array}{c}\text { Muniz (2003), } \\
\text { Muniz et al. (2006) }\end{array}$ \\
\hline São Sebastião - SP & $<2,00$ & $3,00-34,0$ & $2,50-10,1$ & $1,50-11,2$ & $10,0-15,9$ & $4,00-67,0$ & Extração parcial & Mendes (2007) \\
\hline Paranaguá - PR & $0,59-21,7$ & $2,44-69,5$ & $0,55-15,8$ & $2,46-36,9$ & $0,25-37,6$ & $1,65-76,2$ & Extração parcial & $\begin{array}{c}\text { Machado (2007), } \\
\text { Sá \& Machado (2007) }\end{array}$ \\
\hline Plataforma SP & - & $5,00-28,4$ & $1,00-27,0$ & - & $5,00-41,0$ & $1,00-85,0$ & Extração parcial & Tessler (2001), Ferreira (2008) \\
\hline Baía de Guaratuba - PR & - & - & $<0,02-10,0$ & - & $<0,02-10,0$ & $14,0-68,0$ & Extração parcial & $\begin{array}{c}\text { Ferreira (2006), } \\
\text { Sanders et al. (2008) }\end{array}$ \\
\hline Santos - S. Vicente (SP) & $0,10-20,8$ & $<1,00-106$ & $<0,10-167$ & $0,97-57,0$ & $0,05-567$ & $5,20-2600$ & Extração parcial & a \\
\hline Plataforma e Talude RJ & - & $1,30-38,5$ & $<0,01-11,2$ & - & $1,80-17,7$ & $<0,01-60,9$ & Extração parcial & $\begin{array}{l}\text { Dornelles (1993), } \\
\text { Carvalho et al. (2005) }\end{array}$ \\
\hline Cananéia - SP & - & $9,74-21,5$ & $<0,50-14,0$ & $0,33-1,65$ & $<0,40-26,0$ & $15,5-42,4$ & Extração parcial & $\mathrm{b}$ \\
\hline Baía de Sepetiba - RJ & $0,80-607$ & $0,55-141$ & $0,20-3396$ & $1,77-90,0$ & $0,14-28880$ & $0,21-45600$ & Extração parcial & c \\
\hline Canal de Bertioga (SP) & $8,74-10,9$ & $26,1-29,5$ & $9,16-12,9$ & $10,1-12,3$ & $<0,26$ & $57,4-70,2$ & Extração parcial & Quináglia (2006) \\
\hline Canal de Bertioga (SP) & $0,46-14,74$ & $3,14-33,13$ & $0,70-23,29$ & $1,16-12,81$ & $1,54-43,43$ & $7,45-94,39$ & Extração parcial & ESTE TRABALHO \\
\hline
\end{tabular}

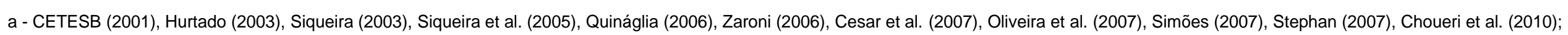

b - Berber et al. (2007), Cunha et al. (2007), Oliveira et al. (2007), Simões (2007), Rodrigues (2008);

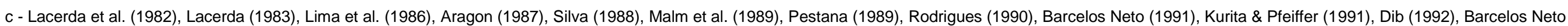

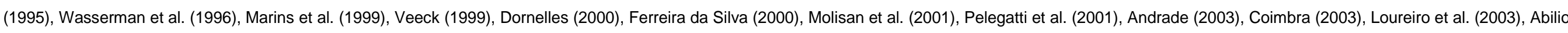
(2004), Cunha (2005), Ribeiro (2006). 
$\mathrm{Na}$ Figura 24 representa-se o Fator de Concentração para $\mathrm{As}, \mathrm{Cr}, \mathrm{Cu}$, $\mathrm{Ni}, \mathrm{Pb}$ e $\mathrm{Zn}$. Algumas amostras para $\mathrm{As}, \mathrm{Cu}, \mathrm{Pb}$ e $\mathrm{Zn}$ apresentaram valores maiores que 1 principalmente na porção ocidental do Canal, indicando que provavelmente há entrada desses elementos na região. Para $\mathrm{Ni}$ e $\mathrm{Cr}$ o FC em todos os pontos amostrados foi abaixo de 1 .

O As é um metalóide com ampla distribuição na superfície terrestre, ocorrendo na maioria das rochas em concentrações que podem atingir 13 $\mathrm{mg} / \mathrm{kg}$ em sedimentos argilosos. Em geral está presente associado a depósitos de minerais metálicos. As principais fontes deste poluente estão relacionadas à extração e beneficiamento desses minerais, ao processamento de metais e à produção de pigmentos, conservantes de madeira e pesticidas a base de arsênio e a indústria de vidro. Não há na região do estuário santista fontes industriais específicas deste poluente (CETESB, 2001).

O Cu é um metal de ampla distribuição pela crosta terrestre, ocorrendo nas rochas magmáticas em valores de até $100 \mathrm{mg} / \mathrm{kg}$. Nos solos, os valores normais oscilam entre 10 e $80 \mathrm{mg} / \mathrm{kg}$ (CETESB, 2001). Está presente no lixo doméstico e nos esgotos em geral por ser um metal de amplo emprego industrial e doméstico, inclusive como fungicida e algicida para piscinas (na forma solúvel de sulfato de cobre) e na forma metálica (tubulações, utensílios e fiação). Na indústria, o cobre é encontrado habitualmente em refinarias, siderúrgicas e indústrias de papel e celulose. Segundo CETESB (2001) na Baixada Santista, o cobre é detectado em efluentes da Companhia Santista de Papel, RPBC-PETROBRÁS, Cosipa, Dow Química e de alguns terminais portuários de granéis líquidos, estando também presente no chorume de lixões e aterros sanitários e nos esgotos lançados no mar e nos estuários.

$\mathrm{O} \mathrm{Pb}$ tem sua ocorrência natural em rochas magmáticas variando de 0,1 a $40 \mathrm{mg} / \mathrm{kg}$. Geralmente está associado à indústria de extração, beneficiamento e fundição do metal e ocorre como contaminante em efluentes de indústrias de refino de petróleo, petroquímicas e siderúrgicas, entre outras. Para o Estuário de Santos as principais fontes de chumbo é a RPBC-PETROBRAS, UltrafértilCB, Cosipa, Dow Química. Como outras fontes potenciais, existem os Lixões, a Usina Henry Borden e a DTCS-Cubatão (CETESB, 2001). 
O Zn é um metal amplamente distribuído na natureza, ocorrendo nos solos e, como nutriente essencial, nas plantas em geral. A concentração média natural deste metal na crosta terrestre é de 65 mg/kg (WEDEPOHL, 1995 apud CETESB, 2001). O uso do zinco em sua forma metálica ou em sais do metal é comum nos mais diversos ramos industriais. Na Baixada Santista, é encontrado nos efluentes de grande parte das indústrias, dos terminais e em áreas contaminadas da região. Além do uso industrial, está presente nas habitações (telhas, utensílios) e em produtos diversos, ocorrendo, portanto, no lixo e nos esgotos domésticos. As fontes industriais potenciais de $\mathrm{Zn}$ para a região são a COSIPA e a Dow Química (CETESB, 2001). 


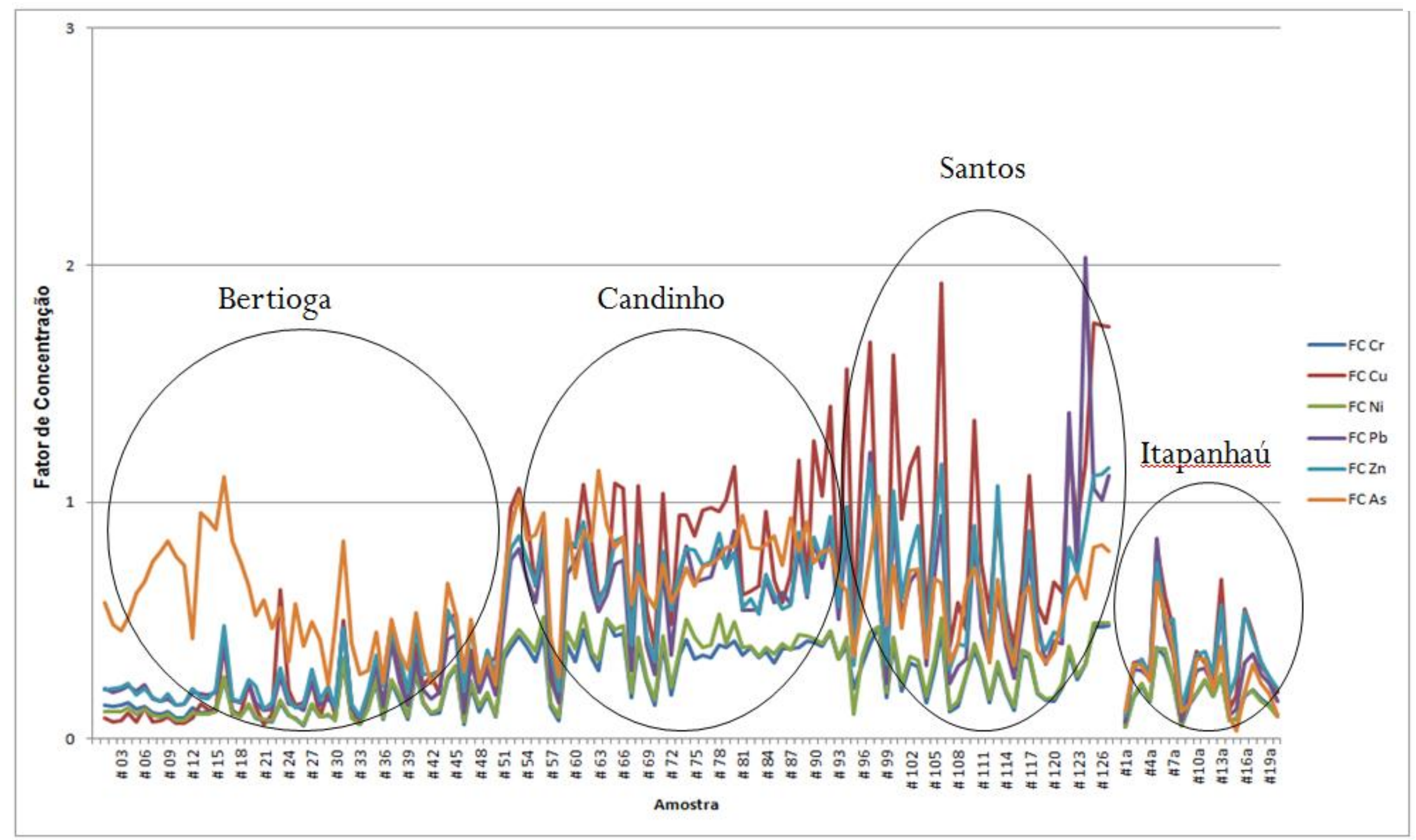

Figura 24. Variação do Fator de Concentração de $\mathrm{Cr}, \mathrm{Cu}, \mathrm{Ni}, \mathrm{Pb}, \mathrm{Zn}$ e As nas amostras de sedimento superficial ao longo do Canal de Bertioga e Rio Itapanhaú. 
Um dos problemas da utilização do $\mathrm{FC}$, é que o mesmo não é normalizado e flutuações decorrentes da granulometria podem influenciar nos valores, por isso para uma caracterização mais detalhada utilizamos também o Fator de Enriquecimento.

De acordo com o gráfico da Figura 25 temos os valores do Fator de Enriquecimento para $\mathrm{Cr}, \mathrm{Cu}, \mathrm{Ni}, \mathrm{Pb}, \mathrm{Zn}$ e As.

Para o As os valores de FE variaram entre 5 e 20 nas amostras próximas à cidade de Bertioga, indicando uma poluição significativa nesse local. No restante das amostras o FE foi menor do que 2, com exceção de alguns pontos que deram entre 2 e 5, sendo consideradas regiões normais e com contaminação moderada (ANDREWS \& SUTHERLAND, 2004). Duas hipóteses podem ser levantadas a respeito dos valores de FE, a primeira seria a descarga de efluentes domésticos e/ou industriais no sistema. A segunda seria que os níveis encontrados estão dentro do esperado para as rochas que formam o embasamento cristalino da Serra do Mar, como a área está sujeita a uma ocupação desordenada, o solo estaria exposto a um maior intemperismo contribuindo para o aporte do As no sistema, contudo essa hipótese só pode ser confirmada com estudo mineralógico. Quando comparamos o valor máximo obtido $\left(14,74 \mathrm{mg} \mathrm{kg}^{-1}\right)$ com a nova legislação do CONAMA 454/2012, que trata da dragagem do material, verificamos que os teores obtidos nesse trabalho estão abaixo do Nível $1\left(19 \mathrm{mg} \mathrm{kg}^{-1}\right)$.

O Cu apresentou a maioria dos valores de FE menores que 2, exceto alguns pontos principalmente próximos ao estuário de Santos com FE entre $2 \mathrm{e}$ 5.

O Fator de Enriquecimento de $\mathrm{Cr}$ e $\mathrm{Ni}$ deram abaixo de $2 \mathrm{em}$ todas as amostras, pode-se considerar que não há nenhuma entrada desses metais na região de estudo. Os valores de FE do $\mathrm{Pb}$ e $\mathrm{Zn}$ foram semelhantes, menores que 2 ao longo do canal e entre 2 e 5 próximos à Santos.

No Rio Itapanhaú todos os valores de FE foram menores do que 2, considerados normais, indicando que não há um aporte desses elementos no rio. 


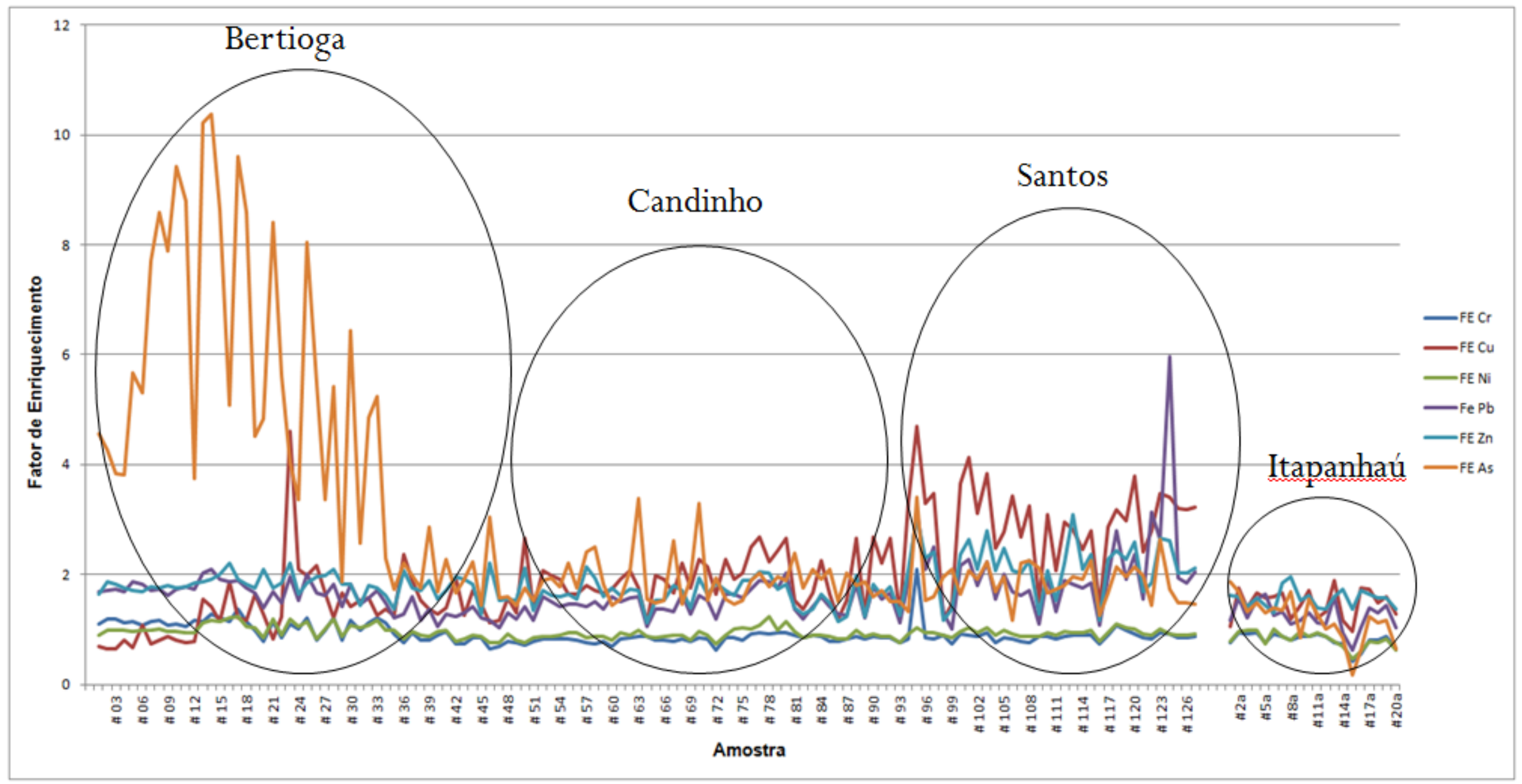

Figura 25. Distribuição do fator de enriquecimento de $\mathrm{Cr}, \mathrm{Cu}, \mathrm{Ni}, \mathrm{Pb}, \mathrm{Zn}$ e As nas amostras de sedimento superficial ao longo do Canal de Bertioga e Rio Itapanhaú. 
Com a finalidade de verificar a existência de correlação entre as variáveis estudadas foi aplicado o teste de corrrelação de Pearson. A Tabela 12 apresenta a matriz de correlação obtida entre as variáveis, com os respectivos coeficientes de correlação ( $r$ ). A matriz mostra que todos os resultados apresentam correlação significativa $(p<0,05)$ e positiva $(r>0)$.

Para melhor compreensão das correlações entre as variáveis foi calculado o coeficiente de determinação $\left(R^{2}\right)$, que é definido elevando o valor do coeficiente de Pearson ao quadrado, ele é interpretado como sendo a proporção da variação de $Y$ que é explicada pela variável $X$ (e vice versa), o valor de $R^{2}$ calculado é multiplicado por 100 , obtendo-se a percentagem de variância comum às duas variáveis (Tabela 13).

As variáveis que apresentaram uma menor correlação com as demais foram As, $\mathrm{Mn}$, porcentagem de carbonato e carbono orgânico total. As melhores correlações foram obtidas pelo $\mathrm{Al}, \mathrm{Fe}, \mathrm{Cr}, \mathrm{Ni}, \mathrm{Sc}, \mathrm{V}$ e a porcentagem de sedimentos finos.

Nas Figuras 26 e 27 estão apresentados os gráficos de correlação dos elementos com o teor de sedimentos finos, a elipse apresenta um intervalo de $95 \%$ de confiança e quanto mais achatadas, maior a correlação entre as variáveis. Estes gráficos demonstram que o comportamento dos metais apresenta forte relação com a presença dos sedimentos finos conforme comentado anteriormente.

Uma Análise de Agrupamento (Cluster Analysis) das 147 amostras (Figura 28) demonstrou a presença de dois grandes grupos distintos (A e B). No Grupo A, $82 \%$ das amostras estão localizadas na parte oriental do canal (até a estação \# 70, localizada no Largo do Candinho). O Grupo B apresenta $73 \%$ das amostras localizadas na parte ocidental do canal. Esta análise evidencia mais uma vez o Largo do Candinho como divisor das águas, com dois grupos de amostras com comportamentos diferentes, um pertencente à região sobre influência direta das marés, onde prevalece a deposição de sedimentos arenosos, e outro sobre influência das águas do canal do Porto, sendo o Largo do Candinho a área de confluência de correntes de maré de sentido de deslocamento opostos (tombo das águas), local onde a influência da maré é praticamente nula e se depositam predominantemente sedimentos argilosos (MIRANDA \& CASTRO, 1991; FÚLFARO \& PONÇANO, 1976). 
$\mathrm{Na}$ Figura 29 temos apresentado a Análise de Agrupamento das variáveis estudadas, nela também podemos observar a presença de dois grandes grupos. Um grupo onde todos os elementos com exceção de Mn e As estão agrupados com os sedimentos finos, evidenciando que o tamanho dos grãos influi diretamente no teor de metais que estão adsorvidos nos grãos finos onde a superfície de contato é maior (FÖRSTNER \& SALOMONS, 1980). Neste grupo podemos observar a formação de outros três pequenos grupos, $\mathrm{Cr}, \mathrm{Ni}, \mathrm{Sc}$ e $\mathrm{V}$ estão juntos, elementos estes que apresentaram valores baixos e nenhum aporte antrópico, encontramos o Al agrupado com o $\mathrm{Fe}$ fazendo parte dos macroelementos com elevadas concentrações, estando presentes em níveis naturais, e os elementos $\mathrm{Cu}, \mathrm{Pb}$ e $\mathrm{Zn}$ que apresentam o mesmo comportamento geoquímico e nos resultados foi encontrado um pequeno aporte antrópico para estes elementos.

No segundo grupo apresentado pela Figura 29 o As foi agrupado junto com o $\mathrm{Mn}$ e o teor de carbonato junto com carbono orgânico total. O As foi deslocado do grupo anterior por apresentar padrões de distribuição diferenciados dos demais elementos, com maiores valores de FE na extremidade oriental do canal, onde prevalecem os sedimentos arenosos. $O$ comportamento do $\mathrm{Mn}$ apresentou grande variabilidade ao longo do canal. 
Tabela 12. Matriz de correlação obtida entre as variáveis estudadas no Canal de Bertioga $(p<0,05)$.

\begin{tabular}{|c|c|c|c|c|c|c|c|c|c|c|c|c|c|c|}
\hline & As & $\mathrm{Al}$ & $\mathrm{Cr}$ & $\mathrm{Cu}$ & $\mathrm{Fe}$ & $\mathrm{Mn}$ & $\mathrm{Ni}$ & $\mathrm{Pb}$ & Sc & V & $\mathrm{Zn}$ & $\%$ finos & $\% \mathrm{CaCO} 3$ & $\%$ COT \\
\hline As & 0 & 8,01E-09 & $2,80 \mathrm{E}-20$ & $8,26 \mathrm{E}-10$ & $9,69 \mathrm{E}-18$ & $1,09 E-29$ & 2,55E-19 & $1,99 \mathrm{E}-12$ & $6,35 \mathrm{E}-16$ & $3,64 \mathrm{E}-21$ & $8,11 \mathrm{E}-13$ & 7,77E-15 & $8,00 \mathrm{E}-08$ & $9,85 \mathrm{E}-13$ \\
\hline $\mathrm{Al}$ & 0,4535 & 0 & $2,06 \mathrm{E}-51$ & $4,35 E-28$ & $1,79 \mathrm{E}-72$ & $2,31 \mathrm{E}-21$ & $5,45 \mathrm{E}-52$ & $2,25 \mathrm{E}-27$ & $5,28 \mathrm{E}-68$ & $3,18 \mathrm{E}-60$ & $1,31 \mathrm{E}-38$ & $1,08 \mathrm{E}-42$ & $1,80 \mathrm{E}-09$ & $3,70 \mathrm{E}-19$ \\
\hline $\mathrm{Cr}$ & 0,66716 & 0,89038 & 0 & $2,38 \mathrm{E}-43$ & $5,41 \mathrm{E}-69$ & $5,63 \mathrm{E}-34$ & $8,65 \mathrm{E}-121$ & $3,23 \mathrm{E}-42$ & $3,62 \mathrm{E}-102$ & $1,91 \mathrm{E}-87$ & $1,43 E-56$ & 2,93E-77 & $2,88 \mathrm{E}-13$ & $3,39 \mathrm{E}-26$ \\
\hline $\mathrm{Cu}$ & 0,47919 & 0,75252 & 0,85582 & 0 & $8,06 \mathrm{E}-32$ & 7,07E-17 & $1,00 \mathrm{E}-44$ & $1,35 E-53$ & $1,44 \mathrm{E}-40$ & $1,39 \mathrm{E}-36$ & $1,33 \mathrm{E}-86$ & $2,84 \mathrm{E}-39$ & $2,80 \mathrm{E}-12$ & $2,85 \mathrm{E}-15$ \\
\hline $\mathrm{Fe}$ & 0,63163 & 0,94539 & 0,9388 & 0,78394 & 0 & $4,36 \mathrm{E}-31$ & $1,43 E-65$ & $1,24 \mathrm{E}-31$ & $7,60 \mathrm{E}-70$ & $3,05 E-72$ & $1,29 E-44$ & 4,90E-55 & $8,65 \mathrm{E}-12$ & $9,54 \mathrm{E}-26$ \\
\hline $\mathrm{Mn}$ & 0,76661 & 0,681 & 0,79998 & 0,6184 & 0,77815 & 0 & $2,86 \mathrm{E}-32$ & $3,05 E-19$ & $2,02 \mathrm{E}-31$ & $4,90 \mathrm{E}-34$ & $5,95 \mathrm{E}-23$ & $3,05 E-24$ & $9,24 \mathrm{E}-08$ & $8,52 \mathrm{E}-11$ \\
\hline $\mathrm{Ni}$ & 0,6543 & 0,89248 & 0,98848 & 0,86246 & 0,93153 & 0,7874 & 0 & $7,92 \mathrm{E}-42$ & $7,42 \mathrm{E}-102$ & $3,79 \mathrm{E}-81$ & 5,99E-61 & $2,22 \mathrm{E}-77$ & $1,34 \mathrm{E}-12$ & $4,54 \mathrm{E}-28$ \\
\hline $\mathrm{Pb}$ & 0,53849 & 0,74592 & 0,85009 & 0,89812 & 0,78247 & 0,65322 & 0,84806 & 0 & $2,77 \mathrm{E}-38$ & $7,04 \mathrm{E}-36$ & $1,77 \mathrm{E}-57$ & $4,30 \mathrm{E}-34$ & $2,47 \mathrm{E}-10$ & $2,21 \mathrm{E}-14$ \\
\hline Sc & 0,60304 & 0,93678 & 0,97908 & 0,84129 & 0,94049 & 0,78081 & 0,97887 & 0,82817 & 0 & $5,64 \mathrm{E}-100$ & $6,95 \mathrm{E}-56$ & $1,95 \mathrm{E}-73$ & $4,29 \mathrm{E}-12$ & $3,62 \mathrm{E}-25$ \\
\hline V & 0,67852 & 0,91831 & 0,96641 & 0,81762 & 0,94497 & 0,80041 & 0,95881 & 0,81303 & 0,97756 & 0 & $4,14 \mathrm{E}-51$ & $8,28 \mathrm{E}-56$ & $1,66 \mathrm{E}-10$ & $2,53 \mathrm{E}-23$ \\
\hline $\mathrm{Zn}$ & 0,54644 & 0,8301 & 0,90777 & 0,96548 & 0,86195 & 0,69996 & 0,92024 & 0,91051 & 0,90563 & 0,88925 & 0 & $6,16 \mathrm{E}-47$ & $2,52 \mathrm{E}-12$ & $2,13 \mathrm{E}-18$ \\
\hline$\%$ finos & 0,58443 & 0,85252 & 0,95327 & 0,83399 & 0,90292 & 0,71434 & 0,95345 & 0,80081 & 0,94707 & 0,90539 & 0,87245 & 0 & $1,94 \mathrm{E}-16$ & $1,01 \mathrm{E}-36$ \\
\hline$\% \mathrm{CaCO} 3$ & 0,42511 & 0,47063 & 0,55532 & 0,53542 & 0,52507 & 0,42326 & 0,54204 & 0,492 & 0,53155 & 0,49611 & 0,5364 & 0,61144 & 0 & $1,23 \mathrm{E}-12$ \\
\hline$\%$ COT & 0,54474 & 0,65205 & 0,73457 & 0,59202 & 0,73007 & 0,50289 & 0,75235 & 0,5763 & 0,72415 & 0,7042 & 0,6413 & 0,81851 & 0,54276 & 0 \\
\hline
\end{tabular}


Tabela 13. Matriz do coeficiente de determinação $\left(r^{2}\right)$ obtida entre as variáveis estudadas no Canal de Bertioga.

\begin{tabular}{|c|c|c|c|c|c|c|c|c|c|c|c|c|c|c|}
\hline & As & $\mathrm{Al}$ & $\mathrm{Cr}$ & $\mathrm{Cu}$ & $\mathrm{Fe}$ & $\mathrm{Mn}$ & $\mathrm{Ni}$ & $\mathrm{Pb}$ & Sc & V & $\mathrm{Zn}$ & $\%$ finos & \% $\mathrm{CaCO} 3$ & $\%$ СOT \\
\hline As & 100 & & & & & & & & & & & & & \\
\hline $\mathrm{Al}$ & 20,56623 & 100 & & & & & & & & & & & & \\
\hline $\mathrm{Cr}$ & 44,51025 & 79,27765 & 100 & & & & & & & & & & & \\
\hline $\mathrm{Cu}$ & 22,96231 & 56,62864 & 73,24279 & 100 & & & & & & & & & & \\
\hline $\mathrm{Fe}$ & 39,89565 & 89,37623 & 88,13454 & 61,45619 & 100 & & & & & & & & & \\
\hline $\mathrm{Mn}$ & 58,76909 & 46,3761 & 63,9968 & 38,24186 & 60,55174 & 100 & & & & & & & & \\
\hline $\mathrm{Ni}$ & 42,81085 & 79,65206 & 97,70927 & 74,38373 & 86,77481 & 61,99988 & 100 & & & & & & & \\
\hline $\mathrm{Pb}$ & 28,99715 & 55,63966 & 72,2653 & 80,66195 & 61,22593 & 42,66964 & 71,92058 & 100 & & & & & & \\
\hline Sc & 36,36572 & 87,75568 & 95,85976 & 70,77689 & 88,45214 & 60,96643 & 95,81865 & 68,58655 & 100 & & & & & \\
\hline V & 46,03894 & 84,32933 & 93,39483 & 66,85025 & 89,29683 & 64,06562 & 91,93166 & 66,10178 & 95,56236 & 100 & & & & \\
\hline $\mathrm{Zn}$ & 29,85967 & 68,9066 & 82,40464 & 93,21516 & 74,29578 & 48,9944 & 84,68417 & 82,90285 & 82,01657 & 79,07656 & 100 & & & \\
\hline$\%$ finos & 34,15584 & 72,67904 & 90,87237 & 69,55393 & 81,52645 & 51,02816 & 90,90669 & 64,12967 & 89,69416 & 81,97311 & 76,1169 & 100 & & \\
\hline$\% \mathrm{CaCO} 3$ & 18,07185 & 22,14926 & 30,83803 & 28,66746 & 27,56985 & 17,9149 & 29,38074 & 24,2064 & 28,25454 & 24,61251 & 28,7725 & 37,38589 & 100 & \\
\hline$\%$ COT & 29,67417 & 42,51692 & 53,95931 & 35,04877 & 53,30022 & 25,28984 & 56,60305 & 33,21217 & 52,43932 & 49,58976 & 41,12657 & 66,99586 & 29,45884 & 100 \\
\hline
\end{tabular}


As
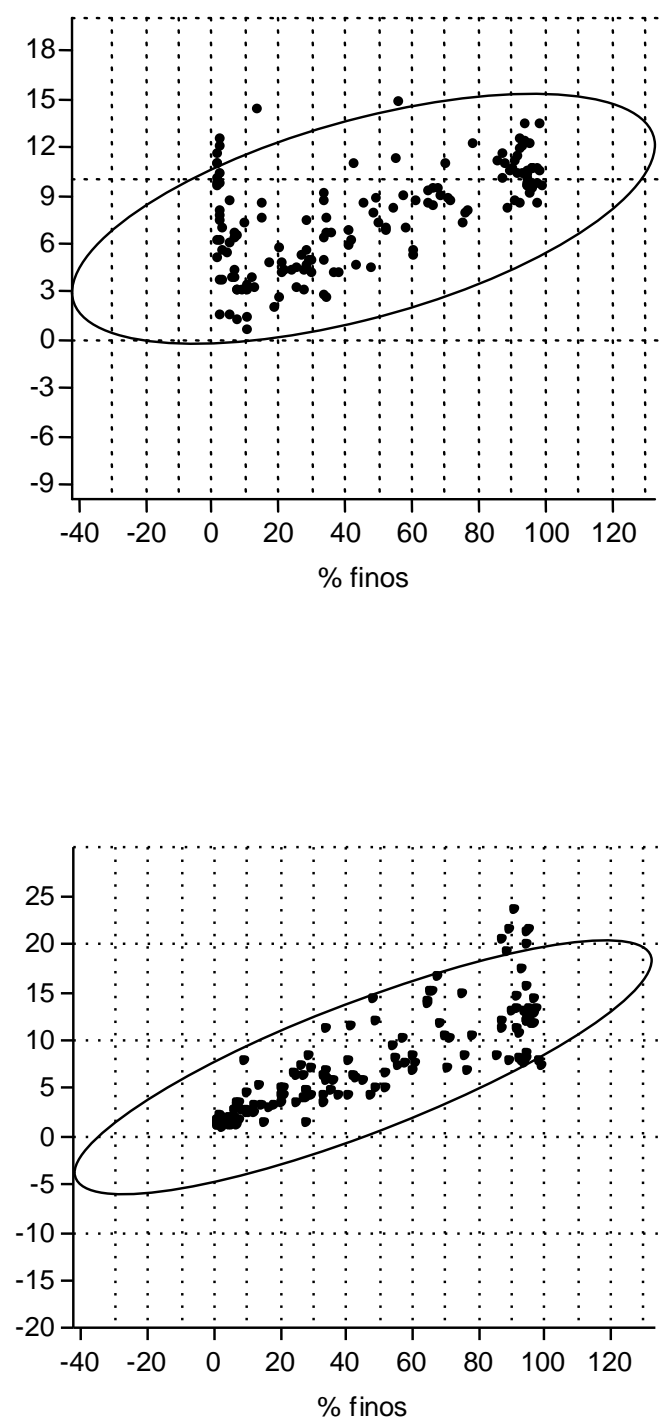
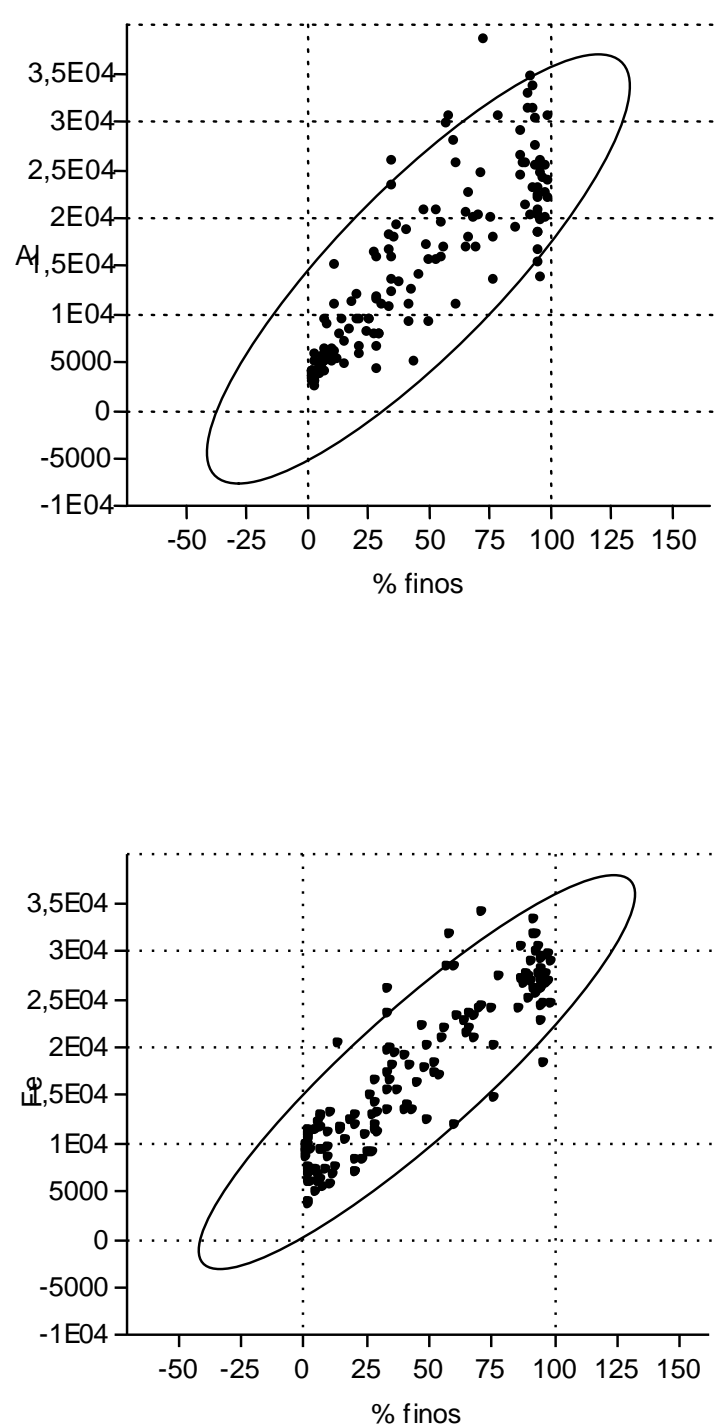
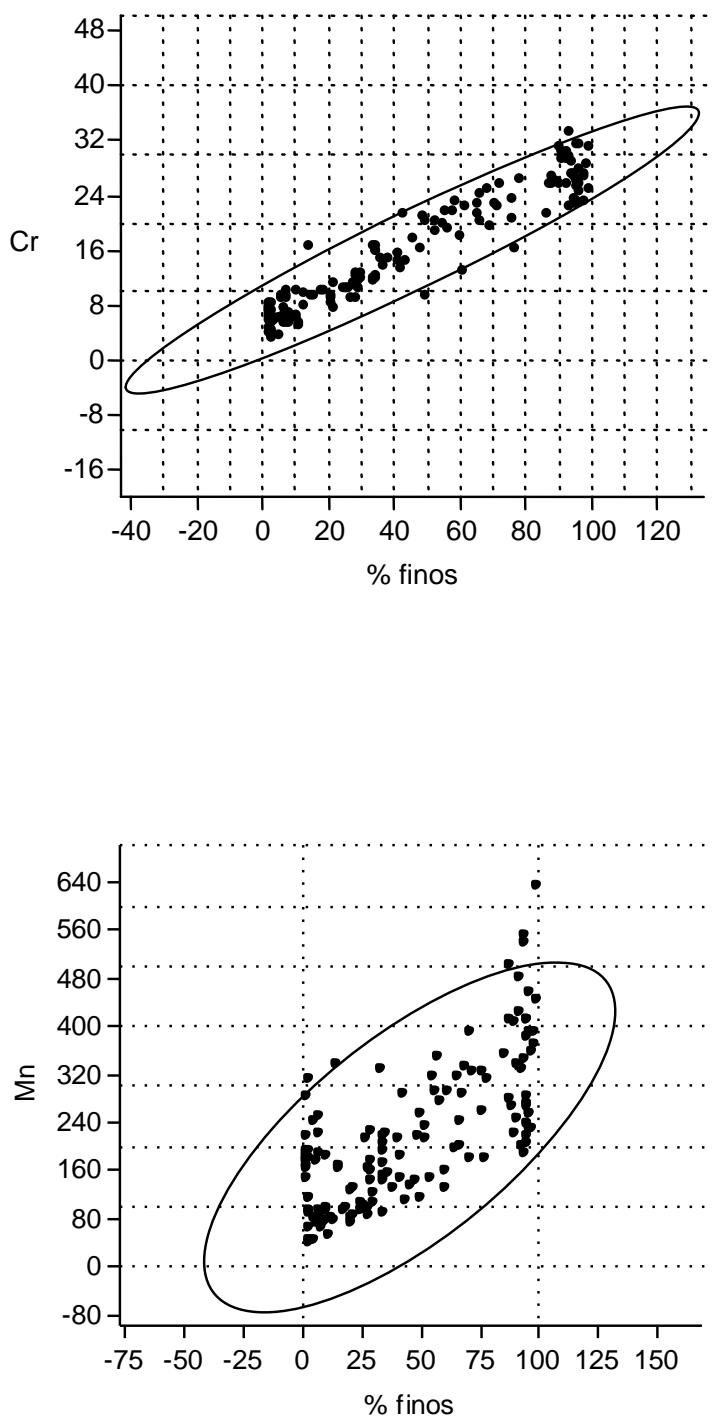

Figura 26. Gráficos de correlação do As, Al, Cr, Cu, Fe e Mn contra a porcentagem de sedimentos finos. 

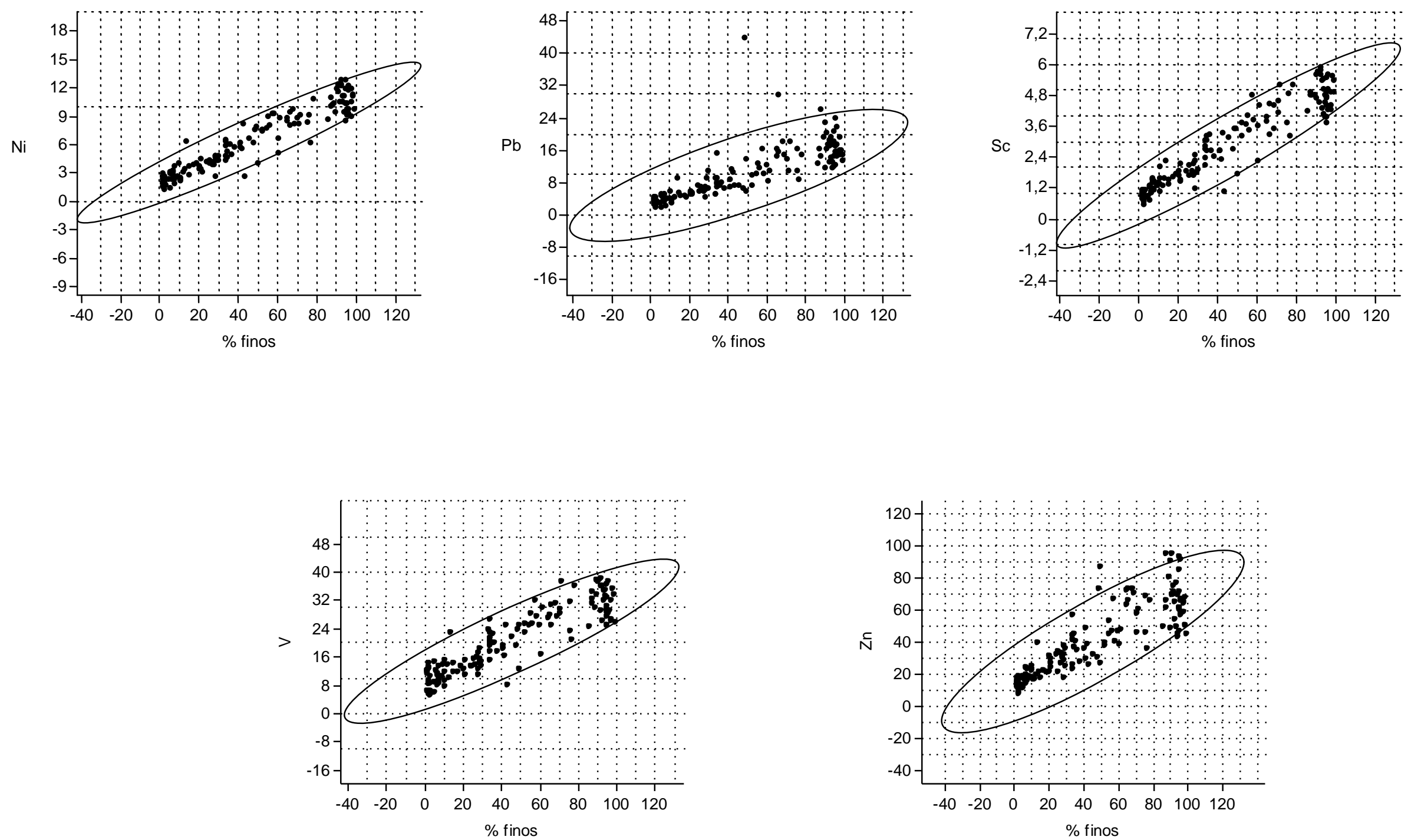

Figura 27. Gráficos de correlação do $\mathrm{Ni}, \mathrm{Pb}, \mathrm{Sc}, \mathrm{V}$ e $\mathrm{Zn}$ contra a porcentagem de sedimentos finos. 
Tree Diagram for 147 Cases

Ward's method

Euclidean distances

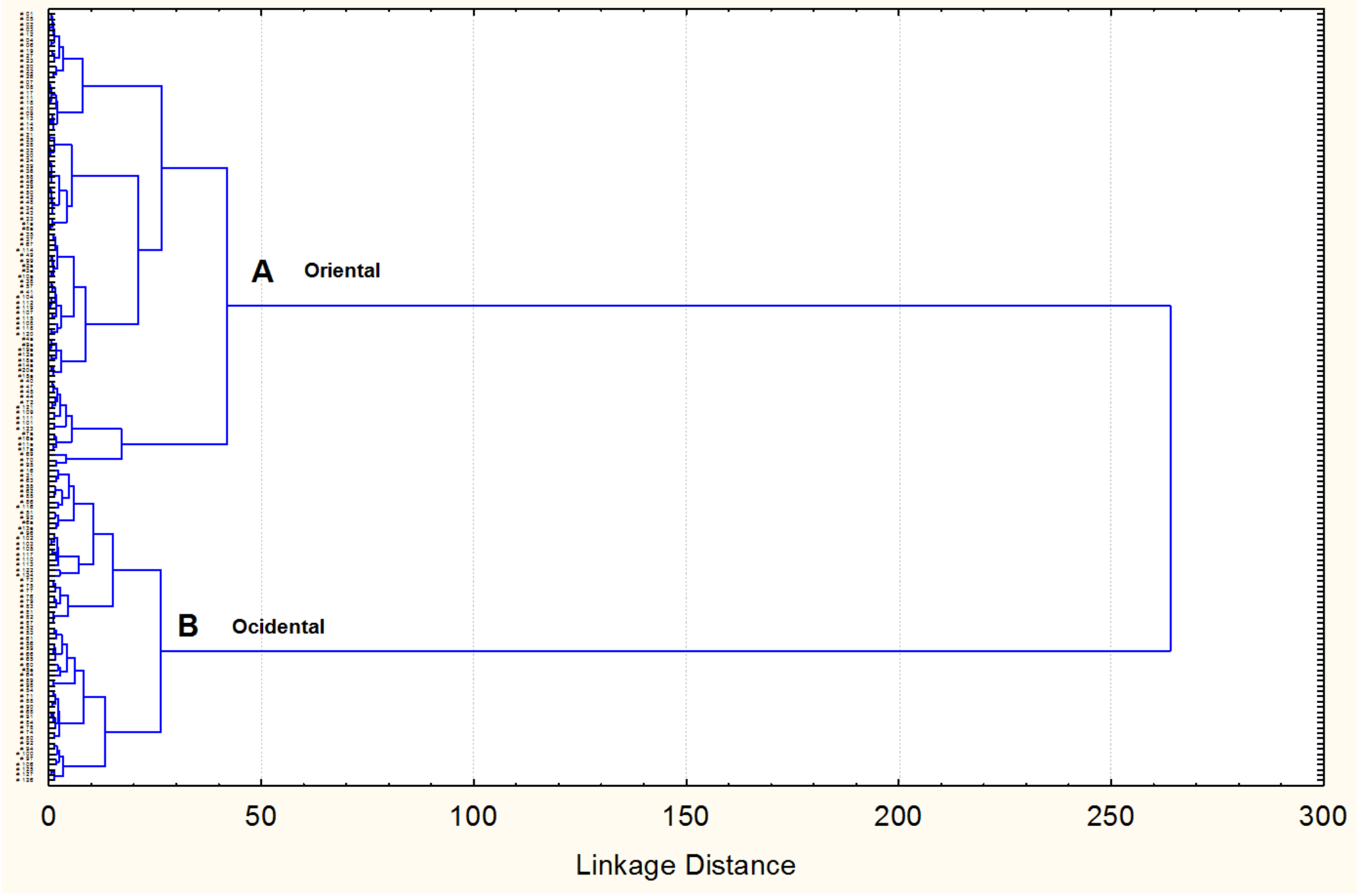

Figura 28. Análise de Agrupamento das amostras coletadas. 


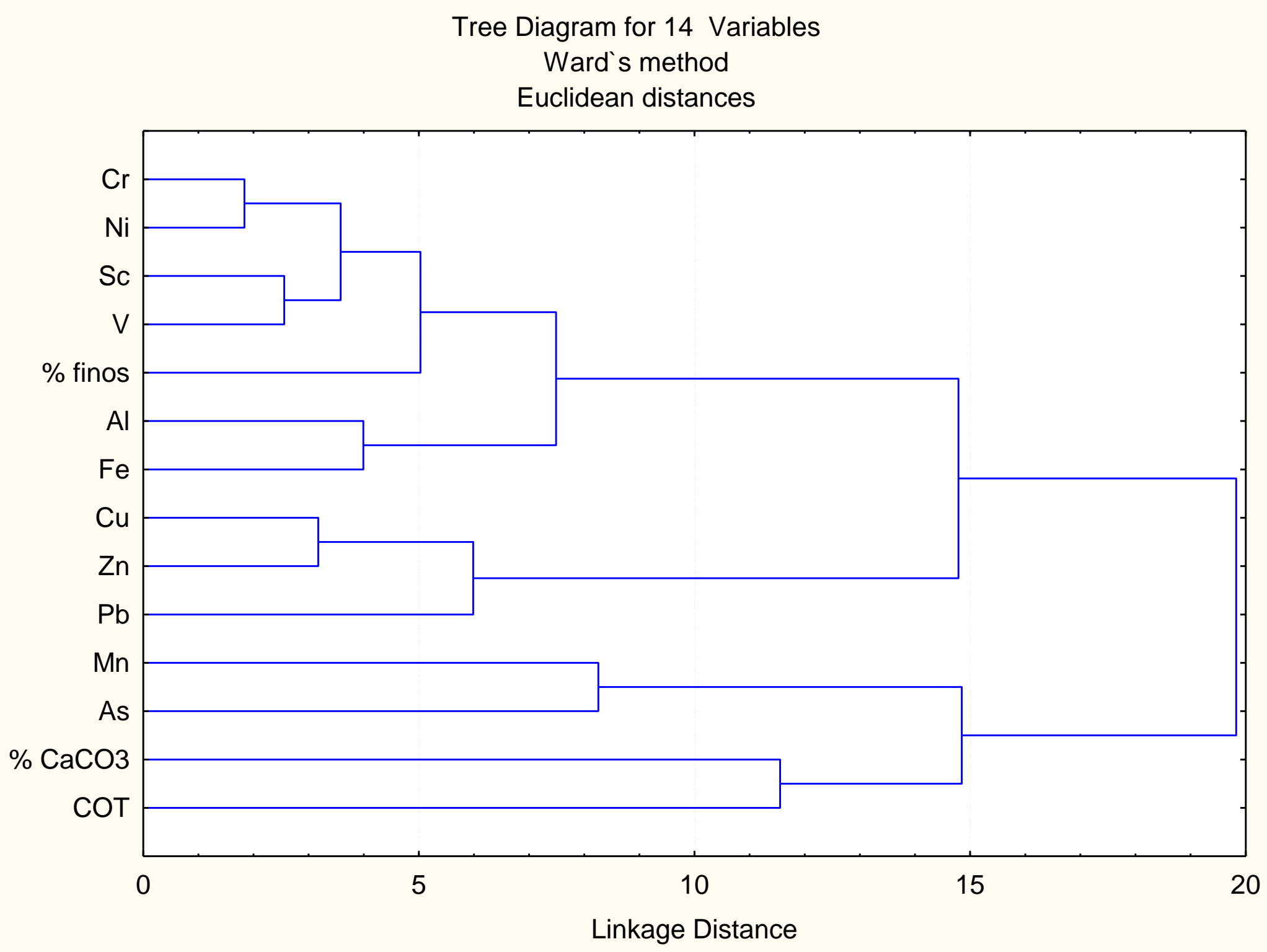

Figura 29. Análise de Agrupamento das variáveis estudadas. 


\subsection{Caracterização da matéria orgânica sedimentar}

A Tabela 14 apresenta os parâmetros descritivos das características composicionais da matéria orgânica sedimentar superficial do Canal de Bertioga e Rio Itapanhaú (\% $\mathrm{CaCO}_{3}, \mathrm{COT}, \mathrm{NT}$, razão $\mathrm{C} / \mathrm{N}, \delta{ }^{13} \mathrm{C} /{ }^{12} \mathrm{C}$ e $\left.\delta^{15} \mathrm{~N} /{ }^{14} \mathrm{~N}\right)$, os resultados obtidos para cada amostra estão na Tabela 15 do Anexo.

Tabela 14. Parâmetros descritivos das características da MO sedimentar.

\begin{tabular}{|c|c|c|c|c|c|c|}
\hline & $\begin{array}{c}\mathrm{CaCO}_{3} \\
(\%)\end{array}$ & $\begin{array}{l}\text { COT } \\
(\%)\end{array}$ & $\begin{array}{l}\text { NT } \\
(\%)\end{array}$ & $\mathrm{C} / \mathrm{N}$ & $\begin{array}{c}\delta^{13} \mathrm{C} /{ }^{12} \mathrm{C} \\
(\% \mathrm{o})\end{array}$ & $\begin{array}{c}\delta^{15} \mathrm{~N} /{ }^{14} \mathrm{~N} \\
(\% \mathrm{o})\end{array}$ \\
\hline Máximo & 66,77 & 13,93 & 0,57 & 198,49 & $-20,66$ & 5,26 \\
\hline Mínimo & 2,55 & 0,08 & 0,01 & 2,52 & $-29,74$ & $-1,24$ \\
\hline Média & 15,48 & 2,60 & 0,18 & 15,59 & $-26,33$ & 2,70 \\
\hline Mediana & 14,29 & 1,09 & 0,13 & 13,75 & $-26,49$ & 2,95 \\
\hline Desvio Padrão & 9,82 & 3,05 & 0,14 & 18,18 & 1,06 & 1,28 \\
\hline
\end{tabular}

Os teores de carbonato de cálcio apresentaram um intervalo entre 2,55 e $66,77 \%$, a média dos valores foi de $(15,48 \pm 9,82) \%$. Os maiores valores apresentados foram na região do Largo do Candinho (Figura 30).

A quantidade de $\mathrm{CaCO}_{3}$ presente nas amostras é um dos constituintes biogênicos mais importantes em sedimentos, sua concentração depende da produção fitoplanctônica e bentônica, da dissolução na coluna d'água durante a sedimentação e da diluição pelo material terrígeno. Sedimento contendo valores inferiores a $30 \%$ são considerados pobres em carbonato, indicando baixa acumulação (SCHNEIDER et al., 2005).

Todos os resultados de carbonato de cálcio foram inferiores a $30 \%$, com exceção de 3 amostras: \# 69 (46,38\%), \# 70 (64,78\%) e \# 95 (66,77\%). Sendo a região estudada considerada pobre em $\mathrm{CaCO}_{3}$. 


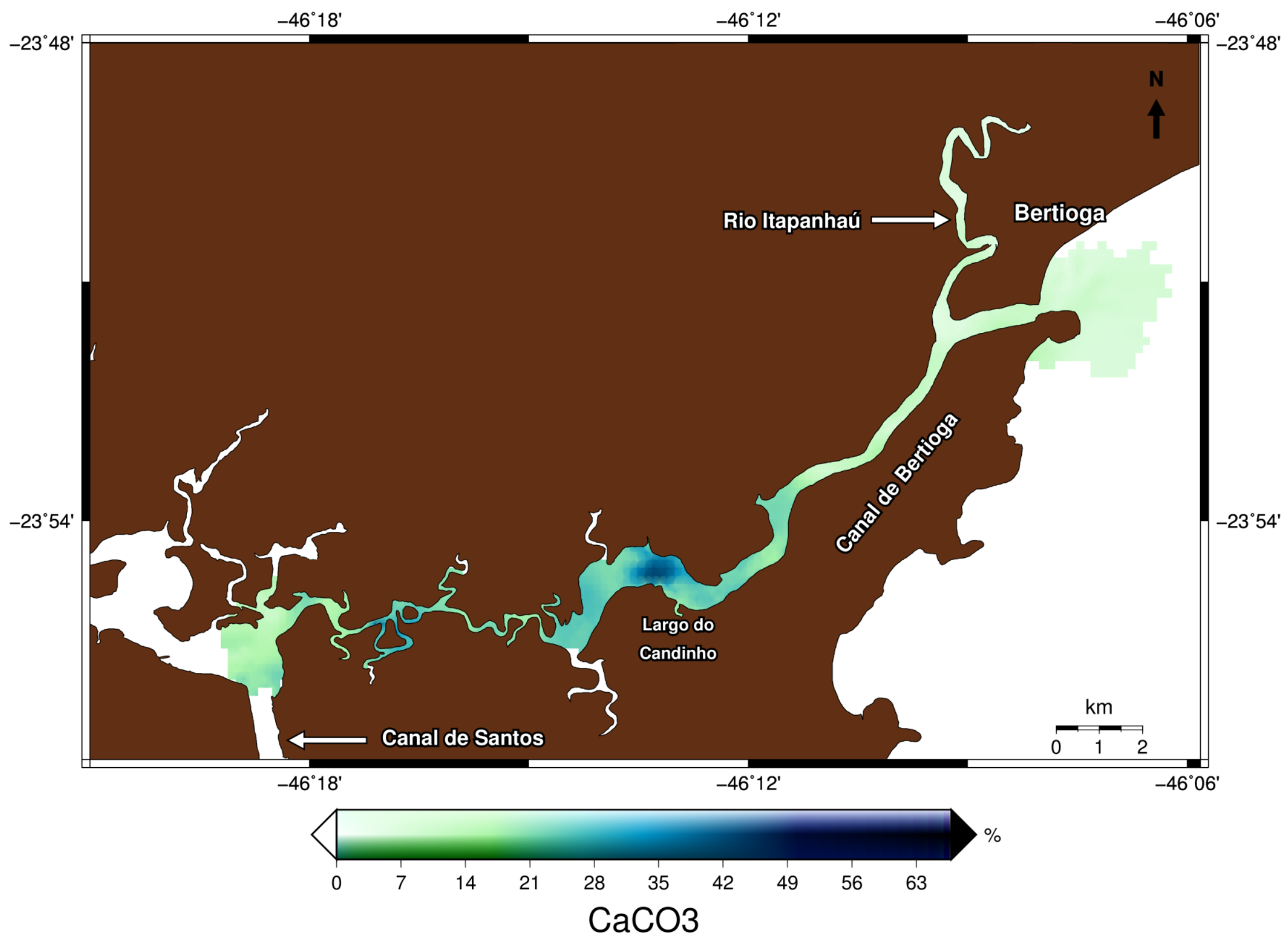

Figura 30. Distribuição espacial de Carbonato de Cálcio em \%. 
O intervalo de carbono orgânico total foi entre 0,08 a $13,93 \%$. A determinação dos teores de COT nas amostras de sedimento é de extrema importância, pois, além de ser o principal determinante da biodisponibilidade de compostos orgânicos não iônicos, afeta também a biodisponibilidade dos metais para os organismos presentes na coluna d'água (QUINÁGLIA, 2006).

Segundo RULLKÖTTER (2005) regiões próximas à costa possuem valores de COT variando de 0,3 a $1 \%$. Ao longo do Canal de Bertioga e do Rio Itapanhaú foram encontrados valores maiores acima de $2 \%$, indicando que a região é rica em COT, devido principalmente a presença dos manguezais que se faz presente ao longo de todo o canal. Estes valores são esperados uma vez que toda a extensão do canal é margeada por uma extensa área de manguezal $\left(23 \mathrm{~km}^{2}\right)$, que constitui a principal área de produtividade (HERZ, 1991). De acordo com a Figura 31 temos os maiores valores encontrados próximos da região do Largo do Candinho, local onde a influência da maré é praticamente nula ocorrendo uma maior deposição da matéria orgânica no sedimento (MIRANDA \& CASTRO, 1991; FÚLFARO \& PONÇANO, 1976).

A importância na determinação da matéria orgânica está diretamente relacionada com a distribuição dos metais, podendo atuar como "aprisionadoras" destes através de reações de superfície ou como liberadoras em função das condições físico-químicas do meio. A MO possui sítios que podem complexar metais-traço, principalmente os cátions divalentes (por exemplo, $\mathrm{Zn}^{2+}, \mathrm{Cd}^{2+}$ e $\mathrm{Cu}^{2+}$ ), e também os microorganismos que produzem matéria orgânica dissolvida podem afetar a disponibilidade desses metais (LOMBARDI et al., 2005). De acordo com SOARES et al. (1999), a tendência de alguns metais se complexarem na $\mathrm{MO}$ segue a seguinte ordem crescente: $\mathrm{Cu}, \mathrm{Zn}, \mathrm{Pb}, \mathrm{Cr}$, Ni e Cd. 


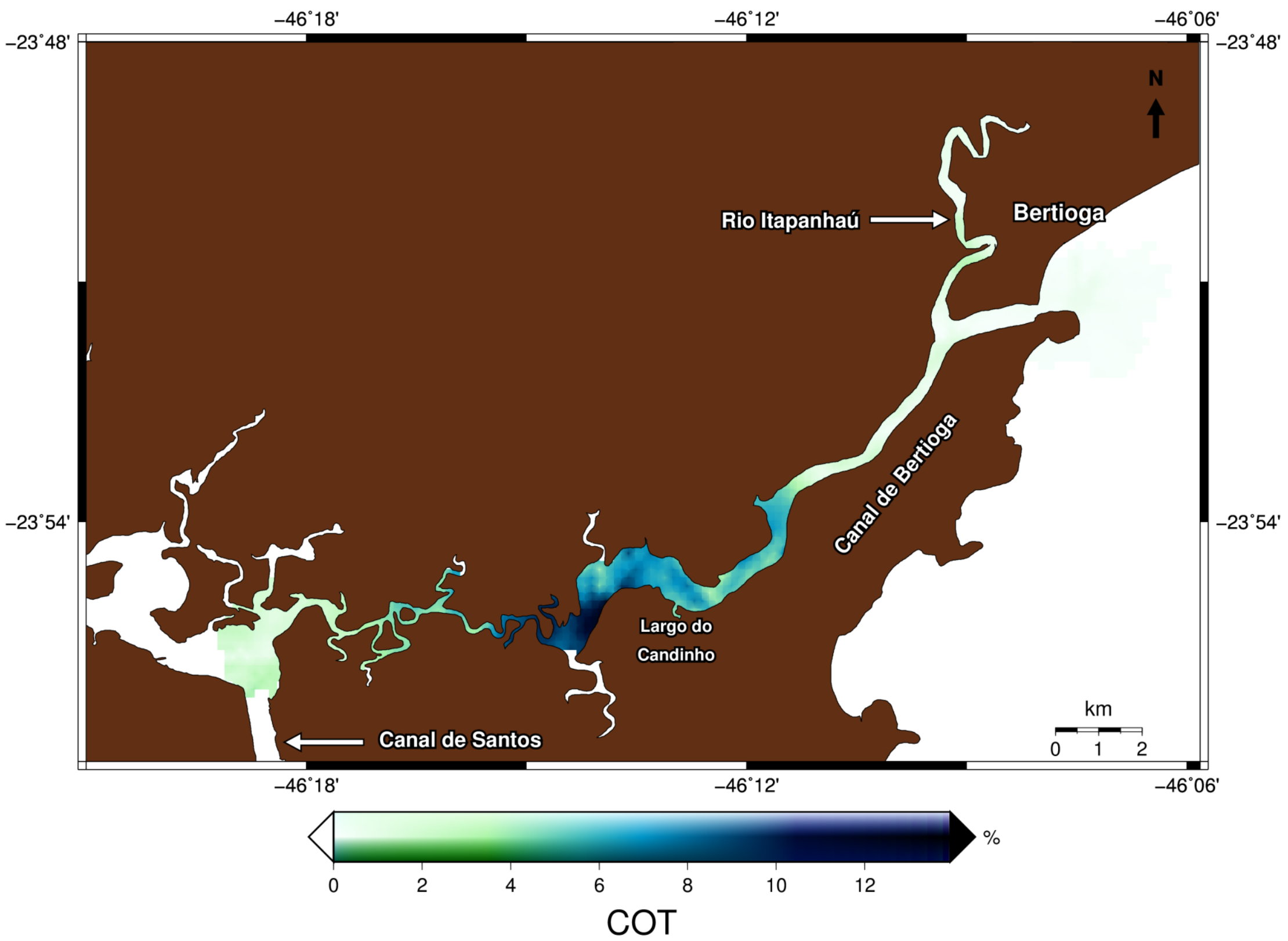

Figura 31. Distribuição espacial de Carbono Orgânico Total em \%. 
O intervalo de Nitrogênio Total foi entre 0,01 e $0,57 \%$, com valores médios de $(0,18 \pm 0,14) \% .23$ amostras das 147 apresentaram valores < LD. A principal fonte de nitrogênio natural vem do ar (80\%), já a de nitrogênio antrópico provém dos esgotos sanitários que sendo lançados nos ambientes aquáticos contribuindo com $\circ \mathrm{N}$ amoniacal devido à hidrólise da ureia $\mathrm{e}$ Norgânico devido à presença de proteínas (CETESB, 2001).

Teores de carbono orgânico e nitrogênio total quando combinados por meio da razão $\mathrm{C} / \mathrm{N}$ fornecem uma caracterização de origem da matéria orgânica devido às diferenças composicionais entre material marinho e terrígeno (MEYERS, 1994).

$A$ aplicação da razão $\mathrm{C} / \mathrm{N}$ é bastante útil para regiões costeiras. $\mathrm{O}$ reservatório de matéria orgânica nos estuários abrange diferentes tipos de materiais (dissolvido, particulado e coloidal) originados de diversas fontes, como os sedimentos fluviais e componentes marinhos alóctones. Estes sedimentos são misturados à biomassa autóctone, constituída da produção primária. Aportes adicionais provêm da vegetação costeira e de fontes antropogênicas. A variação destas fontes é o que determina a razão $\mathrm{C} / \mathrm{N}$ dos sedimentos (MÜLLER \& MATHESIUS, 1999).

A razão $C / N$ apresentou valores entre 2,52 e 198,49. A razão variou bastante ao longo do Canal, sendo seu cálculo prejudicado em 23 pontos amostrados devido ao valor de Nitrogênio Total não ter sido detectado pelo equipamento. Segundo PREMUZIC et al. (1992), o material de origem predominante marinho apresenta valores da razão $\mathrm{C} / \mathrm{N}$ inferiores a 8; já o material com origem terrestre apresenta valor superior a 15. SAITO et al., (1989) sugerem que razão de $\mathrm{C} / \mathrm{N}$ maior do que 20 indique origem terrestre, enquanto razão entre 5 e 7 origem pelágica. Posteriormente, Stein (1991) sugeriu que valores de $\mathrm{C} / \mathrm{N}$ abaixo de 10 indicam origem marinha, valores próximos a 10 indicariam mistura entre contribuição marinha e terrestre.

$\mathrm{O}$ uso da razão $\mathrm{C} / \mathrm{N}$ requer alguns cuidados, processos de degradação seletiva de alguns compostos (carboidratos, lipídeos, proteínas, etc.) tornam a matéria orgânica passível de modificações quanto suas características e fontes que podem alterar os valores da razão (ZHOU et al., 2006). A granulometria é outro fator que interfere na razão $\mathrm{C} / \mathrm{N}$. Sedimento de granulometria mais grossa pode conter uma proporção maior de detritos de plantas terrestres intactos, 0 
que faz com que os valores de $\mathrm{C} / \mathrm{N}$ sejam elevados. Já no material mais fino, em função da sua maior superfície de contato e carga elétrica negativa dos grãos pode ocorrer a adsorção da amônia, causando uma elevação na concentração de nitrogênio inorgânico gerando valores mais baixos de $\mathrm{C} / \mathrm{N}$ (MEYERS, 1997).

A aplicação de isótopos estáveis fornece informações mais precisas referentes às fontes de materiais orgânicos presentes no sedimento marinho, pois são resultados de processos bioquímicos de síntese que geram diferentes níveis de fracionamento isotópico entre fontes distintas (PANCOST \& PAGANI, 2006).

A razão isotópica $\delta^{13} \mathrm{C} /{ }^{12} \mathrm{C}$ apresentou um intervalo de distribuição de 29,74 à $-20,66 \%$, apenas um valor foi acima de $-23 \%$ indicando que as fontes de matéria orgânica da região de estudo são de origem terrestre. De um modo geral, valores de $\delta^{13} \mathrm{C} /{ }^{12} \mathrm{C}$ entre -27 e $-23 \%$ são indicativos de fontes terrígena da matéria orgânica (THORNTON \& MCMANUS, 1994), Segundo MEYERS (1994) valores entre -22 e -20\%o representam um enriquecimento isotópico da matéria orgânica marinha em relação à terrígena.

O valor isotópico de $\delta^{15} \mathrm{~N} /{ }^{14} \mathrm{~N}$ foi obtido no intervalo de $-1,24$ à $5,26 \%$, desses resultados 27 amostras apresentaram valores <L.D. do equipamento. Apenas 5 resultados foram acima de 5\%, o que demonstra mais uma vez a influência continental na matéria orgânica presente no Canal de Bertioga, pois de acordo com THORNTON \& MCMANUS (1994), material sedimentar com origem terrígena o valor de $\delta^{15} \mathrm{~N} /{ }^{14} \mathrm{~N}$ é em média de $2 \%$, já para a matéria orgânica de origem marinha o valor médio encontrado é entre 5 e 7 \%o. (RAMASWAMY et al., 2008). Já as plantas terrestres em sistemas estuarinos apresentam valores de $\delta^{15} \mathrm{~N}$ próximos a 0,4 \% (SCHUBERT \& CALVERT, 2001). 


\section{CONSIDERAÇÕES FINAIS E CONCLUSÃO}

A técnica analítica utilizada no presente estudo (ICP-OES) apresentou boa sensibilidade, precisão e exatidão adequadas para a determinação dos elementos em sedimentos. O método de extração (EPA 3050B) é recomendado para a determinação de metais e semimetais em amostras de sedimentos sendo reconhecido internacionalmente e amplamente utilizado e foi extremamente eficiente conforme as recuperações obtidas dos materiais de referência certificados, apresentando resultados adequados para o presente estudo.

A determinação dos metais e As mostraram-se junto com a porcentagem de finos e outros indicadores geoquímicos combinados (COT, NT, $\delta^{13} \mathrm{C} /{ }^{12} \mathrm{C}$, $\delta^{15} \mathrm{~N} /{ }^{14} \mathrm{~N}, \mathrm{CaCO}_{3}$ ) ferramentas importantes para a compreensão dos processos deposicionais no Canal de Bertioga, permitindo uma caracterização mais detalhada das origens da matéria orgânica sedimentar, com predomínio de material terrestre.

O grau de contaminação dos sedimentos foi avaliado segundo o padrão de qualidade de sedimentos estabelecidos pela agência ambiental canadense (TEL e PEL), todos os valores obtidos foram abaixo do PEL, e a maioria das amostras apresentaram valores abaixo do TEL, com exceção do As (80 amostras), $\mathrm{Cu}$ (7 amostras) e $\mathrm{Pb}$ (1 amostra) que ultrapassaram os valores de referência. Foram calculados o Fator de Concentração $(F C)$ e o Fator de Enriquecimento (FE) para identificar a contribuição antropogênica, os índices indicaram contaminação moderada para $\mathrm{Cu}, \mathrm{Pb}$ e $\mathrm{Zn}$ na região próxima ao estuário de Santos, e para As próximo à cidade de Bertioga. Sendo a entrada desses elementos no sistema possivelmente proveniente das indústrias do estuário santista, e para o As dos efluentes domésticos da cidade de Bertioga ou serem de origem natural da lixiviação das rochas. Para os demais elementos houve ausência de contaminação.

Comparando os valores obtidos neste trabalho com outros desenvolvidos na região e em diferentes regiões do Brasil, os resultados não apresentaram valores anômalos. Além disso, os teores calculados estão dentro da faixa de variação reportada para a região da Plataforma Continental de São Paulo e Rio de Janeiro. As concentrações obtidas também foram ligeiramente 
maiores quando comparadas a uma região não impactada como Cananéia (SP) e muito menor do que em regiões portuárias consideradas como impactadas (Porto de Santos (SP), baía de Guanabara e Sepetiba (RJ)).

Apesar dos valores encontrados dos níveis dos elementos analisados estarem dentro ou abaixo dos limites estabelecidos pela legislação, o Canal da Bertioga é uma importante região da Baixada Santista que tem um equilíbrio bastante delicado, com a presença de importantes manguezais. Os planos de ampliação do complexo portuário que resultam na necessidade de execução de extensivas dragagens do Canal do Porto e de novas instalações indicam uma necessidade frequente de monitoramento dessas regiões limítrofes, destacando o Canal da Bertioga, de forma que se possa equacionar o potencial da área em suportar as modificações advindas das questões ambientais existentes. A presença de marinas, a ocupação de forma desordenada e 0 lançamento de efluentes domésticos in natura, também colocam em risco o equilíbrio desse importante sistema. A base de dados dos níveis de metais e As gerados por este trabalho são importantes, pois poderão auxiliar nos processos de gestão costeira e ambiental da região. 


\section{REFERÊNCIAS}

AB'SABER, A.N. 2003. Litoral do Brasil. São Paulo: Metalivros, 288 p.

ABESSA, D. M. 2002. Avaliação da qualidade de sedimentos do Sistema Estuarino de Santos. Tese de Doutorado. Instituto Oceanográfico, Universidade de São Paulo, 209 p.

ABÍLIO, G.S. 2004. Caracterização ambiental prévia de áreas sujeitas à exploração de reservas de petróleo - bacia de santos, brasil. Monografia. Instituto de Geociências, Universidade Federal do Rio de Janeiro, 75 p.

ANDRADE, R. C. B. 2003. Piritização de metais-traço na Baía de Sepetiba RJ. Tese (doutorado). Instituto de Química, Universidade Federal Fluminense, $167 \mathrm{p}$.

ANDREWS, S.; SUTHERLAND, R. A. 2004. $\mathrm{Cu}, \mathrm{Pb}$ and $\mathrm{Zn}$ contamination in Nuuanu watershed, Oahu, Hawaii. The Science of the Total Environment, v. 324, p. 173-182.

ARAGON, G. T. 1987. Estudo geoquímico de metais pesados em sedimentos da planície de maré na enseada das garças, Baía de Sepetiba, RJ. Dissertação de Mestrado. Instituto de Geoquímica, Universidade Federal Fluminense, $135 \mathrm{p}$.

BAIRD, C. 2002. Química Ambiental. Porto Alegre: Bookman, 300 p.

BAPTISTA NETO, J.A.; PONZI, V.R.A.; SICHEL, S.E. 2004. Introdução à Geologia Marinha. Rio de Janeiro: Interciência, 315 p.

BARCELLOS NETO, C. C. 1991. Distribuição e comportamento de metais pesados em uma área de lançamento de rejeitos de uma indústria de zinco e cádmio (Baía de Sepetiba, RJ). Dissertação de Mestrado. Biofísica, Universidade Federal do Rio de Janeiro, 102 p. 
BARCELLOS NETO, C. C. 1995. Geodinâmica de cádmio e zinco na Baía de Sepetiba. Tese de Doutorado. Instituto de Química, Universidade Federal Fluminense, $147 \mathrm{p}$.

BERBER,G.B.B.; $\quad$ AMORIM,E.P.; RODRIGUES,M.; MAHIQUES,M.M.; FÁVARO,D.; BRAGA, E. DE S. 2007. Distribuição espacial de CNPS e suas relações com metais nos sedimentos superficiais do estuário de Cananéia (SP) - inverno de 2005. In: XI Congresso Brasileiro de Geoquímica, Atibaia (SP), p.1-4.

BOSS, C. B.; FREDEEN, K. J. 1997. Concepts, Instrumentation and Techniques in Inductively Coupled Plasma Optical Emission Spectrometry, $2^{\text {nd }}$. edition, Perkin Elmer Corporation, $154 \mathrm{p}$.

BRYAN, G. W. 1971. The effects of heavy metals (other than Mercury) on marine and estuarine organisms. Proc. Roy. Soc. Lond. B., v. 177, p. 389 $-410$

BURUAEM, L. M.; HORTELLANI, M. A.; SARKIS, J. E.; COSTA-LOTUFO, L. V.; ABESSA, D. M. S. 2012. Contamination of port zone sediments by metals from Large Marine Ecosystems of Brazil. Marine Pollution Bulletin. Hong Kong, v. 64, p. 479-488.

CARVALHO, A. M. DE; NetO, A. R. P.; SANTOS, V. L. C. S. 2005. Distribuição geoquímica dos teores de carbonato, carbono orgânico total, lipídios, hidrocarbonetos (HPAs) e metais pesados nos sedimentos da região oceânica do Rio de Janeiro. revista virtual, v.1, n.1, p.70-84.

CEQG - Canadian Environmental Quality Guidelines. 2001. Canadian Sediment Quality Guidelines for the Protection of Aquatic Life. Disponível em <ceqg-rcqe.ccme.ca.download/en/239/>. 
CESAR, A.; CHOUERI, R. B.; RIBA I.; MORALES-CASELLES, C.; PEREIRA, C. D. S.; SANTOS, A. R.; ABESSA, D. M. S.; DELVALLS, T. A. 2007. Comparative sediment quality assessment in different ecosystems from Spain (Gulf of Cadiz) and Brazil (Santos and São Vicente estuarine system). Rev. Environment International, v.33 (4), p. 429-435.

CETESB, COMPANHIA DE TECNOLOGIA DE SANEAMENTO AMBIENTAL. 1998. Mapeamento dos ecossistemas costeiros do Estado de São Paulo. São Paulo: Ed. Páginas \& Letras, 108 p.

CETESB, COMPANHIA DE TECNOLOGIA DE SANEAMENTO AMBIENTAL. 2001. Sistema Estuarino de Santos e São Vicente. Relatório Técnico, $178 \mathrm{p}$.

CHOUERI, R.B.; CESAR, A.; ABESSA, D.M.S.; TORRES, R.J.; RIBA, I.; PEREIRA, C.D.S.; NASCIMENTO, M.R.L.; MORAIS, R.D.; MOZETO, A.A.; DELVALLES, T.A. 2010. Harmonised framework for ecological risk assessment of sediments from ports and estuarine zones of north and south atlantic. ecotoxicology, v.19, p. 678-696.

COIMBRA, A. G. 2003. Distribuição de metais pesados em moluscos e sedimentos nos manguezais de Coroa Grande e da Enseada das Graças, Baía de Sepetiba, RJ. Dissertação de Mestrado. Geoquímica, Universidade Federal Fluminense, $72 \mathrm{p}$.

CONSELHO NACIONAL DO MEIO AMBIENTE (CONAMA). 2004. Resolução 344, de 25 de março de 2004. http://www.mma.gov.br.

CONSELHO NACIONAL DO MEIO AMBIENTE (CONAMA). 2012. Resolução 454, de 01 de novembro de 2012. http://www.mma.gov.br.

CORTESÃO, C.; VALE, C. 1995. Metals in Sediments of the Sado Estuary, Portugal. Marine Pollution Bulletin, v. 30 (1), p. 34-37. 
CLARK, M. W.; DAVIES-MCCONCHIE, F.; MCCONCHIE, D.; BIRCH, G. F. 2000. Selective chemical extraction and grainsize normalisation for environmental assessment of anoxic sediments: validation of in integrated procedure. Science Total Environment, v. 258 (3), p. 149-170.

COTTA, J. A. O.; REZENDE, M. O. O.; PIOVANI, M. R. 2006. Avaliação do teor de metais e sedimento do rio Betari no Parque Estadual Turístico do Alto Ribeira - PETAR, São Paulo, Brasil. Quim. Nova, v. 29 (1), p. 40-45.

CUNHA, A. T. S. 2005. Cronologia da deposição de elementos traço nos últimos 50 anos nas baías de Sepetiba e llha Grande (RJ). Dissertação de Mestrado. Universidade Federal Fluminense, $91 \mathrm{p}$.

CUNHA, D. G. F. 2007. Avaliação do estado trófico do rio Pariquera-Açu, Vale do Ribeira de lguape, SP, em diferentes períodos hidrológicos. Monografia. Escola de Engenharia de São Carlos, Universidade de São Paulo, $97 \mathrm{p}$.

DIB, K. A. 1992. O transporte de sedimentos em suspensão e a concentração de metais pesados em sedimentos de fundo nos rios da baixada de Sepetiba, Rio de Janeiro. Dissertação de Mestrado. Universidade Federal Fluminense, $107 \mathrm{p}$.

DIEGUES, A. C. 1987. Conservação e desenvolvimento sustentado de ecossistemas litorâneos no Brasil. In: Simpósio sobre Ecossistemas da Costa Sul e Sudeste Brasileira, Cananéia (SP), p. 196-243.

DORNELLES, L. M. A. 1993. Metais pesados nos sedimentos na plataforma continental entre Ilha Grande e Cabo Frio (RJ) e suas associações com a granulometria, conteúdo de carbonato de cálcio e matéria orgânica. Dissertação de Mestrado - UFF, Niterói. 
DORNELLES, L.M.A. 2000. Monitoramento de metais pesados na Baía de Sepetiba, RJ, Brasil, com base em geoprocessamento. Tese de Doutorado. Instituto de Geociências, Universidade Federal do Rio de Janeiro, $557 \mathrm{p}$.

ECOSAN. 2007. A Influência do complexo estuarino da Baixada Santista sobre o ecossistema da plataforma adjacente. Relatório Técnico, 3v.

EICHLER, P. P. B. 2001. Avaliação e diagnóstico do Canal de Bertioga (São Paulo, Brasil) através da utilização de foraminíferos como indicadores ambientais. Tese de Doutorado. Instituto Oceanográfico, Universidade de São Paulo, 256 p.

ENVIRONMENT CANADA. 1999. Canadian Sediment Quality Guidelines for the Protection of Aquatic Life. Summary Tables. http://www.ec.gc.ca.

FERREIRA DA SILVA, L.F. 2000. Ciclagem de mercúrio em um ecossistema de manguezal na floresta de Itacuruçá, baía de Sepetiba, RJ. Tese de Doutorado - UFF, Niterói.

FERREIRA, J. A., 2008. Estudo das associações de anelídeos Polychaeta da Baía de Santos e Plataforma Continental Adjacente (SP, Brasil) e suas interrelações com parâmetros físicos e geoquímicos estruturadores. Tese de Doutorado do Instituto Oceanográfico da USP. 204p.

FÖRSTNER, U.; SALOMONS, W. 1980.Trace metals analysis on polluted sediments. Part I: Assessments of sources and intensities. Environ. Technol. Lett., v.1, p. 495-505.

FÖRSTNER, U. ; PATCHINEELAM , S. R. 1981. Chemical associations of metals in marine deposits with special reference to pollution in the German North Sea. Reun. Cons. Int. Explor. Mer, v. 181, p. 49-58. 
FRAZÃO, E. P. 2003. Caracterização Hidrodinâmica e Morfo-Sedimentar do Estuário Potengi e Área Adjacente: Subsídios para Controle e Recuperação Ambiental no Caso de Derrames de Hidrocarbonetos. Dissertação de Mestrado. Universidade Federal do Rio Grande do Norte, $97 \mathrm{p}$.

FUKUMOTO, M. M. 2007. Determinação da história deposicional recente do Alto Estuário Santista, com base nos teores de metais e na susceptibilidade magnética dos sedimentos. Tese de Doutorado. Instituto Oceanográfico, Universidade de São Paulo, 123p.

FÚLFARO, V. J.; PONÇANO, W. L. 1976. Sedimentação atual do estuário e baía de Santos: um modelo geológico aplicado a projetos de expansão da zona portuária. In: Congresso Brasileiro de Geologia de Engenharia, Anais do I Congresso Brasileiro de Geologia de Engenharia, Rio de Janeiro (RJ), v. 2, p. 67-90.

FUNDESPA, 1991. Condições Oceanográficas no Canal da Bertioga: Relatório Técnico Final. Fundação de Estudos e Pesquisas Aquáticas. 251p.

GONÇALVES, C.; FIGUEIRA, R. C. L.; SARTORETTO, J. R.; SALAROLI, A. B.; RIBEIRO, A. P.; FERREIRA, P. A. L.; MAHIQUES, M. M. 2013. Reconstruction of Historical Trends in Potentially Toxic Elements from Sediment Cores Collected in Bertioga Channel, Southeastern Brazi. Brazil Journal of Oceanography, v. 61 (2), p. 149-160.

HALPERN, B. S.; WALBRIDGE, S; SELKOE, K. A.; KAPPEL, C.V; MICHELI, F.; D’AGROSA, C.; BRUNO, J. F.; CASEY, K. S.; EBERT, C.; FOX, H. E.; FUJITA, R.; HEINEMANN, D.; LENIHAN, H. S.; MADIM, E. M. P.; PERRY, M. T.; SELIG, E. R.; SPALDING, M.; STENECK, R.; WATSON, R. 2008. A Global Map of Human Impact on Marine Ecosystems. Science, v. 319, p. 948-952. 
HAYNES, D.; MULLER, J.; CARTER, S. 2000. Pesticide and herbicide residues in sediments and seagrasses from the Great Barrier Reef World Heritage Area and Queensland coast. Marine Pollution Bulletin, n. 41, p. 279-287.

HERZ, R., 1991. Manguezais do Brasil. Instituto Oceanográfico da USP. São Paulo, Brasil. 227p.

HORTELLANI, M. A.; SARKIS, J. E. S.; ABESSA, D. M. S.; SOUSA, E. C. P. M. 2008. Avaliação da contaminação por elementos metálicos dos sedimentos do estuário de Santos, São Vicente. Química Nova, v. 31, p. 10-19.

HURTADO, S. N. 2003. Dinâmica de sedimentação atual associada à contaminação por metais nos sedimentos do estuário santista e do Canal da Bertioga, SP. Monografia. Instituto de Geociências, Universidade de São Paulo, 74 p.

IPT - INSTITUTO DE PESQUISAS TECNOLÓGICAS. 1981. Mapa geológico do Estado de São Paulo. 2 volumes. Governo do Estado de São Paulo. Secretaria da Indústria, Comércio, Ciência e Tecnologia, v.1, 126 p.

KERSTEN, M.; DICKE, M.; KRIEWS, M.; NAUMANN, K.; SCHMIDT D.; SCHULZ, M.; SCHWIKOWSKI, M. \& STEIGER, M. 1989. Distribution and fate of heavy metals in the North sea. In: Pollution of the North Sea. Eds. Salomons, W.; B. L. Baune; E. k. Duursma \& U. Förstner. SpringerVerlag, Berlin, p. 152-347.

KERSTEN, M.; FÖRSTNER, U. 1995. Speciation of Trace Metals in Sediments and Combustion Waste. Chemical Speciation in the Environment, Blackie Academic \& Professional, Glascow.

KURITA, M. H.; PFEIFFER, W. C. 1991. Heavy metal in sediment and biota of Sepetiba Bay, RJ, Brazil. In: Heavy metals in the environment proceedings. Edinburgh: Cep Consultants, p. 519-522. 
LACERDA, L. D.; PFEIFFER, W. C.; FISZMAN, M. 1982. Níveis naturais de metais pesados em sedimentos marinhos da Baía Ribeira, Angra dos Reis. Ciência e Cultura, v.34 (7), p. 921-924.

LACERDA, L. D. 1983. Aplicação de metodologia de abordagem pelos parâmetros críticos no estudo da poluição por metais pesados na Baía de Sepetiba, RJ. Tese de Doutorado. Instituto de Biofísica, Universidade Federal do Rio de Janeiro, 136p.

LAMPARELLI, M. C.; COSTA, M. P.; PRÓSPERI, V. A.; BEVILACQUA, J. E.; ARAÚJO, R. P. A.; EYSINK, G. G. K. \& POMPÉIA. 2001. Sistema estuarino de Santos e São Vicente. Relatório Técnico CETESB, 183 p.

LAW, R. J.; BISCAYA, J. L. 1994. Polyciclic aromatic hydrocarbons (PAH) Problems and progress in sampling, analysis and interpretation. Mar. Pollut. Bull., v. 29, p. 235-241.

LI, X.; WAI, O. W. H.; LI, Y. S.; COLES, B. J.; RAMSEY, H.; THORNTON, I. 2000. Heavy metal distribution in the sediment profiles of the Pearl River estuary. South China. Appl. Geochem., v. 15, p. 567-581.

LIMA, N.R.W.; PFEIFFER, W.C.; FISZMAN,M. 1986. Ciclagem de metais pesados em bancos de spartina alterniflora na Baía de Sepetiba, RJ. Acta Limnologica Brasileira, v.1, p. 317-340.

LOMBARDI, A. T.; HIDALGO, T. M. R.; VIEIRA, A. A. H. 2005. Copper complexing properties of dissolved organic matter exuded by freshwater microalgae Scenedesmus acuminatus (Chlorophyceae). Chemosphere, v. 60 (4), p. 453-459.

LORING, D. H.; RANTALA, R. T. T. 1992. Manual for the geochemical analysis of marine sediments and suspended particulate matter. Earth Science Reviews, v. 32, p. 235-283. 
LOUREIRO, D.D.; TORTOZA, J.; HERMS, F.W. 2003. Distribuição espacial de metais pesados no sedimento superficial da Baía de Sepetiba, RJ. In: II Congresso sobre planejamento e gestão das zonas costeiras dos países de expressão portuguesa, $5 p$.

LUIZ-SILVA, W.; MATOS, R. H. R; KRISTOSCH, G. C.; MACHADO, W. 2006. Variabilidade espacial e sazonal da concentração de elementos-traço em sedimentos do sistema estuarino de Santos-Cubatão (SP). Quim. Nova, v. 29 (2), p. 256-263.

MACHADO, W.; SILVA-FILHO, E. V.; OLIVEIRA, R. R. \& LACERDA, L. D. 2002. Trace metal retention in mangrove ecosystems in Guanabara Bay, SE Brazil. Marine Pollution Bulletin, n. 44, p. 1277-1280.

MACHADO, C. G. 2007. Caracterização química do material particulado em suspensão e sedimentos superficiais na zona de máxima turbidez no eixo leste-oeste do Complexo Estuarino de Paranaguá (CEP), PR, Brasil. Dissertação de Mestrado. Universidade Federal do Paraná, 85 p.

MAHIQUES, M. M.; FIGUEIRA, R. C. L.; SALAROLI, A. B.; ALVES, D. P. V.; GONÇALVES, C. 2013. 150 years of anthropogenic metal input in a Biosphere Reserve: the case study of the Cananéia-Iguape coastal system, Southearstern Brazil. Environ Earth Sci, v. 68 (4), p. 1073-1087.

MALM, O.; PFEIFFFER, W. C.; LACERDA, L. D.; FIZSMAN, M.; LIMA, N. R. W. 1989. Heavy metals pollution monitoring through the critical pathways analysis: the Sepetiba Bay case. In: NEVES, C. (ed.), costlines of Brazil, p. 249-254. New York: asce, 304p. 
MARINS, R. V.; LACERDA, L. D.; VILLAS BOAS, R. C. 1999. Relative importance of non point sources of mercury to an industrialized coastal system, Sepetiba Bay, SE Brazil. In: EBINGHAUS, R.; TURNER, R. R.; LACERDA, L. D.; VASILIEV,O. (EDS), Mercury contaminated sites: characterization, risk assessment and remediation. Berlin: springer, $p$. 207-220.

MARINS, R. V.; LACERDA, L. D.; VILLAS BOAS, R. C. 2002. Impacts of landbased activites on the Ceará coast, NE Brazil. South American Basins: LOICZ Global Change Assessment and Synthesis of River CatchmentCoastal Sea Interaction and Human Dimensions. LOICZ Reports e Studies, v. 21, p. $92-98$,

MCLAREN, J. W.; BERMANN, S. S.; BOYKO, V. J.; RUSSEL, D. S. 1981. Simultaneous Determination of Major, Minor, and Trace Elements in Marine Sediments by Inductively Coupled Plasma Atomic Emission Spectrometry,.Analytical Chemistry, v. 53 (12), p. 1802-1806.

MENDES, F. M. 2007. Estrutura da comunidade macrozoobentônica na região de influência do Terminal Almirante Barroso (TEBAR) no canal de São Sebastião (SP, Brasil). Dissertação de Mestrado. Instituto Oceanográfico, USP, São Paulo, 88p.

MEYERS, P. A. 1994. Preservation of Elemental and isotopic source identification of sedimentary organic matter. Mar Geol., v. 160, p. 251270.

MEYERS, P. A. 1997. Organic geochemical proxies of paleoceanographic, paleolimnologic, and paleoclimatic processes. Organic Geochimistry, v. $27(5 / 6)$, p. 213-250,

MIRANDA, L. B.; CASTRO, B. M. 1991. Condições oceanográficas no Canal de Bertioga. Relatório Técnico. Fundação de Estudos e Pesquisas Aquáticas (FUNDESPA), p. 1-97. 
MIRANDA, L. B. ; KJERFVE, B. ; CASTRO, B. M. 1998. Circulation and Mixing due to Tidal Forcing in the Bertioga Channel, São Paulo, Brazil. Estuaries, v. 21 (2), p. 204-211.

MIRANDA, L. B.; CASTRO, B. M.; KJERFVE, B. 2002. Princípios de oceanografia física de estuários. São Paulo: Edusp. 411 p.

MOLISANI, M. M.; MARINS, R. V.; MACHADO, W.; PARAQUETTI, H. H. M.; LACERDA, L. D. 2001. Some implications of inter-basin water transfers mercury emissions to Sepetiba Bay from the Paraiba do Sul River Basin, SE Brazil. p. 113-117. IN:LACERDA, L.D.; KREMER, H. H.; KJERFVE, B.; SALOMONS, W.; MARSHALL CROSSLAND, J. I.; CROSSLAND,C.J.(EDS), South American Basins-Sambas: LOICZ catchment impacts on the coastal zone and human dimension. Texel:IGBP-LOICZ, $212 \mathrm{p}$.

MOZETO, A. A.; UMBUZEIRO, G. A.; JARDIM, W. F. 2006. Métodos de coletas, análises físico-químicas e ensaios biológicos e ecotoxicológicos de sedimentos de água doce. São Carlos: Cubo Multimídia, 224 p.

MÜLLER, A. \& MATHESIUS, U. 1999. The palaeornvironments of coastal lagoons in the southern Baltic Sea. The application of sedimentary Corg/ $\mathrm{N}$ ratios as source indicators of organic matter. Palaeogeogr. Palaeoclimatol. Palaeoecol., v. 145, p. 1-16.

MUNIZ, P. 2003. Comunidades macrobênticas como indicadoras da qualidade ambiental de ecossistemas costeiros rasos: estudo de caso - Enseada de Ubatuba (SP, Brasil), Tese de Doutorado - Instituto Oceanográfico, USP, São Paulo, 205p.

MUNIZ, P.; PIRES-VANIN, A. M. S.; MARTINS, C. C.; MONTONE, R. C.; BÍCEGO, M. C. 2006. Trace metals and organic compounds in the bentic environment of a subtropical embayment (Ubatuba Bay, Brazil). Marine Pollution Bulletin, n. 52, p.1090-1117. 
MUTHU, R.; JAYAPRAKASH, E. M. 2008.Distribution and enrichment of trace metals in marine sediments of Bay of Bengal, off Ennore, south-east coast of India. Environ. Geol., v. 56, p. 207-217.

OLIVEIRA, E. 2003. Sample preparation of atomic spectroscopy: Evolution and Future trends. J. Braz. Chem. Soc., v. 14 (2), p. 174-183.

OLIVEIRA, M. L. J.; VIDAL-TORRADO; OTERO, X.L. \& FERREIRA, J.F. 2007. Mercúrio total em solos de manguezais da Baixada Santista e llha do Cardoso, Estado de São Paulo. Química Nova, v. 30(3), p. 519-524.

PANCOST, R. D.; PAGANI, M. 2006. Controls on the carbon isotopic composition of lipids in marine environment. Handbook of Environmental Chemistry, 2(N): 209-249.

PELLEGATTI, F.; FIGUEREDO, A. M. G.; WASSERMAN, J. C. 2001. Neutron activation analysis applied to the determination of heavy metals and other trace elements in sediments from Sepetiba Bay (RJ), Brazil. Geostandards Newsletter, v.25 (2-3), p. 307-315.

PESTANA, M. H. D. P. 1989. Partição geoquímica de metais pesados em sedimentos estuarinos nas bacias de Sepetiba e da Ribeira, RJ. Dissertação de Mestrado. Departamento de Geoquímica. Universidade Federal Fluminense, $89 \mathrm{p}$.

PREMUZIC, E. T.; BENKOVITZ, C. M.; GAFINEY, J. S.; WALSH, J. J. 1982. The nature and distribution of organic matter in surface sediments of world oceans and seas. Org Geochem., v.4(2), p. 63-77.

QUEVAUVILLER, P. 1998. Operationally defined extraction procedures for soil and sediment analysis I. Standardization. TrAC Trends in analytical chemistry, v. 17 (5), p. 289-298. 
QUINÁGLIA, G. A. 2006. Caracterização dos níveis basais de concentração de metais nos sedimentos do sistema estuarino da Baixada Santista. Tese de Doutorado. Instituto de Química, Universidade de São Paulo, 239 p.

RAMASWMY, V.; GAYE, B.; SHIRODKAR, P. V.; RAO, P. S.; CHIVAS, A. R. 2008. Distribution and sources of organic carbon, nitrogen and their isotopic signatures in sediments from the Ayeyarwady (Irrawaddy) continental shelf, northern Andaman. Sea. Mar Chem., v.111, p. 137150.

RAND, G. M.; WELLS, P. G.; MCCARTY, L. S. 1995. Introduction to aquatic toxicology. Fundamentals of aquatic toxicology: Effects, environmental fate and risk assessment. Flórida: CRC Press, p. 3-67.

RIBEIRO, A. P. 2006. Procedimento de fracionamento comparado a modelo de atenuação para a avaliação de mobilidade de metais pesados em sedimentos da Baía de Sepetiba, Rio de Janeiro. Tese de Doutorado. Instituto de Pesquisas Energéticas e Nucleares, 148 p.

RODRIGUES, P. P. G. W. 1990. Aporte de metais pesados para a Baía de Sepetiba e seu comportamento na região estuarina. Dissertação de Mestrado. Instituto de Química, Universidade Federal Fluminense, 90 p.

RODRIGUES, L. C. V. 2008. Estudo da biodisponibilidade química do arsênio e chumbo em sedimentos de corrente no Vale do Ribeira - SP. Tese de Doutorado. Instituto de Química, Universidade Federal Fluminense, 137 p.

RULLKÖTTER, J. 2006. Organic matter: the driving force for early diagenesis. In: SCHULZ, H. D.; ZABEL, M. (Ed.). Marine Geochemistry. $2^{\text {nd }}$ Ed. Berlin: Springer, p. 125-146.

SÁ, F.; MACHADO, E. C. 2007. Metais pesados e arsênio em sedimentos do canal de acesso aos portos do estado do Paraná (PR). In: BOLDRINI E. 
B.; SOARES C. R.; DE PAULA E. V. (Eds.), Dragagens portuárias no Brasil: licenciamento e monitoramento ambiental. Antonina: Governo do Estado do Paraná; SEMA/PR; ADEMADAN; UNIBEM, p. 253-263.

SAITO, Y.; NISHIMURA, A.; MATSUMOTO, E. 1989. Transgressive sand sheet covering the shelf and upper slope off Sendai, Northeast Japan, Marine Geology, v. 89, p. 245-258.

SANDERS, C.J.; SANTOS, I.R.; SILVA-FILHO, E.V. \& PATCHINEELAM, S.R. 2008. Contrasting mercury and manganese deposition in a mangrovedominated estuary (Guaratuba bay, Brazil). Geo-Marine Letters, v.28, n.4, p.239-244.

SARTORETTO, J. R. 2011. Níveis de metais e semimetais em colunas sedimentares recentes coletadas no Canal de Bertioga. Monografia. Instituto Oceanográfico, Universidade de São Paulo, 68 p.

SCHAEFFER-NOVELLI, Y. 1984. Barcaça Gisela. Avaliação de impacto ambiental. Baixada Santista, Brasil. 111 p.

SCHAEFFER-NOVELLI, Y. 1986. Rompimento do óleoduto: avaliação de impacto ambiental. Canal da Bertioga, São Paulo, Brasil. 135 p.

SCHNEIDER, R. R.; SCHULZ, H. D.; HENSEN, C. 2005. Marine carbonates: their formation and desctruction. In: SCHULZ, H. D.; ZOBEL, M. Marine Geochemistry. $2^{\text {nd }}$ edition. Germany: Spring, p. 311-338.

SCHUBERT, C. J.; CALVERT, S. E. 2001. Nitrogen and carbon isotopic composition of marine and terrestrial organic matter in Arctic Ocean sediments: implications for nutrient utilization and organic matter composition. Deep-Sea Res Part I., v.48, p. 789-810. 
SEMA/FEEMA - Fundação Estadual de Engenharia e Meio Ambiente. 1982. Levantamento de metais pesados na Baía de Guanabara Relatório Final, Sema/Feema, 30p.

SILVA, C. A. R. 1988. Distribuição e ciclagem de metais pesados em um ecossistema de manguezal dominado por rhizophora mangle I., Baía de Sepetiba, RJ. Dissertação de Mestrado. Universidade Federal Fluminense, $70 \mathrm{p}$.

SILVA, I. X.; MORAES R. P.; SANTOS, R. P.; MARTINS, S. E.; POMPÉIA, S. L. A. 1994. Degradação dos ecossistemas da Baixa Santista, São Paulo In: Simpósio de Ecossistemas da Costa Brasileira, Anais. Serra Negra. ACIESP, v. 3, p. 30-38.

SILVA, L. F. F. 2000. Ciclagem de mercúrio em um ecossistema de manguezal na floresta de Itacuruçá, Baía de Sepetiba, RJ. Tese de Doutorado. Universidade Federal Fluminense, $259 \mathrm{p}$.

SILVÉRIO, P. F. 2003. Bases técnico - científicas para a derivação de valoresguias de qualidade de sedimentos para metais: experimentos de campo e laboratório. Tese de Doutorado. Escola de Engenharia de São Carlos, Universidade de São Paulo, 132 p.

SIMÕES, E. C. 2007. Diagnóstico ambiental em manguezais dos complexos estuarinos da Baixada Santista e de Cananéia - São Paulo, no tocante a metais e compostos organoclorados. Dissertação de Mestrado. Instituto de Química de São Carlos, Universidade de São Paulo, 183 p.

SINDERMAN, C. J. 1996. Ocean Pollution: effects on living resources and humans. Boca Raton: CRC Press., $275 \mathrm{p}$.

SIQUEIRA, G.W. 2003. Estudos dos teores de metais pesados e outros elementos em sedimentos superficiais do sistema estuarino de Santos 
(Baixada Santista/São Paulo) e plataforma continental do Amazonas (margem continental norte do Brasil). Tese de Doutorado. Instituto Oceanográfico, Universidade de São Paulo, 386 p.

SIQUEIRA, G. W.; BRAGA, E. S.; PEREIRA, S. F. P.; SILVA, E. 2005. Distribuição do mercúrio em sedimentos de fundo no Estuário de Santos - SP/ Brasil. Revista Escola de Minas, Ouro Preto, v. 58 (4), p. 309-316.

SKOOG, D. A.; WEST, D. M.; HOLLER, F. J. 1998. Fundamentals of analytical chemistry. Saunders College Publishing, 7 ed., 577p.

SOARES, M. L. G. 1997. Estudo da biomassa aérea de manguezais do sudeste do Brasil - Análise de Modelos. Tese de Doutorado. Instituto Oceanográfico, Universidade de São Paulo, 294p.

SOARES, H. M. V. M.; BOAVENTURA, R. A. R.; MACHADO, A. A. S. C.; ESTEVES DA SILVA, J. C. G. 1999. Sediments as monitors of heavy metal contamination in the Ave river basin (Portugal): multivariate analysis of data. Environmental Pollution, v.105, p. 311-323.

STEIN, R. 1991. Accumulation of organic carbom in marine sediments. Results from the deep sea drilling project/Ocean Drilling Program. Lectures Notes in Earth Science, v. 34, 217p.

STEPHAN, M. C. 2007. Avaliação dos níveis de metais pesados em amostras de sedimentos da região estuarina de Santos e Cubatão - SP. Dissertação de Mestrado. Universidade Católica de Santos, 67p.

SUGUIO, K.; MARTIN, L. 1978.Formações quaternárias marinhas do litoral paulista e sul-fluminense. In: International Symposium on Coastal Evolution in the Quaternary. Special Publication. São Paulo, Instituto de Geociências da Universidade de São Paulo - Sociedade Brasileira de Geologia, v. 1, p. 1-5. 
SZEFER, P.; KUSAK, A.; SZEFER, K.; GLASBY, G. P.; JANKOWSKA, H.; WOLOWICZ, M. \& ALI, A. A. 1998. Evaluation of the anthropogenic influx of metallic pollutants into Puck Bay, southern Baltic. Appl. Geochem., v. 13, p. 293-304.

TEMPLETON, D. M.; ARIESE, F.; CORNELIS, R.; DANIELSSON, L. G.; MUNTAU, H.; LEEUWEN, H. P. V.; LOBINSKI, R. 2000. Guidelines for Terms Related to Chemical Seciation and Fractionation of Elements. Definitions, Structural Aspects, and Methodological Approaches (IUPAC Recommendations 200). Pure Appl. Chem., v. 72 (8), p. 1453-1470.

TESSLER, M. G. 2001. Taxas de sedimentação Holocênica na plataforma continental sul do estado de São Paulo. Tese de livre-docente - USP, São Paulo, 155p.

THORNTON, S. F.; MCMANUS, J. 1994. Application of organic carbon and nitrogen stable isotopic and $\mathrm{C} / \mathrm{N}$ ratios as source indicators of organic matter provenance in estuarine systems: evidence from the Tay Estuary, Scotland. Est Coast Self Sci., v.38, p. 219-233.

TOMMASI, L. R. 1979. Considerações ecológicas sobre o Sistema Estuarino de Santos, São Paulo. Tese de Livre Docência. Universidade de São Paulo, São Paulo, 2vols. 489p.

USEPA (United States Environmental Protection Agency). 1996. Method 3050B. Acid digestion of sediments, sludges and soil. Revision 2.

USEPA (United States Environmental Protection Agency). 2007. Method 6010C. Inductively coupled plasma-atomic emission spectrometry. Revision 3.

USEPA (United States Environmental Protection Agency). 2001. Methods for Collection, Storage and Manipulation of Sediments for Chemical and Toxicological Analyses: Technical Manual EPA 823-B-01-002. U.S. Environmental Protection Agency, Office of Water, Washington. DC. 
VEECK, L. 1999. Estudo da distribuição do mercúrio em sedimentos da Baía de Sepetiba RJ. Dissertação de Mestrado. Geociências, Universidade Federal Fluminense, 73p.

WADE, T. L.; CANTILLO, Y. A. 1994. Use of standards and reference material in the measurement of chlorinated hydrocarbon residues. Chemestry Workbook. NOAA. Technical Memorandus NOS ORCA 77, Silver Spring, Marylan, $59 \mathrm{p}$.

WASSERMAN, J. C.; FIGUEIREDO, A. M. G., \& FÁVARO, D. T. I. 1996. A preliminary study on a magrove core using neutron activation technique. In: International symposium on environmental geochemistry in tropical countries, Cartagena, p.431-434.

WEBER, R. R. 1992. Sistemas costeiros e oceânicos. Quím Nova, v. 15 (2), p. 137-143.

ZARONI, L. P. 2006. Avaliação da qualidade dos sedimentos marinhos e estuarinos no município de Bertioga - SP. Tese de Doutorado. Instituto Oceanográfico, Universidade de São Paulo, 193 p.

ZHOU, J.; WU, Y.; ZHANG, J.; KANG, Q.; LIU, Z. 2006. Carbon and nitrogen composition and stable isotopes as potencial indicators of source and fate of organic matter in the salt marsh of the Changjiang Estuary, China. Chemosphere, v.65, p. 310-317.

ZHOU, F.; GUO, H.; HAO, Z. 2007. Spatial distribution of heavy metals in Hong Kong's marine sediments and their human impacts: A GIS-based chemometric approach. Marine Pollution Bulletion, v. 54, p. 1372-1384. 
ANEXOS 
Tabela 1. Coordenadas Geográficas dos pontos de coleta no Canal de Bertioga - SP.

\begin{tabular}{|c|c|c|c|c|c|c|c|c|}
\hline ESTAÇÃO & LATITUDE (S) & LONGITUDE (w) & ESTAÇÃO & LATITUDE (S) & LONGITUDE (w) & ESTAÇÃO & LATITUDE (S) & LONGITUDE (w) \\
\hline \# 01 & $23^{\circ} 51.880^{\prime}$ & $46^{\circ} 07.374^{\prime}$ & \# 26 & $23^{\circ} 51.576^{\prime}$ & $46^{\circ} 08.629^{\prime}$ & \# 51 & $23^{\circ} 53.525^{\prime}$ & $46^{\circ} 11.043^{\prime}$ \\
\hline$\# 02$ & $23^{\circ} 51.701^{\prime}$ & $46^{\circ} 07.231^{\prime}$ & $\# 27$ & $23^{\circ} 51.612^{\prime}$ & $46^{\circ} 08.591^{\prime}$ & $\# 52$ & $23^{\circ} 53.948^{\prime}$ & $46^{\circ} 11.477^{\prime}$ \\
\hline$\# 03$ & $23^{\circ} 51.569^{\prime}$ & $46^{\circ} 07.108^{\prime}$ & $\# 28$ & $23^{\circ} 51.694^{\prime}$ & $46^{\circ} 08.915^{\prime}$ & $\# 53$ & $23^{\circ} 53.937^{\prime}$ & $46^{\circ} 11.565^{\prime}$ \\
\hline$\# 04$ & $23^{\circ} 51.467^{\prime}$ & $46^{\circ} 07.035^{\prime}$ & $\# 29$ & $23^{\circ} 51.496^{\prime}$ & $46^{\circ} 09.092^{\prime}$ & $\# 54$ & $23^{\circ} 53.404^{\prime}$ & $46^{\circ} 11.626^{\prime}$ \\
\hline$\# 05$ & $23^{\circ} 51.256^{\prime}$ & $46^{\circ} 06.870^{\prime}$ & $\# \mathbf{3 0}$ & $23^{\circ} 51.503^{\prime}$ & $46^{\circ} 08.949^{\prime}$ & $\# 55$ & $23^{\circ} 53.875^{\prime}$ & $46^{\circ} 11.685^{\prime}$ \\
\hline$\# 06$ & $23^{\circ} 50.992^{\prime}$ & $46^{\circ} 06.800^{\prime}$ & \# 31 & $23^{\circ} 51.815^{\prime}$ & $46^{\circ} 09.159^{\prime}$ & $\# 56$ & $23^{\circ} 54.424^{\prime}$ & $46^{\circ} 11.845^{\prime}$ \\
\hline$\# 07$ & $23^{\circ} 50.723^{\prime}$ & $46^{\circ} 06.871^{\prime}$ & $\# 32$ & $23^{\circ} 51.719^{\prime}$ & $46^{\circ} 09.223^{\prime}$ & $\# 57$ & $23^{\circ} 54.474^{\prime}$ & $46^{\circ} 11.751^{\prime}$ \\
\hline$\# 08$ & $23^{\circ} 51.086^{\prime}$ & $46^{\circ} 07.628^{\prime}$ & \# 33 & $23^{\circ} 51.671^{\prime}$ & $46^{\circ} 09.303^{\prime}$ & \# 58 & $23^{\circ} 54.498^{\prime}$ & $46^{\circ} 11.719^{\prime}$ \\
\hline$\# 09$ & $23^{\circ} 51.162^{\prime}$ & $46^{\circ} 07.565^{\prime}$ & $\# 34$ & $23^{\circ} 51.692^{\prime}$ & $46^{\circ} 09.391^{\prime}$ & \# 59 & $23^{\circ} 54.538^{\prime}$ & $46^{\circ} 11.675^{\prime}$ \\
\hline$\# 10$ & $23^{\circ} 51.250^{\prime}$ & $46^{\circ} 07.492^{\prime}$ & \# 35 & $23^{\circ} 52.142^{\prime}$ & $46^{\circ} 09.505^{\prime}$ & $\# 60$ & $23^{\circ} 54.877^{\prime}$ & $46^{\circ} 12.164^{\prime}$ \\
\hline \# 11 & $23^{\circ} 51.313^{\prime}$ & $46^{\circ} 07.411^{\prime}$ & $\# 36$ & $23^{\circ} 52.175^{\prime}$ & $46^{\circ} 09.438^{\prime}$ & $\# 61$ & $23^{\circ} 54.839^{\prime}$ & $46^{\circ} 12.205^{\prime}$ \\
\hline$\# 12$ & $23^{\circ} 51.437^{\prime}$ & $46^{\circ} 07.437^{\prime}$ & \# 37 & $23^{\circ} 52.199^{\prime}$ & $46^{\circ} 09.413^{\prime}$ & $\# 62$ & $23^{\circ} 54.781^{\prime}$ & $46^{\circ} 12.266^{\prime}$ \\
\hline$\# 13$ & $23^{\circ} 51.388^{\prime}$ & $46^{\circ} 07.796^{\prime}$ & \# 38 & $23^{\circ} 52.578^{\prime}$ & $46^{\circ} 09.646^{\prime}$ & $\# 63$ & $23^{\circ} 54.764^{\prime}$ & $46^{\circ} 12.311^{\prime}$ \\
\hline$\# 14$ & $23^{\circ} 51.312^{\prime}$ & $46^{\circ} 07.879^{\prime}$ & \# 39 & $23^{\circ} 52.530^{\prime}$ & $46^{\circ} 09.746^{\prime}$ & \# 64 & $23^{\circ} 54.734^{\prime}$ & $46^{\circ} 12.771^{\prime}$ \\
\hline$\# 15$ & $23^{\circ} 51.232^{\prime}$ & $46^{\circ} 07.930^{\prime}$ & $\# 40$ & $23^{\circ} 52.494^{\prime}$ & $46^{\circ} 09.806^{\prime}$ & $\# 65$ & $23^{\circ} 54.765^{\prime}$ & $46^{\circ} 12.796^{\prime}$ \\
\hline$\# 16$ & $23^{\circ} 51.335^{\prime}$ & $46^{\circ} 08.191^{\prime}$ & \# 41 & $23^{\circ} 52.875^{\prime}$ & $46^{\circ} 10.177^{\prime}$ & \# 66 & $23^{\circ} 54.858^{\prime}$ & $46^{\circ} 12.861^{\prime}$ \\
\hline$\# 17$ & $23^{\circ} 51.422^{\prime}$ & $46^{\circ} 08.163^{\prime}$ & $\# 42$ & $23^{\circ} 52.902^{\prime}$ & $46^{\circ} 10.143^{\prime}$ & \# 67 & $23^{\circ} 54.948^{\prime}$ & $46^{\circ} 12.929^{\prime}$ \\
\hline$\# 18$ & $23^{\circ} 51.488^{\prime}$ & $46^{\circ} 08.147^{\prime}$ & \# 43 & $23^{\circ} 52.943^{\prime}$ & $46^{\circ} 10.103^{\prime}$ & \# 68 & $23^{\circ} 54.764^{\prime}$ & $46^{\circ} 13.196^{\prime}$ \\
\hline$\# 19$ & $23^{\circ} 51.521^{\prime}$ & $46^{\circ} 08.135^{\prime}$ & $\# 44$ & $23^{\circ} 52.973^{\prime}$ & $46^{\circ} 10.092^{\prime}$ & \# 69 & $23^{\circ} 54.715^{\prime}$ & $46^{\circ} 13.210^{\prime}$ \\
\hline$\# 20$ & $23^{\circ} 51.556^{\prime}$ & $46^{\circ} 08.384^{\prime}$ & $\# 45$ & $23^{\circ} 53.319^{\prime}$ & $46^{\circ} 10.489^{\prime}$ & $\# 70$ & $23^{\circ} 54.657^{\prime}$ & $46^{\circ} 13.205^{\prime}$ \\
\hline \# 21 & $23^{\circ} 51.472^{\prime}$ & $46^{\circ} 08.370^{\prime}$ & \# 46 & $23^{\circ} 53.271^{\prime}$ & $46^{\circ} 10.553^{\prime}$ & \# 71 & $23^{\circ} 54.513^{\prime}$ & $46^{\circ} 13.211^{\prime}$ \\
\hline \# 22 & $23^{\circ} 51.409^{\prime}$ & $46^{\circ} 08.343^{\prime}$ & $\# 47$ & $23^{\circ} 53.235^{\prime}$ & $46^{\circ} 10.582^{\prime}$ & $\# 72$ & $23^{\circ} 54.703^{\prime}$ & $46^{\circ} 13.827^{\prime}$ \\
\hline$\# 23$ & $23^{\circ} 51.323^{\prime}$ & $46^{\circ} 08.366^{\prime}$ & $\# 48$ & $23^{\circ} 53.384^{\prime}$ & $46^{\circ} 11.120^{\prime}$ & $\# 73$ & $23^{\circ} 54.693^{\prime}$ & $46^{\circ} 13.682^{\prime}$ \\
\hline \# 24 & $23^{\circ} 51.384^{\prime}$ & $46^{\circ} 08.605^{\prime}$ & $\# 49$ & $23^{\circ} 53.423^{\prime}$ & $46^{\circ} 11.091^{\prime}$ & $\# 74$ & $23^{\circ} 54.792^{\prime}$ & $46^{\circ} 13.759^{\prime}$ \\
\hline$\# 25$ & $23^{\circ} 51.480^{\prime}$ & $46^{\circ} 08.619^{\prime}$ & \# 50 & $23^{\circ} 53.477^{\prime}$ & $46^{\circ} 11.047^{\prime}$ & $\# 75$ & $23^{\circ} 55.023^{\prime}$ & $46^{\circ} 14.122^{\prime}$ \\
\hline
\end{tabular}


Tabela 1 (Cont.). Coordenadas Geográficas dos pontos de coleta no Canal de Bertioga - SP.

\begin{tabular}{|c|c|c|c|c|c|c|c|c|}
\hline ESTAÇÃO & LATITUDE (S) & LONGITUDE (w) & ESTAÇÃO & LATITUDE (S) & LONGITUDE (w) & ESTAÇÃO & LATITUDE (S) & LONGITUDE (w) \\
\hline \# 76 & $23^{\circ} 55.116^{\prime}$ & $46^{\circ} 14.058^{\prime}$ & \# 94 & $23^{\circ} 55.177^{\prime}$ & $46^{\circ} 16.864^{\prime}$ & \# 112 & $23^{\circ} 55.204^{\prime}$ & $46^{\circ} 18.366^{\prime}$ \\
\hline \# 77 & $23^{\circ} 55.479^{\prime}$ & $46^{\circ} 14.437^{\prime}$ & \# 95 & $23^{\circ} 55.305^{\prime}$ & $46^{\circ} 17.150^{\prime}$ & \# 113 & $23^{\circ} 55.154^{\prime}$ & $46^{\circ} 18.405^{\prime}$ \\
\hline \# 78 & $23^{\circ} 55.409^{\prime}$ & $46^{\circ} 14.543^{\prime}$ & \# 96 & $23^{\circ} 55.277^{\prime}$ & $46^{\circ} 17.155^{\prime}$ & \# 114 & $23^{\circ} 55.298^{\prime}$ & $46^{\circ} 18.544^{\prime}$ \\
\hline \# 79 & $23^{\circ} 55.273^{\prime}$ & $46^{\circ} 14.800^{\prime}$ & \# 97 & $23^{\circ} 55.318^{\prime}$ & $46^{\circ} 17.154^{\prime}$ & $\# 115$ & $23^{\circ} 55.346^{\prime}$ & $46^{\circ} 18.503^{\prime}$ \\
\hline$\# 80$ & $23^{\circ} 55.195^{\prime}$ & $46^{\circ} 14.941^{\prime}$ & \# 98 & $23^{\circ} 55.348^{\prime}$ & $46^{\circ} 17.486^{\prime}$ & \# 116 & $23^{\circ} 55.405^{\prime}$ & $46^{\circ} 18.510^{\prime}$ \\
\hline \# 81 & $23^{\circ} 55.221^{\prime}$ & $46^{\circ} 15.101^{\prime}$ & \# 99 & $23^{\circ} 55.406^{\prime}$ & $46^{\circ} 17.509^{\prime}$ & \# 117 & $23^{\circ} 55.422^{\prime}$ & $46^{\circ} 18.706^{\prime}$ \\
\hline \# 82 & $23^{\circ} 55.245^{\prime}$ & $46^{\circ} 15.256^{\prime}$ & $\# 100$ & $23^{\circ} 55.208^{\prime}$ & $46^{\circ} 17.739^{\prime}$ & \# 118 & $23^{\circ} 55.499^{\prime}$ & $46^{\circ} 18.655^{\prime}$ \\
\hline \# 83 & $23^{\circ} 55.374^{\prime}$ & $46^{\circ} 15.303^{\prime}$ & \# 101 & $23^{\circ} 55.161^{\prime}$ & $46^{\circ} 17.641^{\prime}$ & \# 119 & $23^{\circ} 55.492^{\prime}$ & $46^{\circ} 18.623^{\prime}$ \\
\hline \# 84 & $23^{\circ} 55.342^{\prime}$ & $46^{\circ} 15.452^{\prime}$ & \# 102 & $23^{\circ} 55.138^{\prime}$ & $46^{\circ} 17.586^{\prime}$ & \# 120 & $23^{\circ} 55.542^{\prime}$ & $46^{\circ} 18.590^{\prime}$ \\
\hline \# 85 & $23^{\circ} 55.350^{\prime}$ & $46^{\circ} 15.624^{\prime}$ & \# 103 & $23^{\circ} 55.201^{\prime}$ & $46^{\circ} 17.561^{\prime}$ & \# 121 & $23^{\circ} 55.608^{\prime}$ & $46^{\circ} 18.543^{\prime}$ \\
\hline \# 86 & $23^{\circ} 55.282^{\prime}$ & $46^{\circ} 15.760^{\prime}$ & \# 104 & $23^{\circ} 55.021^{\prime}$ & $46^{\circ} 17.829^{\prime}$ & \# 122 & $23^{\circ} 55.654^{\prime}$ & $46^{\circ} 18.512^{\prime}$ \\
\hline \# 87 & $23^{\circ} 55.155^{\prime}$ & $46^{\circ} 15.868^{\prime}$ & $\# 105$ & $23^{\circ} 54.981^{\prime}$ & $46^{\circ} 17.869^{\prime}$ & \# 123 & $23^{\circ} 55.709^{\prime}$ & $46^{\circ} 18.479^{\prime}$ \\
\hline \# 88 & $23^{\circ} 55.100^{\prime}$ & $46^{\circ} 16.014^{\prime}$ & \# 106 & $23^{\circ} 54.958^{\prime}$ & $46^{\circ} 17.896^{\prime}$ & \# 124 & $23^{\circ} 55.752^{\prime}$ & $46^{\circ} 18.461^{\prime}$ \\
\hline \# 89 & $23^{\circ} 55.102^{\prime}$ & $46^{\circ} 16.191^{\prime}$ & \# 107 & $23^{\circ} 55.066^{\prime}$ & $46^{\circ} 18.059^{\prime}$ & \# 125 & $23^{\circ} 55.811^{\prime}$ & $46^{\circ} 18.434^{\prime}$ \\
\hline \# 90 & $23^{\circ} 55.141^{\prime}$ & $46^{\circ} 16.367^{\prime}$ & \# 108 & $23^{\circ} 55.042^{\prime}$ & $46^{\circ} 18.086^{\prime}$ & \# 126 & $23^{\circ} 55.869^{\prime}$ & $46^{\circ} 18.416^{\prime}$ \\
\hline \# 91 & $23^{\circ} 55.088^{\prime}$ & $46^{\circ} 16.356^{\prime}$ & \# 109 & $23^{\circ} 55.009^{\prime}$ & $46^{\circ} 18.105^{\prime}$ & \# 127 & $23^{\circ} 55.921^{\prime}$ & $46^{\circ} 18.401^{\prime}$ \\
\hline \# 92 & $23^{\circ} 55.236^{\prime}$ & $46^{\circ} 16.737^{\prime}$ & \# 110 & $23^{\circ} 55.316^{\prime}$ & $46^{\circ} 18.269^{\prime}$ & & & \\
\hline \# 93 & $23^{\circ} 55.203^{\prime}$ & $46^{\circ} 16.804^{\prime}$ & \# 111 & $23^{\circ} 55.277^{\prime}$ & $46^{\circ} 18.319^{\prime}$ & & & \\
\hline
\end{tabular}


Tabela 2. Coordenadas Geográficas dos pontos de coleta no Rio Itapanhaú.

\begin{tabular}{|c|c|c|}
\hline ESTAÇÃO & LATITUDE (S) $^{\circ}$ & LONGITUDE (w) \\
\hline \# 1a & $23^{\circ} 51.481^{\prime}$ & $46^{\circ} 09.391^{\prime}$ \\
\hline \# 2a & $23^{\circ} 51.210^{\prime}$ & $46^{\circ} 09.377^{\prime}$ \\
\hline \# 3a & $23^{\circ} 51.044^{\prime}$ & $46^{\circ} 09.292^{\prime}$ \\
\hline \# 4a & $23^{\circ} 50.867^{\prime}$ & $46^{\circ} 09.233^{\prime}$ \\
\hline \# 5a & $23^{\circ} 50.832^{\prime}$ & $46^{\circ} 09.046^{\prime}$ \\
\hline \# 6a & $23^{\circ} 50.781^{\prime}$ & $46^{\circ} 08.861^{\prime}$ \\
\hline \# 7a & $23^{\circ} 50.664^{\prime}$ & $46^{\circ} 08.735^{\prime}$ \\
\hline \# 8a & $23^{\circ} 50.592^{\prime}$ & $46^{\circ} 08.607^{\prime}$ \\
\hline \# 9a & $23^{\circ} 50.436^{\prime}$ & $46^{\circ} 08.674^{\prime}$ \\
\hline \# 10a & $23^{\circ} 50.572^{\prime}$ & $46^{\circ} 08.875^{\prime}$ \\
\hline \# 11a & $23^{\circ} 50.533^{\prime}$ & $46^{\circ} 09.026^{\prime}$ \\
\hline \# 12a & $23^{\circ} 50.419^{\prime}$ & $46^{\circ} 09.112^{\prime}$ \\
\hline \# 13a & $23^{\circ} 50.284^{\prime}$ & $46^{\circ} 09.139^{\prime}$ \\
\hline \# 14a & $23^{\circ} 50.113^{\prime}$ & $46^{\circ} 09.130^{\prime}$ \\
\hline \# 15a & $23^{\circ} 49.921^{\prime}$ & $46^{\circ} 09.089^{\prime}$ \\
\hline \# 16a & $23^{\circ} 49.759^{\prime}$ & $46^{\circ} 09.338^{\prime}$ \\
\hline \# 17a & $23^{\circ} 49.432^{\prime}$ & $46^{\circ} 09.318^{\prime}$ \\
\hline \# 18a & $23^{\circ} 49.156^{\prime}$ & $46^{\circ} 09.273^{\prime}$ \\
\hline \# 19a & $23^{\circ} 49.327^{\prime}$ & $46^{\circ} 08.715^{\prime}$ \\
\hline \# 20a & $23^{\circ} 48.876^{\prime}$ & $46^{\circ} 08.459^{\prime}$ \\
\hline
\end{tabular}


Tabela 7. Dados da análise granulométrica para as amostras de sedimento, em \% finos (silte + argila).

\begin{tabular}{|c|c|c|c|c|c|c|c|c|c|c|c|}
\hline ESTAÇÃO & $\%$ finos & ESTAÇÃO & $\%$ finos & ESTAÇÃO & $\%$ finos & ESTAÇÃO & $\%$ finos & ESTAÇÃO & $\%$ finos & ESTAÇÃO & $\%$ finos \\
\hline \# 01 & 15,17 & \# 26 & 1,70 & \# 51 & 61,34 & \# 76 & 94,81 & \# 101 & 41,58 & $\# 126$ & 95,83 \\
\hline$\# 02$ & 6,88 & \# 27 & 7,19 & \# 52 & 87,21 & \# 77 & 95,00 & $\# 102$ & 64,74 & $\# 127$ & 94,90 \\
\hline \#03 & 5,54 & \# 28 & 2,99 & \# 53 & 93,88 & \# 78 & 94,80 & $\# 103$ & 66,07 & & \\
\hline \# 04 & 7,07 & \# 29 & 8,70 & \# 54 & 87,64 & \# 79 & 95,95 & \# 104 & 25,55 & $\# 1 a$ & 2,48 \\
\hline$\# 05$ & 2,45 & $\# 30$ & 2,29 & \# 55 & 55,02 & $\# 80$ & 97,50 & $\# 105$ & 68,68 & $\# 2 a$ & 29,81 \\
\hline \# 07 & 2,17 & \# 32 & 4,80 & \# 57 & 20,43 & \# 82 & 89,68 & \# 107 & 21,31 & $\# 4 a$ & 25,12 \\
\hline \# 08 & 2,08 & \# 33 & 2,30 & \# 58 & 10,65 & \# 83 & 94,61 & $\# 108$ & 26,77 & $\# 5 a$ & 71,65 \\
\hline \# 09 & 1,88 & \# 34 & 12,29 & \# 59 & 78,07 & \# 84 & 95,80 & \# 109 & 45,72 & $\# 6 a$ & 58,22 \\
\hline$\# 10$ & 1,39 & \# 35 & 41,10 & \# 60 & 57,29 & $\# 85$ & 85,81 & $\# 110$ & 68,11 & $\# 7 a$ & 33,89 \\
\hline$\# 11$ & 1,48 & \#36 & 7,15 & \# 61 & 91,93 & \# 86 & 99,11 & $\# 111$ & 54,38 & $\# 8 \mathrm{a}$ & 5,11 \\
\hline$\# 12$ & 28,33 & \# 37 & 34,30 & \# 62 & 70,33 & \# 87 & 95,00 & $\# 112$ & 24,21 & $\# 9 a$ & 18,48 \\
\hline$\# 14$ & 1,90 & \# 39 & 6,30 & \# 64 & 92,53 & \# 89 & 93,40 & \# 114 & 60,44 & \#11a & 47,87 \\
\hline$\# 15$ & 1,80 & $\# 40$ & 52,34 & \# 65 & 98,13 & \# 90 & 94,61 & $\# 115$ & 20,94 & $\# 12 \mathrm{a}$ & 33,67 \\
\hline$\# 16$ & 13,72 & \# 41 & 17,20 & $\# 66$ & 90,56 & \# 91 & 94,90 & $\# 116$ & 75,84 & \#13a & 60,12 \\
\hline$\# 17$ & 1,50 & $\# 42$ & 7,70 & \# 67 & 28,50 & \# 92 & 93,26 & \# 117 & 65,01 & \#14a & 7,62 \\
\hline$\# 18$ & 1,40 & \# 43 & 6,55 & \# 68 & 95,52 & \# 93 & 70,87 & \# 118 & 29,48 & $\# 15 a$ & 10,48 \\
\hline \# 19 & 14,80 & \# 44 & 33,46 & \# 69 & 76,66 & \# 94 & 88,92 & \# 119 & 27,81 & \#16a & 34,00 \\
\hline$\# 20$ & 2,99 & $\# 45$ & 52,29 & \# 70 & 49,55 & \# 95 & 43,15 & $\# 120$ & 29,08 & \#17a & 36,45 \\
\hline$\# 21$ & 2,40 & $\# 46$ & 2,71 & \# 71 & 97,30 & \# 96 & 75,50 & $\# 121$ & 40,63 & $\# 18 a$ & 27,26 \\
\hline$\# 22$ & 1,79 & \# 47 & 35,56 & \# 72 & 34,37 & \# 97 & 87,33 & $\# 122$ & 66,04 & \#19a & 20,48 \\
\hline$\# 23$ & 9,80 & \# 48 & 12,62 & $\# 73$ & 97,30 & \# 98 & 98,60 & $\# 123$ & 33,90 & $\# 20 a$ & 10,40 \\
\hline$\# 24$ & 6,47 & $\# 49$ & 28,19 & \# 74 & 96,11 & \# 99 & 33,69 & $\# 124$ & 48,62 & & \\
\hline$\# 25$ & 2,39 & \# 50 & 10,23 & \# 75 & 92,70 & \# 100 & 94,66 & \# 125 & 89,78 & & \\
\hline
\end{tabular}


Tabela 9. Resultados dos níveis de metais e As, em mg kg-1 em sedimentos superficiais do Canal da Bertioga.

\begin{tabular}{|c|c|c|c|c|c|c|c|c|c|c|}
\hline Estação & Al & As & $\mathrm{Cr}$ & $\mathrm{Fe}$ & $\mathrm{Mn}$ & $\mathrm{Ni}$ & $\mathrm{Pb}$ & Sc & $\mathbf{V}$ & $\mathrm{Zn}$ \\
\hline \# 01 & 4724,31 & 7,49 & 9,21 & 11063,70 & 160,83 & 2,72 & 4,54 & 1,28 & 11,40 & 16,77 \\
\hline \# 02 & 3991,02 & 6,30 & 8,89 & 11486,80 & 184,87 & 2,71 & 4,17 & 1,15 & 10,62 & 17,23 \\
\hline \# 03 & 4562,30 & 5,93 & 9,26 & 11920,20 & 173,89 & 2,79 & 4,43 & 1,21 & 11,66 & 17,52 \\
\hline \# 04 & 5388,62 & 6,60 & 9,87 & 12582,00 & 245,95 & 3,19 & 4,79 & 1,35 & 13,12 & 19,02 \\
\hline \# 05 & 3974,71 & 7,99 & 8,19 & 10570,60 & 189,85 & 2,48 & 4,33 & 1,10 & 12,64 & 15,04 \\
\hline \# 06 & 4470,96 & 8,60 & 8,87 & 11194,50 & 239,27 & 2,95 & 4,86 & 1,26 & 14,11 & 16,98 \\
\hline \# 07 & 3848,28 & 9,70 & 7,23 & 10635,30 & 177,17 & 2,31 & 3,55 & 0,98 & 12,63 & 13,97 \\
\hline \# 08 & 3426,49 & 10,26 & 7,00 & 9589,70 & 178,82 & 2,21 & 3,41 & 0,93 & 12,77 & 12,98 \\
\hline \# 09 & 3963,33 & 10,82 & 7,47 & 10823,70 & 214,99 & 2,47 & 3,66 & 1,07 & 13,62 & 15,42 \\
\hline \# 10 & 2870,71 & 9,99 & 5,84 & 8786,71 & 143,45 & 1,89 & 3,02 & 0,83 & 11,68 & 11,59 \\
\hline \# 11 & 3233,22 & 9,52 & 5,74 & 9059,03 & 185,52 & 1,87 & 3,16 & 0,85 & 11,22 & 11,97 \\
\hline \# 12 & 4299,59 & 5,50 & 8,70 & 11523,50 & 222,34 & 2,56 & 4,19 & 1,15 & 10,64 & 16,93 \\
\hline \# 13 & 3892,98 & 12,40 & 7,08 & 10186,40 & 187,60 & 2,52 & 4,05 & 0,95 & 12,21 & 14,17 \\
\hline \# 14 & 3435,14 & 12,02 & 7,52 & 10241,30 & 175,57 & 2,48 & 3,99 & 0,90 & 12,31 & 13,76 \\
\hline \# 15 & 3995,41 & 11,51 & 8,17 & 11226,80 & 281,05 & 2,81 & 4,18 & 1,04 & 13,96 & 16,73 \\
\hline \# 16 & 9348,79 & 14,35 & 16,36 & 20047,20 & 332,18 & 6,28 & 8,72 & 2,21 & 22,42 & 38,73 \\
\hline \# 17 & 3579,28 & 10,82 & 7,77 & 9652,59 & 162,54 & 2,58 & 3,52 & 0,88 & 11,74 & 13,49 \\
\hline \# 18 & 3476,09 & 9,71 & 6,53 & 8390,61 & 173,33 & 2,21 & 3,26 & 0,88 & 10,80 & 12,83 \\
\hline \# 19 & 6896,35 & 8,40 & 9,38 & 11375,30 & 163,85 & 3,56 & 5,10 & 1,45 & 13,77 & 20,26 \\
\hline \# 20 & 5020,30 & 6,80 & 5,63 & 9103,93 & 306,76 & 2,18 & 3,22 & 1,10 & 10,10 & 18,23 \\
\hline \# 21 & 2972,81 & 7,62 & 5,22 & 6943,41 & 109,35 & 1,97 & 2,51 & 0,71 & 8,39 & 9,97 \\
\hline \# 22 & 3857,38 & 6,05 & 4,68 & 6485,74 & 172,84 & 1,78 & 2,63 & 0,84 & 8,02 & 12,31 \\
\hline \# 23 & 4920,00 & 7,16 & 9,90 & 9292,64 & 178,89 & 3,90 & 5,71 & 1,38 & 13,25 & 24,21 \\
\hline \# 24 & 4911,30 & 4,26 & 6,44 & 6442,97 & 75,40 & 2,49 & 3,17 & 0,99 & 8,34 & 13,01 \\
\hline \# 25 & 2797,43 & 7,37 & 5,67 & 7168,52 & 108,36 & 1,94 & 3,02 & 0,72 & 8,98 & 10,47 \\
\hline
\end{tabular}


Tabela 9 (Cont.). Resultados dos níveis de metais e As, em mg kg-1, em sedimentos superficiais do Canal da Bertioga.

\begin{tabular}{|c|c|c|c|c|c|c|c|c|c|c|}
\hline Estação & Al & As & $\mathrm{Cr}$ & $\mathrm{Fe}$ & $\mathrm{Mn}$ & $\mathbf{N i}$ & $\mathrm{Pb}$ & Sc & $\mathbf{V}$ & $\mathrm{Zn}$ \\
\hline \# 26 & 3223,67 & 5,06 & 3,77 & 5720,57 & 158,57 & 1,41 & 2,51 & 0,72 & 6,14 & 11,29 \\
\hline \# 27 & 6255,85 & 6,38 & 9,41 & 12385,00 & 219,00 & 3,55 & 5,06 & 1,48 & 13,06 & 23,53 \\
\hline \# 28 & 2988,61 & 5,44 & 6,15 & 6765,36 & 85,82 & 2,20 & 3,02 & 0,78 & 8,07 & 13,13 \\
\hline \# 29 & 5791,63 & 2,94 & 6,49 & 6999,96 & 68,53 & 2,54 & 3,66 & 1,23 & 9,98 & 17,92 \\
\hline \# 30 & 3039,19 & 6,10 & 5,61 & 6963,38 & 87,94 & 1,90 & 2,85 & 0,74 & 8,17 & 10,69 \\
\hline \# 31 & 12346,80 & 10,86 & 21,00 & 17809,40 & 283,16 & 8,16 & 10,16 & 3,31 & 24,57 & 37,67 \\
\hline \# 32 & 3550,10 & 5,25 & 6,14 & 6935,30 & 78,54 & 2,16 & 2,79 & 0,84 & 8,30 & 12,11 \\
\hline \# 33 & 2305,14 & 3,56 & 4,15 & 3593,08 & 37,90 & 1,46 & 1,91 & 0,53 & 5,03 & 7,45 \\
\hline \# 34 & 5249,83 & 3,77 & 9,41 & 6375,74 & 76,28 & 3,02 & 4,01 & 1,28 & 13,50 & 16,46 \\
\hline \# 35 & 10867,20 & 5,81 & 15,51 & 13224,50 & 179,81 & 6,12 & 6,66 & 2,62 & 18,91 & 28,43 \\
\hline \# 36 & 5808,32 & 3,06 & 5,39 & 6015,42 & 68,33 & 2,15 & 2,93 & 1,08 & 8,06 & 18,00 \\
\hline \# 37 & 13545,00 & 6,57 & 15,72 & 16362,60 & 190,13 & 5,94 & 8,77 & 2,59 & 20,03 & 36,42 \\
\hline \# 38 & 9397,23 & 4,73 & 10,86 & 8108,76 & 124,94 & 4,40 & 5,15 & 2,10 & 14,79 & 28,49 \\
\hline \# 39 & 5341,73 & 3,83 & 5,39 & 5819,05 & 70,58 & 2,17 & 3,03 & 1,05 & 7,71 & 15,75 \\
\hline \# 40 & 15557,40 & 6,93 & 18,58 & 17179,30 & 210,65 & 7,31 & 7,08 & 3,19 & 22,66 & 39,26 \\
\hline \# 41 & 8324,16 & 4,72 & 10,10 & 9988,96 & 90,73 & 3,79 & 4,39 & 1,61 & 11,22 & 21,91 \\
\hline \# 42 & 5229,06 & 3,00 & 6,74 & 5149,36 & 83,65 & 2,59 & 3,64 & 1,41 & 9,75 & 22,06 \\
\hline \# 43 & 9304,36 & 3,73 & 7,34 & 8980,07 & 91,21 & 3,01 & 4,18 & 1,53 & 11,04 & 23,17 \\
\hline \# 44 & 16519,30 & 8,56 & 16,45 & 19255,60 & 326,36 & 6,31 & 8,95 & 2,99 & 23,13 & 43,72 \\
\hline \# 45 & 20644,70 & 6,77 & 20,08 & 18152,60 & 230,47 & 7,48 & 9,43 & 3,67 & 24,98 & 37,34 \\
\hline \# 46 & 5646,26 & 3,64 & 3,93 & 5685,20 & 62,81 & 1,67 & 2,30 & 0,93 & 6,02 & 16,38 \\
\hline \# 47 & 17920,10 & 6,56 & 14,66 & 17883,90 & 219,44 & 5,85 & 7,00 & 3,23 & 21,97 & 39,68 \\
\hline \# 48 & 7881,23 & 3,08 & 7,66 & 7371,86 & 71,88 & 3,32 & 4,18 & 1,52 & 9,65 & 18,74 \\
\hline \# 49 & 11641,10 & 4,54 & 12,03 & 12604,00 & 159,92 & 4,70 & 6,23 & 2,47 & 16,57 & 30,17 \\
\hline \# 50 & 6196,36 & 2,94 & 6,04 & 8179,95 & 89,06 & 2,37 & 3,93 & 1,31 & 8,82 & 22,11 \\
\hline
\end{tabular}


Tabela 9 (Cont.). Resultados dos níveis de metais e As, em mg kg-1, em sedimentos superficiais do Canal da Bertioga.

\begin{tabular}{|c|c|c|c|c|c|c|c|c|c|c|}
\hline Estação & Al & As & $\mathrm{Cr}$ & $\mathrm{Fe}$ & $\mathrm{Mn}$ & $\mathbf{N i}$ & $\mathrm{Pb}$ & Sc & V & $\mathrm{Zn}$ \\
\hline \# 51 & 25451,40 & 8,49 & 22,14 & 23014,20 & 286,37 & 8,73 & 10,67 & 4,36 & 29,37 & 46,68 \\
\hline \# 52 & 24240,60 & 11,50 & 25,34 & 26935,50 & 496,71 & 9,88 & 16,13 & 4,77 & 34,02 & 64,88 \\
\hline \# 53 & 30089,20 & 13,38 & 28,70 & 30195,90 & 534,86 & 11,05 & 17,12 & 5,38 & 34,29 & 69,14 \\
\hline \# 54 & 26402,80 & 10,92 & 25,51 & 26213,80 & 408,63 & 10,08 & 14,36 & 4,79 & 31,76 & 61,01 \\
\hline \# 55 & 19290,10 & 11,22 & 21,36 & 20718,30 & 312,39 & 8,87 & 12,32 & 3,98 & 27,63 & 52,45 \\
\hline \# 56 & 31220,90 & 12,41 & 29,10 & 31424,10 & 418,59 & 12,30 & 16,97 & 5,54 & 37,83 & 69,07 \\
\hline \# 57 & 9453,73 & 5,64 & 9,05 & 11736,20 & 123,62 & 3,66 & 5,41 & 1,83 & 12,18 & 31,04 \\
\hline \# 58 & 5866,92 & 3,35 & 4,94 & 5485,40 & 50,00 & 2,17 & 3,31 & 1,04 & 7,07 & 16,17 \\
\hline \# 59 & 30390,20 & 12,06 & 26,07 & 27187,80 & 308,71 & 10,75 & 14,78 & 5,14 & 35,74 & 65,14 \\
\hline \# 60 & 29658,40 & 8,82 & 21,41 & 28044,80 & 344,53 & 9,12 & 15,94 & 4,75 & 31,34 & 66,32 \\
\hline \# 61 & 34689,40 & 11,41 & 30,29 & 33052,00 & 477,89 & 12,81 & 18,10 & 5,71 & 35,52 & 74,21 \\
\hline \# 62 & 20075,60 & 10,83 & 22,43 & 23694,60 & 385,50 & 8,74 & 13,60 & 4,08 & 27,72 & 56,56 \\
\hline \# 63 & 16687,00 & 14,74 & 19,06 & 21686,40 & 286,37 & 7,94 & 11,47 & 3,41 & 25,02 & 46,36 \\
\hline \# 64 & 33661,50 & 11,74 & 33,13 & 31423,20 & 324,88 & 12,09 & 12,93 & 5,87 & 35,50 & 52,97 \\
\hline \# 65 & 30568,50 & 10,49 & 28,50 & 29352,50 & 385,26 & 11,09 & 15,80 & 5,49 & 35,00 & 67,34 \\
\hline \# 66 & 32670,20 & 11,06 & 29,11 & 28777,70 & 333,91 & 11,48 & 16,12 & 5,61 & 36,85 & 68,89 \\
\hline \# 67 & 11488,30 & 7,38 & 11,35 & 13995,10 & 155,45 & 4,68 & 6,19 & 2,21 & 15,16 & 31,90 \\
\hline \# 68 & 24428,70 & 9,07 & 26,19 & 27265,00 & 252,16 & 10,28 & 16,93 & 4,88 & 27,97 & 66,32 \\
\hline \# 69 & 17909,90 & 7,86 & 15,92 & 20021,20 & 175,28 & 6,08 & 8,43 & 3,15 & 20,34 & 35,11 \\
\hline \# 70 & 8999,73 & 7,19 & 9,27 & 12056,60 & 109,68 & 3,90 & 5,77 & 1,70 & 11,97 & 26,17 \\
\hline \# 71 & 25185,10 & 9,60 & 26,51 & 27451,80 & 354,06 & 10,36 & 15,70 & 4,89 & 31,34 & 64,18 \\
\hline \# 72 & 15790,30 & 7,44 & 12,23 & 19613,90 & 201,84 & 5,23 & 7,49 & 3,00 & 20,71 & 44,04 \\
\hline \# 73 & 22351,60 & 8,34 & 23,08 & 26326,60 & 227,00 & 8,88 & 14,46 & 4,20 & 25,78 & 57,53 \\
\hline \# 74 & 23954,60 & 9,35 & 27,48 & 27163,80 & 387,51 & 12,07 & 17,32 & 5,01 & 28,77 & 65,08 \\
\hline \# 75 & 22923,90 & 8,36 & 22,11 & 25210,10 & 194,88 & 10,34 & 14,09 & 4,27 & 25,91 & 64,38 \\
\hline
\end{tabular}


Tabela 9 (Cont.). Resultados dos níveis de metais e As, em mg kg-1, em sedimentos superficiais do Canal da Bertioga.

\begin{tabular}{|c|c|c|c|c|c|c|c|c|c|c|}
\hline Estação & Al & As & $\mathrm{Cr}$ & $\mathrm{Fe}$ & $\mathrm{Mn}$ & $\mathbf{N i}$ & $\mathrm{Pb}$ & Sc & $\mathbf{V}$ & $\mathrm{Zn}$ \\
\hline \# 76 & 18445,40 & 9,46 & 23,10 & 25751,80 & 212,75 & 9,29 & 14,31 & 3,92 & 24,64 & 59,37 \\
\hline \# 77 & 15293,10 & 9,60 & 22,42 & 22575,00 & 235,31 & 9,45 & 14,62 & 3,68 & 24,59 & 60,39 \\
\hline \# 78 & 22120,60 & 9,91 & 26,02 & 26723,20 & 278,27 & 12,66 & 17,14 & 4,36 & 26,93 & 70,29 \\
\hline \# 79 & 13676,10 & 10,52 & 25,32 & 17964,90 & 225,23 & 9,68 & 15,51 & 4,19 & 28,19 & 58,18 \\
\hline \# 80 & 19831,10 & 10,58 & 26,96 & 26687,90 & 365,88 & 11,81 & 18,81 & 4,38 & 26,22 & 63,48 \\
\hline \# 81 & 18436,70 & 12,28 & 23,29 & 27352,30 & 184,53 & 9,26 & 11,57 & 4,03 & 32,86 & 44,60 \\
\hline \# 82 & 21239,00 & 10,48 & 25,52 & 24695,20 & 217,79 & 9,32 & 11,55 & 4,65 & 33,22 & 47,70 \\
\hline \# 83 & 16448,80 & 10,45 & 22,46 & 24058,30 & 199,46 & 8,39 & 11,76 & 3,91 & 28,24 & 42,55 \\
\hline \# 84 & 19535,50 & 10,60 & 24,38 & 24387,40 & 250,22 & 9,21 & 14,44 & 4,31 & 28,51 & 56,21 \\
\hline \# 85 & 18961,90 & 11,10 & 21,13 & 23779,00 & 348,45 & 8,63 & 12,33 & 4,13 & 24,08 & 49,21 \\
\hline \# 86 & 22022,20 & 9,50 & 24,87 & 24201,90 & 440,11 & 9,58 & 13,19 & 4,90 & 25,37 & 44,31 \\
\hline \# 87 & 20677,20 & 12,07 & 24,98 & 25711,10 & 262,27 & 9,03 & 12,22 & 4,63 & 32,26 & 45,69 \\
\hline \# 88 & 20183,20 & 10,30 & 25,30 & 25777,70 & 328,29 & 10,49 & 17,16 & 4,47 & 28,87 & 70,52 \\
\hline \# 89 & 25378,20 & 11,93 & 27,03 & 25906,50 & 548,09 & 10,35 & 12,70 & 5,01 & 31,37 & 48,96 \\
\hline \# 90 & 21838,40 & 9,68 & 26,79 & 26786,70 & 378,10 & 10,21 & 17,73 & 4,76 & 30,04 & 69,02 \\
\hline \# 91 & 22920,70 & 10,31 & 25,76 & 27297,70 & 265,65 & 9,69 & 15,35 & 4,70 & 29,15 & 60,99 \\
\hline \# 92 & 27386,60 & 10,31 & 29,57 & 29770,40 & 341,55 & 10,99 & 18,80 & 5,34 & 34,27 & 75,86 \\
\hline \# 93 & 24459,80 & 8,69 & 22,19 & 24079,50 & 178,35 & 8,06 & 10,80 & 4,53 & 29,12 & 45,12 \\
\hline \# 94 & 25634,40 & 8,11 & 25,73 & 27430,10 & 263,77 & 10,32 & 18,84 & 4,75 & 29,46 & 79,45 \\
\hline \# 95 & 4850,99 & 4,51 & 14,10 & 13244,60 & 105,04 & 2,52 & 6,90 & 1,04 & 7,47 & 25,10 \\
\hline \# 96 & 19949,80 & 7,18 & 20,25 & 23687,00 & 254,85 & 8,26 & 16,20 & 3,68 & 22,90 & 67,82 \\
\hline \# 97 & 28996,00 & 10,02 & 26,52 & 30199,80 & 274,27 & 10,81 & 25,85 & 4,89 & 30,52 & 94,39 \\
\hline \# 98 & 23732,40 & 13,31 & 31,00 & 28780,30 & 630,04 & 11,26 & 14,67 & 5,32 & 33,35 & 49,50 \\
\hline \# 99 & 10597,90 & 6,29 & 11,31 & 13206,20 & 138,96 & 4,68 & 4,95 & 2,35 & 16,91 & 25,59 \\
\hline \# 100 & 20200,00 & 9,48 & 26,45 & 27788,70 & 408,39 & 10,28 & 20,40 & 4,49 & 28,73 & 84,36 \\
\hline
\end{tabular}


Tabela 9 (Cont.). Resultados dos níveis de metais e As, em mg kg-1, em sedimentos superficiais do Canal da Bertioga.

\begin{tabular}{|c|c|c|c|c|c|c|c|c|c|c|}
\hline Estação & Al & As & $\mathrm{Cr}$ & $\mathrm{Fe}$ & $\mathrm{Mn}$ & $\mathbf{N i}$ & $\mathrm{Pb}$ & Sc & V & $\mathrm{Zn}$ \\
\hline \# 101 & 8986,29 & 6,03 & 13,29 & 13710,70 & 144,38 & 5,51 & 10,90 & 2,28 & 15,69 & 47,72 \\
\hline \# 102 & 20363,60 & 9,21 & 21,13 & 22351,90 & 194,60 & 8,34 & 14,11 & 3,74 & 26,51 & 62,69 \\
\hline \# 103 & 17851,80 & 9,30 & 19,89 & 23214,10 & 197,22 & 7,95 & 15,20 & 3,25 & 24,73 & 72,64 \\
\hline \# 104 & 9231,43 & 4,41 & 10,15 & 8932,31 & 97,94 & 4,28 & 6,67 & 2,04 & 15,10 & 33,72 \\
\hline \# 105 & 16913,00 & 8,80 & 19,28 & 20689,30 & 330,13 & 8,09 & 14,79 & 3,49 & 27,14 & 69,27 \\
\hline \# 106 & 31180,70 & 8,50 & 30,14 & 26595,90 & 240,21 & 12,20 & 20,15 & 5,69 & 37,50 & 93,88 \\
\hline \# 107 & 6396,68 & 4,19 & 7,44 & 6688,61 & 82,79 & 3,04 & 5,02 & 1,48 & 10,69 & 23,81 \\
\hline \# 108 & 7664,39 & 5,16 & 8,82 & 8696,81 & 207,70 & 3,73 & 6,51 & 1,80 & 13,48 & 32,47 \\
\hline \# 109 & 13930,40 & 8,41 & 17,49 & 16148,90 & 129,80 & 6,47 & 7,20 & 3,10 & 21,05 & 31,71 \\
\hline \# 110 & 19957,40 & 9,35 & 24,69 & 22921,60 & 284,15 & 9,68 & 18,05 & 4,39 & 30,66 & 72,57 \\
\hline \# 111 & 15674,20 & 8,09 & 19,55 & 16877,40 & 143,24 & 7,68 & 10,10 & 3,62 & 24,68 & 44,31 \\
\hline \# 112 & 7944,16 & 4,16 & 10,15 & 8045,43 & 91,17 & 4,11 & 7,21 & 1,81 & 13,03 & 31,83 \\
\hline \# 113 & 15543,70 & 8,72 & 20,17 & 19776,60 & 252,46 & 7,81 & 13,40 & 3,49 & 24,54 & 86,29 \\
\hline \# 114 & 10802,30 & 5,51 & 12,93 & 11765,00 & 125,83 & 4,99 & 8,31 & 2,24 & 16,19 & 37,53 \\
\hline \# 115 & 5674,92 & 4,04 & 8,06 & 6693,31 & 70,31 & 3,28 & 5,44 & 1,40 & 10,43 & 26,41 \\
\hline \# 116 & 13567,20 & 7,76 & 23,13 & 14545,40 & 320,17 & 8,95 & 10,81 & 4,82 & 30,99 & 44,99 \\
\hline \# 117 & 16713,90 & 8,39 & 22,62 & 21290,20 & 311,50 & 8,65 & 16,18 & 3,93 & 27,56 & 71,19 \\
\hline \# 118 & 7802,31 & 4,90 & 12,58 & 10785,80 & 120,38 & 4,65 & 10,52 & 1,79 & 12,85 & 34,80 \\
\hline \# 119 & 6590,16 & 4,18 & 10,61 & 8727,50 & 92,47 & 4,04 & 6,73 & 1,67 & 12,16 & 30,27 \\
\hline \# 120 & 7909,78 & 4,83 & 10,43 & 11258,30 & 140,01 & 4,17 & 8,81 & 1,76 & 13,77 & 36,59 \\
\hline \# 121 & 18694,60 & 6,63 & 14,20 & 18776,70 & 208,19 & 5,58 & 8,55 & 2,60 & 17,88 & 35,17 \\
\hline \# 122 & 22400,00 & 8,23 & 24,04 & 21740,10 & 236,92 & 9,38 & 29,37 & 4,44 & 30,20 & 65,40 \\
\hline \# 123 & 12240,40 & 9,01 & 16,34 & 15240,30 & 146,74 & 6,34 & 14,84 & 2,66 & 18,66 & 56,45 \\
\hline \# 124 & 17182,50 & 7,71 & 20,72 & 17641,00 & 212,83 & 7,53 & 43,43 & 3,46 & 23,50 & 72,08 \\
\hline \# 125 & 25615,30 & 10,52 & 30,97 & 27123,80 & 403,15 & 11,75 & 22,55 & 5,54 & 37,15 & 89,79 \\
\hline
\end{tabular}


Tabela 9 (Cont.). Resultados dos níveis de metais e As, em mg kg-1 em sedimentos superficiais do Canal da Bertioga.

\begin{tabular}{|c|c|c|c|c|c|c|c|c|c|c|}
\hline Estação & Al & As & $\mathbf{C r}$ & $\mathbf{F e}$ & $\mathbf{M n}$ & $\mathbf{N i}$ & $\mathbf{P b}$ & $\mathbf{S c}$ & $\mathbf{V}$ & $\mathbf{Z n}$ \\
\hline \# 126 & 25850,10 & 10,63 & 31,11 & 29154,10 & 454,63 & 11,66 & 21,59 & 5,57 & 36,71 & 90,22 \\
\hline \# 127 & 25236,70 & 10,27 & 31,26 & 28934,30 & 408,99 & 11,76 & 23,77 & 5,48 & 36,26 & 92,47 \\
\hline & & & & & & & & & & \\
\hline Máximo & 34689,40 & 14,74 & 33,13 & 33052,00 & 630,04 & 12,81 & 43,43 & 5,87 & 37,83 & 94,39 \\
\hline Mínimo & 2305,14 & 2,94 & 3,77 & 3593,08 & 37,90 & 1,41 & 1,91 & 0,53 & 5,03 & 7,45 \\
\hline Mediana & 13567,20 & 8,40 & 15,92 & 16877,40 & 207,70 & 6,12 & 8,77 & 2,99 & 20,71 & 37,67 \\
\hline Média & 14225,30 & 8,12 & 16,45 & 17193,05 & 225,43 & 6,38 & 10,19 & 2,92 & 20,58 & 41,60 \\
\hline DP & 9006,82 & 2,81 & 8,58 & 8270,07 & 118,12 & 3,51 & 6,75 & 1,65 & 9,49 & 23,55 \\
\hline
\end{tabular}


Tabela 10. Resultados dos níveis de metais e As, em mg kg${ }^{-1}$, em sedimentos superficiais do Rio Itapanhaú.

\begin{tabular}{|c|c|c|c|c|c|c|c|c|c|c|}
\hline Estação & Al & As & $\mathrm{Cr}$ & $\mathrm{Fe}$ & $M n$ & $\mathrm{Ni}$ & $\mathrm{Pb}$ & Sc & V & $\mathrm{Zn}$ \\
\hline \# 1a & 3355,39 & 1,50 & 3,14 & 3348,12 & 42,13 & 1,16 & 1,54 & 0,63 & 4,72 & 8,10 \\
\hline$\# 2 a$ & 10851,40 & 4,06 & 11,58 & 12855,20 & 100,36 & 4,29 & 6,25 & 1,88 & 14,16 & 24,03 \\
\hline \# 3a & 13188,00 & 4,05 & 14,50 & 15233,40 & 127,56 & 5,60 & 6,18 & 2,41 & 17,15 & 27,15 \\
\hline \# 4a & 9383,76 & 3,16 & 10,22 & 10728,60 & 101,58 & 3,90 & 5,47 & 1,66 & 12,84 & 20,95 \\
\hline \# 5a & 38336,30 & 8,58 & 25,31 & 33747,80 & 319,53 & 9,09 & 18,03 & 5,19 & 36,74 & 59,95 \\
\hline \# 6a & 30492,80 & 6,86 & 22,95 & 31384,50 & 269,68 & 9,13 & 10,06 & 3,83 & 27,21 & 39,86 \\
\hline$\# 7 a$ & 23324,80 & 4,83 & 15,59 & 25866,10 & 213,10 & 5,79 & 7,71 & 2,78 & 22,49 & 40,98 \\
\hline \# 8a & 4787,67 & 1,47 & 3,54 & 4640,63 & 38,88 & 1,31 & 1,59 & 0,69 & 5,54 & 10,68 \\
\hline$\# 9 a$ & 11128,40 & 1,88 & 9,78 & 12139,50 & 92,23 & 3,89 & 4,20 & 1,71 & 12,96 & 20,81 \\
\hline$\# 10 a$ & 15699,30 & 4,37 & 12,42 & 16226,30 & 171,29 & 4,59 & 6,11 & 2,21 & 17,77 & 28,36 \\
\hline$\# 11 a$ & 20755,30 & 4,40 & 16,05 & 21907,60 & 138,23 & 6,01 & 6,37 & 2,68 & 18,70 & 29,94 \\
\hline$\# 12 a$ & 17973,00 & 2,65 & 11,78 & 17077,70 & 83,60 & 4,27 & 4,78 & 2,07 & 14,51 & 22,52 \\
\hline \# 13a & 27942,90 & 5,10 & 17,73 & 28182,70 & 156,63 & 6,56 & 12,03 & 3,59 & 24,44 & 45,76 \\
\hline$\# 14 a$ & 8831,53 & 1,18 & 5,11 & 8952,21 & 61,87 & 1,79 & 2,14 & 1,08 & 8,69 & 14,89 \\
\hline \# 15a & 14965,40 & 0,46 & 5,31 & 12864,40 & 95,09 & 2,13 & 2,65 & 1,98 & 14,73 & 21,74 \\
\hline$\# 16 a$ & 25780,40 & 2,57 & 11,66 & 23132,80 & 168,88 & 4,59 & 6,84 & 3,17 & 26,28 & 43,43 \\
\hline$\# 17 a$ & 19147,00 & 4,10 & 13,60 & 19131,30 & 149,71 & 4,86 & 7,68 & 2,60 & 19,54 & 34,04 \\
\hline \# 18a & 16299,40 & 3,02 & 11,05 & 14615,70 & 83,31 & 3,76 & 5,78 & 2,10 & 15,33 & 26,16 \\
\hline$\# 19 a$ & 11973,80 & 2,50 & 9,32 & 12580,30 & 76,43 & 3,28 & 5,04 & 1,67 & 12,16 & 20,95 \\
\hline$\# 20 a$ & 10893,70 & 1,30 & 6,46 & 10896,60 & 72,51 & 2,29 & 3,37 & 1,56 & 11,40 & 17,09 \\
\hline Máximo & 38336,30 & 8,58 & 25,31 & 33747,80 & 319,53 & 9,13 & 18,03 & 5,19 & 36,74 & 59,95 \\
\hline Mínimo & 3355,39 & 0,46 & 3,14 & 3348,12 & 38,88 & 1,16 & 1,54 & 0,63 & 4,72 & 8,10 \\
\hline Mediana & 15332,35 & 3,09 & 11,62 & 14924,55 & 100,97 & 4,28 & 5,94 & 2,08 & 15,03 & 25,10 \\
\hline Média & 16755,51 & 3,40 & 11,85 & 16775,57 & 128,13 & 4,41 & 6,19 & 2,27 & 16,87 & 27,87 \\
\hline DP & 8909,88 & 2,01 & 5,88 & 8346,51 & 73,33 & 2,22 & 3,85 & 1,09 & 7,74 & 12,88 \\
\hline
\end{tabular}


